\title{
Performance of the Horizontal Wells in a Naturally Fractured Carbonate Reservoir
}

\author{
Fuad Al-Bayati
}

Follow this and additional works at: https://researchrepository.wvu.edu/etd

\section{Recommended Citation}

Al-Bayati, Fuad, "Performance of the Horizontal Wells in a Naturally Fractured Carbonate Reservoir" (2017). Graduate Theses, Dissertations, and Problem Reports. 5052.

https://researchrepository.wvu.edu/etd/5052

This Thesis is protected by copyright and/or related rights. It has been brought to you by the The Research Repository @ WVU with permission from the rights-holder(s). You are free to use this Thesis in any way that is permitted by the copyright and related rights legislation that applies to your use. For other uses you must obtain permission from the rights-holder(s) directly, unless additional rights are indicated by a Creative Commons license in the record and/ or on the work itself. This Thesis has been accepted for inclusion in WVU Graduate Theses, Dissertations, and Problem Reports collection by an authorized administrator of The Research Repository @ WVU. For more information, please contact researchrepository@mail.wvu.edu. 


\title{
Performance of the Horizontal Wells in a Naturally Fractured Carbonate Reservoir
}

\author{
Fuad Al-Bayati \\ Thesis submitted to the \\ Benjamin M. Statler College of Engineering and Mineral Resources \\ at West Virginia University \\ in partial fulfillment of the requirements \\ for the degree of \\ Master of Science \\ in \\ Petroleum and Natural Gas Engineering \\ Kashy Aminian, Ph.D., Chair \\ Samuel Ameri, M.S. P.E. \\ Fatemeh Belyadi, Ph.D. \\ Department of Petroleum and Natural Gas Engineering \\ Morgantown, West Virginia \\ 2017
}

Keywords: Reservoir Simulation, Naturally Fractured Reservoirs, Carbonate, Horizontal Wells

Copyright 2017 Fuad Al-Bayati 


\title{
ABSTRACT \\ Performance of the Horizontal Wells in a Naturally Fractured Carbonate Reservoir
}

Fuad H. Al-Bayati

\begin{abstract}
About 60 percent of the world's proven oil reserves and 40 percent of gas reserves are trapped in carbonate reservoirs. Recovery rates are relatively low in carbonate reservoirs, and it is extremely challenging to predict due to the heterogeneous nature of these reservoirs. The majority of carbonate reservoirs contain fractures which may vary in size from millimeters to kilometers. A typical example of this type of reservoirs is oil and gas fields in the northern Iraq. These fields are almost all developed by vertical wells. This study will investigate the use of horizontal wells to enhance the productivity in one of these reservoirs.

CMG software is used to simulate the Upper Qamchuqa reservoir of the Khabbaz oil field northeastern of Iraq. The Upper Qamchuqa reservoir is a subsurface anticline with a major normal fault on the eastern flank. Moreover, it mainly consists of dolomite, dolomitic limestone, limestone and marly limestone. The simulation model was validated by the history matching the production rates. Subsequently, horizontal wells were added to the model, and the optimum placement and lateral length investigated. Furthermore, the reservoir parameters that have a significant influence on the history matching and the predicted horizontal wells' performance were identified for future development of the field. The results of this study can provide a guideline for reducing the operating costs and increasing the productivity of similar naturally fractured reservoirs in the area.
\end{abstract}




\section{DEDICATION}

This thesis is dedicated to my wonderful family and special relatives for their tremendous support, love, and encouragement throughout my life. 


\section{ACKNOWLEDGMENTS}

I would like to express my sincere gratitude to my research advisor, Dr. Kashy Aminian for his continuous support, advice and guidance during my graduate studies at West Virginia University. I am particularly thankful to Professor Samuel Ameri, Chairman of Petroleum and Gas Engineering Department, for his support and encouragement. He has always been compassionate and considerate during the entire program. My appreciation and gratitude as well go to Dr. Fatemeh Belyadi, for her valuable advice during my research and course work and for taking the time to participate in the examination committee.

I am also highly grateful to my brothers, Talaat and Abbas, for their continuous support, trust and motivation. They were always there for me.

Also, I would like to thank Schlumberger and Computer Modeling Group for making the Petrel and CMG software available for me to accomplish this research.

Finally, I would like to show my gratitude and appreciation to the North Oil Company for providing the necessary field data for the research and my sincere appreciation to the Higher Committee for Educational Development in Iraq (HCED) for sponsoring my graduate study. 


\section{TABLE OF CONTENTS}

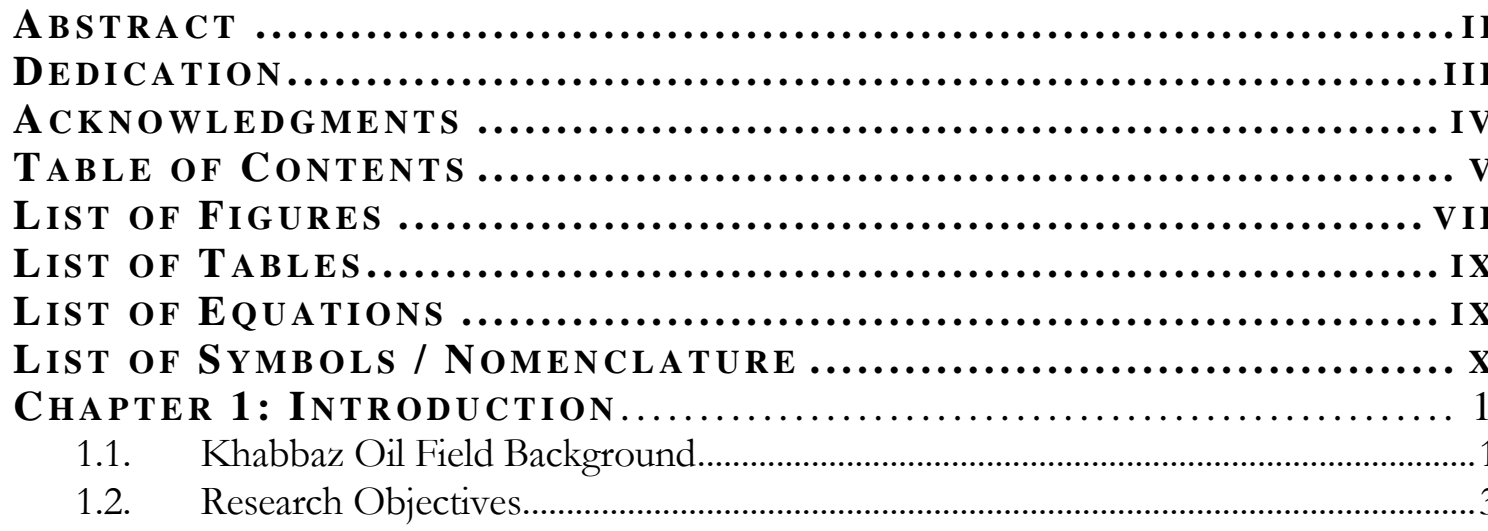

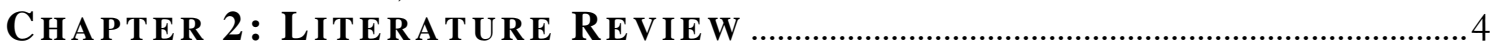

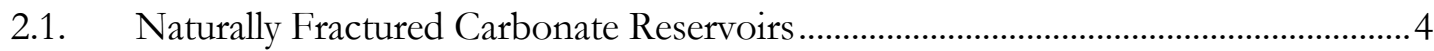

2.2. Dual Porosity Concept and Applications ........................................................................

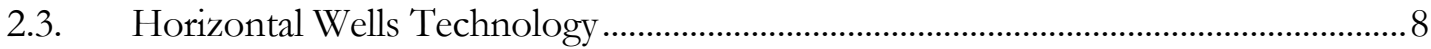

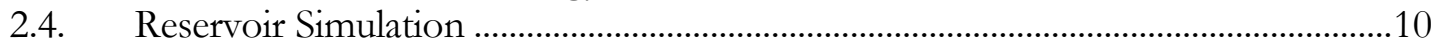

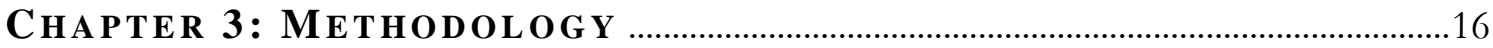

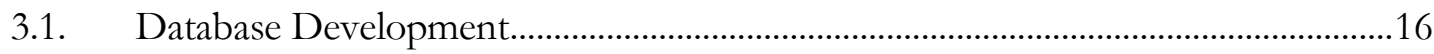

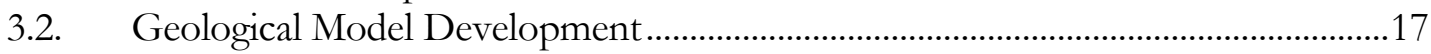

3.2.1. Wellheads Preparation .....................................................................................18

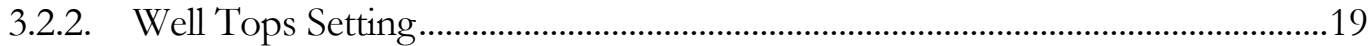

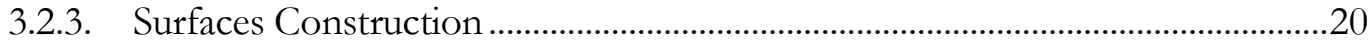

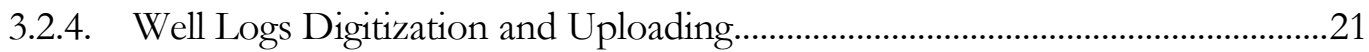

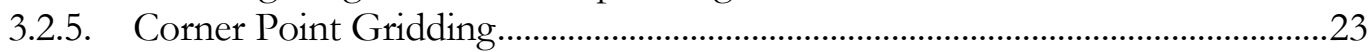

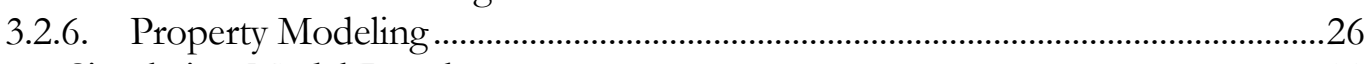

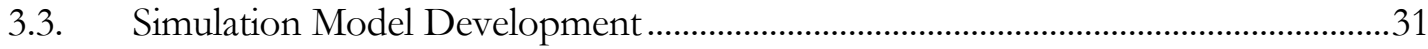

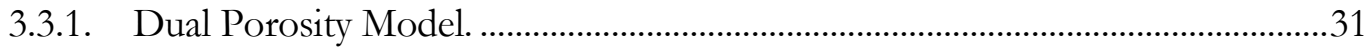

3.3.2. Importing The Geological Model into the Simulator...........................................32

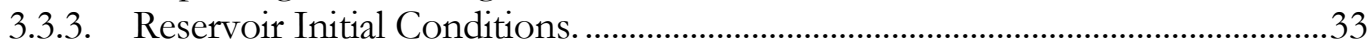

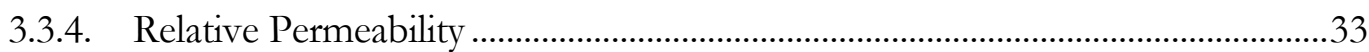

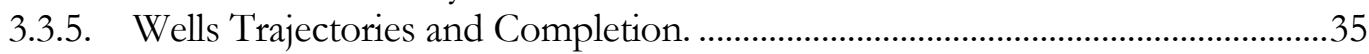

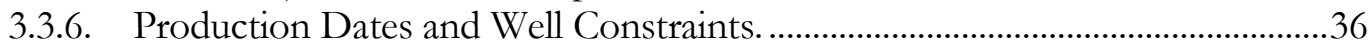

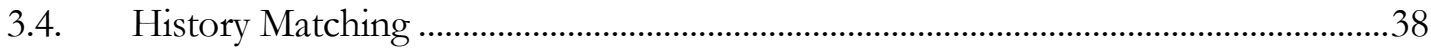

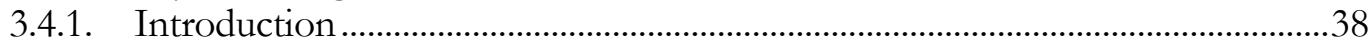

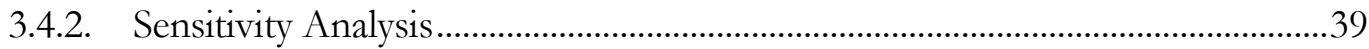

3.4.3. Automated and Manual History Matching ...........................................................4

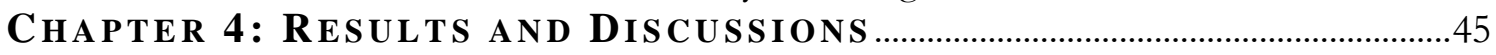

4.1. Natural Fractures Parameters' Impact on the History Matching..............................45

4.1.1. Natural Fracture Permeability.....................................................................................46 


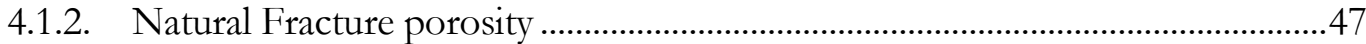

4.1.3. Natural Fracture Spacing ..........................................................................................48

4.2. The Impact of Uncertainty on The Predicted Horizontal Well's Performance......50

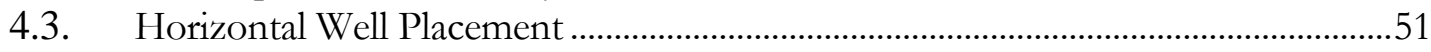

Chapter 5: Summary, Conclusions, And ReCommendations .....62

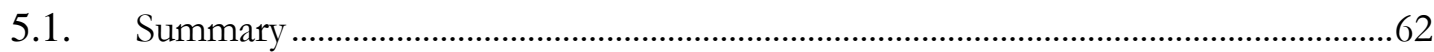

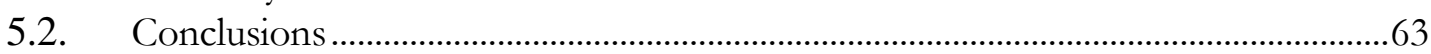

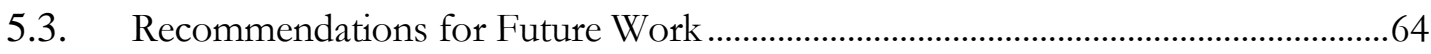

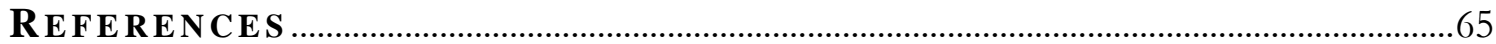




\section{LIST OF FIGURES}

Figure 1: The Khabbaz Oil Field on Iraq map (The Economist, 2009)......................................1

Figure 2: Tectonic subdivision of north of Iraq (after Buday and Jassim, 1987) ......................2

Figure 3: Typical Horizontal Well by Burgess and Van de Slijke (1988)............................... 10

Figure 4: Structural contour map of the Upper Qamchuqa reservoir in the Khabbaz field.

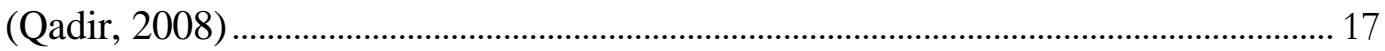

Figure 5: Digitized structure contour map and surface of the Upper Qamchuqa reservoir.. 20 Figure 6: The Upper Sarmord formation surface (base of Upper Qamchuqa reservoir) ...... 21

Figure 7: Neuralog Digitizer Results for the well KZ-12 ..................................................... 22

Figure 8: An example of well section flattened on the top of the Upper Qamchuqa............. 23

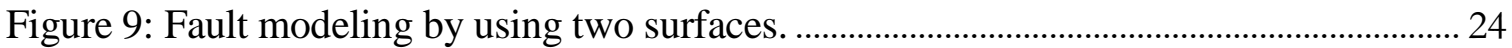

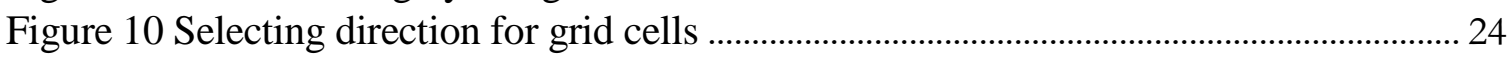

Figure 11: Produced skeletons from pillar gridding process.................................................... 25

Figure 12: New gridded horizon and layers of the Upper Qamchuqa reservoir ..................... 25

Figure 13: Comparison of well logs porosity with core analysis porosity for well KZ-16.. 26

Figure 14 Comparison of calculated permeability with core analysis permeability for well

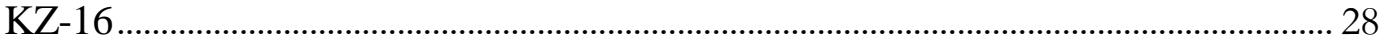

Figure 15: Scale-Up process for Porosity and Permeability, wells KZ-1, KZ-13 and KZ-

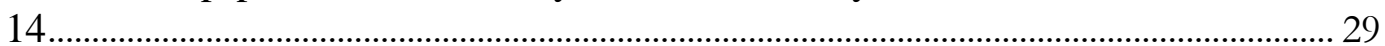

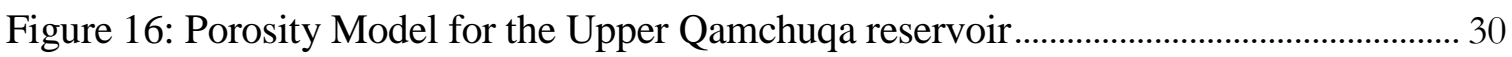

Figure 17: Permeability Model for the Upper Qamchuqa reservoir ............................................. 30

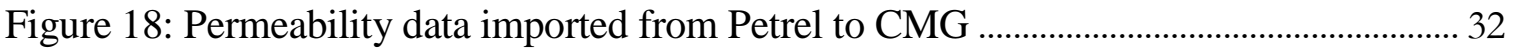

Figure 19: Relative permeability for oil and water well KZ_11 .............................................. 34

Figure 20: Relative permeability diagram for oil and gas well KZ_11 ..................................... 34

Figure 21: Wells trajectory of the Upper Qamchuqa reservoir ................................................ 35

Figure 22: Daily oil production rate from Upper Qamchuqa reservoir ...................................... 36

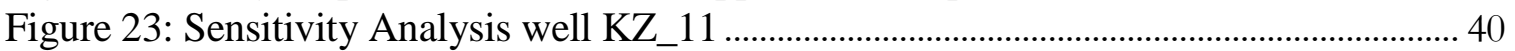

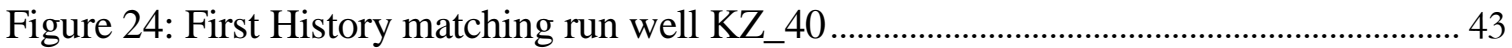

Figure 25: History matched model of cumulative oil production, well KZ_11 ……............. 44

Figure 26: History matched model of cumulative gas production, well KZ_4 ....................... 44

Figure 27: Tornado plot for cumulative oil production (objective function), KZ_16 ........... 45

Figure 28: Fracture permeability impact on history matching process, KZ_16..................... 46

Figure 29: Sensitivity Analysis showing fracture porosity impact on production, KZ_31.. 47

Figure 30: Sensitivity analysis highlighting the fracture spacing impact on production,

KZ 38

Figure 31: Compares two simulation runs with different fracture spacing for a horizontal well

Figure 32: Impact of history matching uncertainty on the horizontal well performance...... 50

Figure 33: Suggested area to investigate for drilling the new horizontal well ....................... 51 
Figure 34: Scenario 1, the new horizontal well (KZ_41) location. .......................................... 52

Figure 35: Scenario 1, monthly production rate for the new horizontal well (KZ_41)........ 53

Figure 36: Scenario 2, new horizontal well (KZ-41) completed in layer K1 .......................... 53

Figure 37: Comparison of monthly oil rate for scenario 1 and 2 ........................................... 54

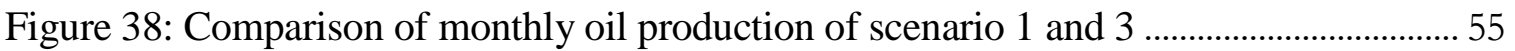

Figure 39: Comparison of monthly oil production of scenario 3 in different layers.............. 55

Figure 40: Scenario 4, comparison of horizontal wells with two different lateral length..... 56

Figure 41: horizontal well placement in the north of the reservoir. ............................................ 57

Figure 42: Comparison of horizontal wells in the North-South orientation.............................. 58

Figure 43: Scenario 6, horizontal well placement in the north-east of the reservoir.............. 58

Figure 44: Scenario 6, monthly oil production from 3500 feet horizontal well in NE of the

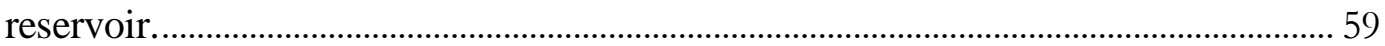

Figure 45: Scenario 7 monthly production rate comparison ........................................................ 60

Figure 46: Optimal horizontal well's placement and lateral length in the southeast of the reservoir with average production rate of $2500 \mathrm{bbl} / \mathrm{day}$................................................. 61

Figure 47: Optimal horizontal well's placement and lateral length in the northeast of the reservoir with average production rate of $2000 \mathrm{bbl} / \mathrm{day}$ 


\section{LIST OF TABLES}

Table 1: State of the reservoir simulation capabilities (Watts, 199) .......................................... 12

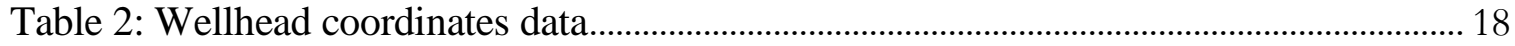

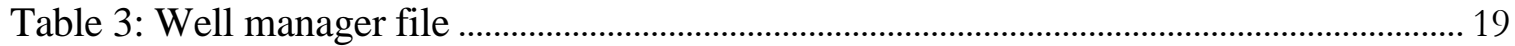

Table 4: the Upper Qamchuqa well tops and thickness data.................................................... 19

Table 5: Well tops spreadsheets for the Upper Qamchuqa and Upper Sarmord formation. 20

Table 6: Input data for Guo-Ghalambor method to calculate BHFP ......................................... 37

Table 7: Range of input parameters for sensitivity analysis process........................................... 39

Table 8: Property map created according to history matching data ......................................... 42

\section{LIST OF EQUATIONS}

Equation 1: Darcy law for single phase flow in three dimensions ........................................... 14

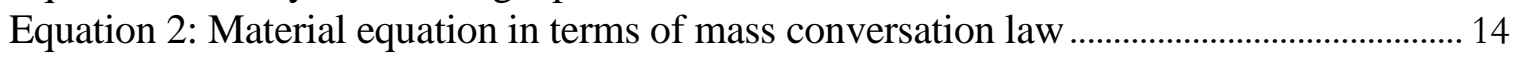

Equation 3: Mass conversation equation single phase flow in multi-dimensions .................. 14

Equation 4: Flow equation for single phase flow................................................................ 15 


\section{LIST OF SYMBOLS / NOMENCLATURE}

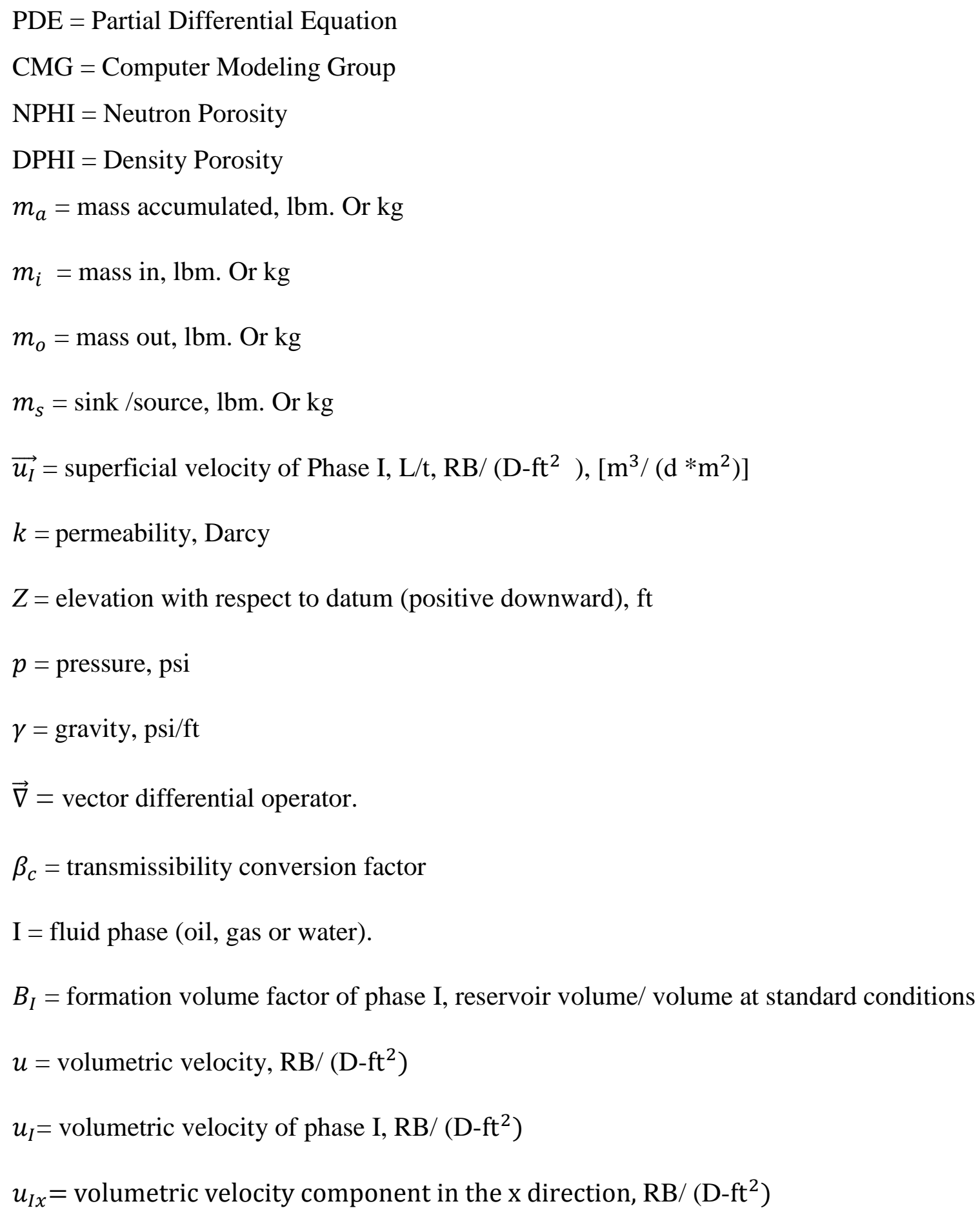




$$
\begin{aligned}
& u_{I y}=\text { volumetric velocity component in the } \mathrm{y} \text { direction, } \mathrm{RB} /\left(\mathrm{D}-\mathrm{ft}^{2}\right) \\
& u_{I z}=\text { volumetric velocity component in the } \mathrm{z} \text { direction, } \mathrm{RB} /\left(\mathrm{D}-\mathrm{ft}^{2}\right) \\
& \mu=\text { viscosity, cp } \\
& \emptyset=\text { porosity, fraction } \\
& x=\text { distance in the } \mathrm{x} \text { direction in Cartesian coordinate system, } \mathrm{ft} \\
& A=\text { cross- sectional area normal to flow, } \mathrm{ft}{ }^{2} \\
& A_{x}=\text { cross- sectional area normal to } x \text { direction, } \mathrm{ft}{ }^{2} \\
& A_{y}=\text { cross- sectional area normal to } y \text { direction, } \mathrm{ft}^{2} \\
& A_{c}=\text { volume conversion factor } \\
& A_{b}=\text { bulk volume, control volume, or gridblock bulk volume, } \mathrm{ft}^{3} \\
& u_{I x}=\text { volumetric velocity component in the } \mathrm{x} \text { direction, } \\
& u_{I y}=\text { volumetric velocity component in the } \mathrm{y} \text { direction } \\
& u_{I z}=\text { volumetric velocity component in the } \mathrm{z} \text { direction } \\
& \Delta x=\text { difference along } x \text { direction, } \mathrm{ft}
\end{aligned}
$$




\section{CHAPTER 1: INTRODUCTION}

\subsection{KHABBAZ OIL Field BaCKGROUND}

The Khabbaz oil field is one of the giant oil fields in Iraq with estimated reserves of 2 billion barrels. The Field has multiple pay zones like most of northern Iraq oil fields. In 1965, the first seismic survey was started in the Khabbaz area by the Iraqi Petroleum Company (IPC). Northwest plunging structure indicated in that survey. In 1971, another survey was conducted and showed the existence of Khabbaz prospect (Figure 1). The first exploration well (Kz-1) drilled in August 1976. Also, France's Technip Geoproduction has started the field development in 1987 for the North Oil Company (Al-Qayim and others, 2010).

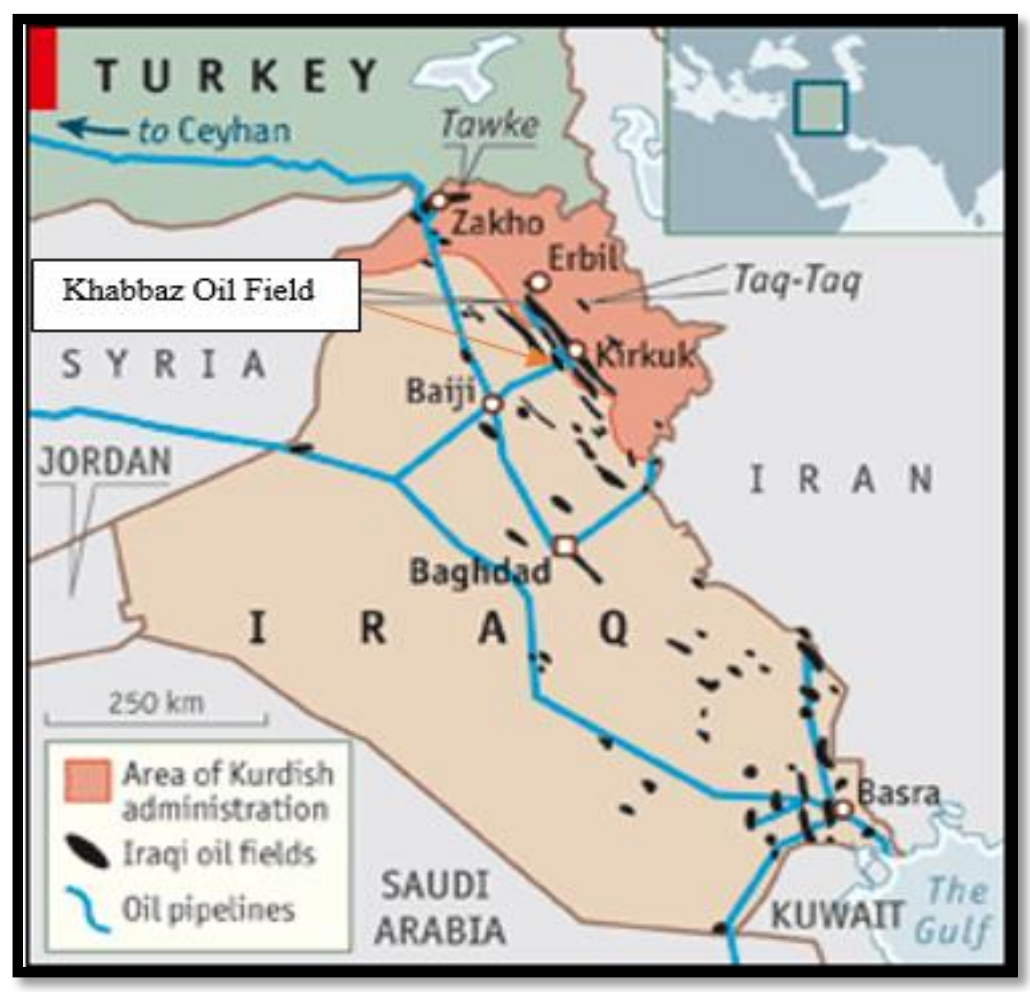

Figure 1: The Khabbaz Oil Field on Iraq map (The Economist, 2009) 
According to the structure contour map of the top of the Upper Qamchuqa Formation, the field characterizes as a small subsurface anticline around 12 miles long and 2.5 miles wide (Qadir, 2008). Also, it is trending to the northwest as most Iraqi oil fields do.

Jassim and Goff (2006) stated that the Upper Qamchuqa formation is equivalent to the Mauddud Formation in the south of Iraq, which is geographically the largest Lower Cretaceous formation. Due to lateral facies change and erosional truncation, the thickness of the Upper Qamchuqa reservoir varies. The formation extends on the Stable Shelf, the Foothill and High Folded zones (Figure 2).

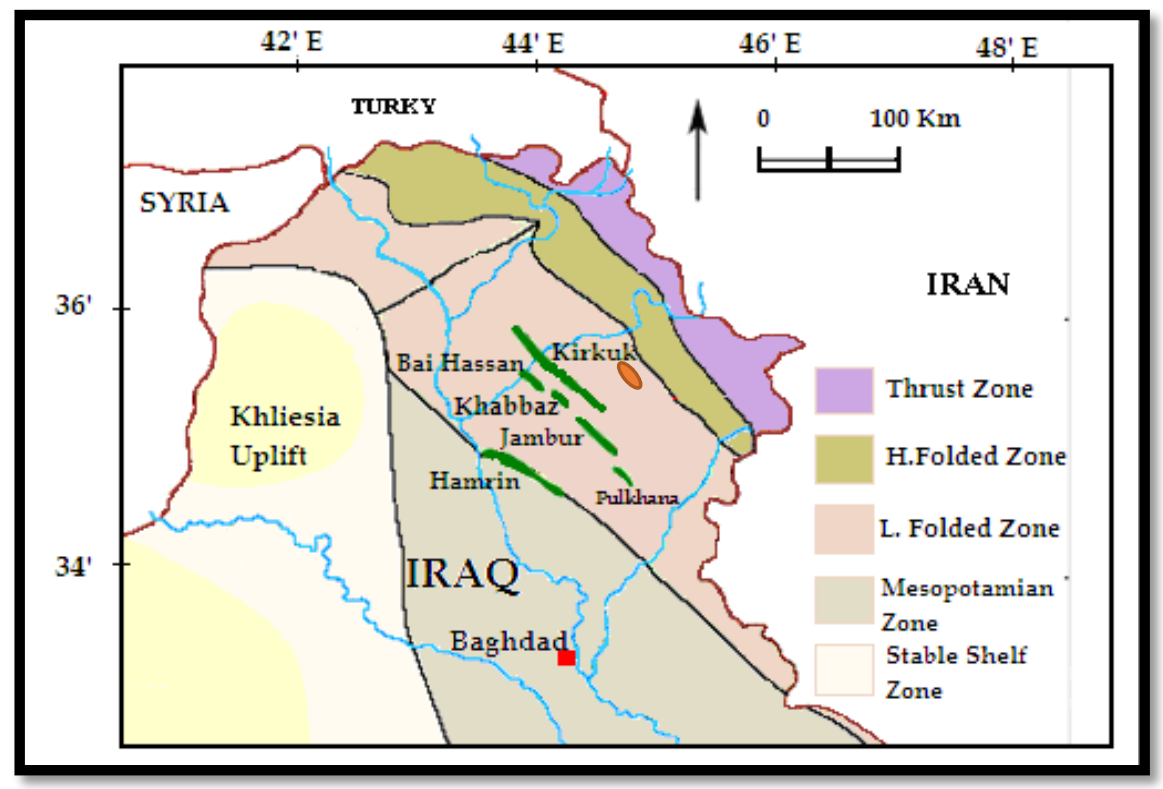

Figure 2: Tectonic subdivision of north of Iraq (after Buday and Jassim, 1987)

Also, "It was deposited in a neritic, sometimes high-energy, shoal environment. The average thickness ranges from 50 to $250 \mathrm{~m}$ (164-820 ft.) Depending upon the structural position and whether there has been the erosional removal of some of the formation" (Alsharhan, \& Nairn, 1997).

There are 40 vertical wells already drilled in the both the tertiary and cretaceous reservoirs of the Khabbaz oil field with an average production rate of 30,000 bbl/day (as in 2012). As the production continued since 1990, the oil column decreased, and the vertical drilling 
became no longer economical. In consequence, to develop the field and improve production, several scenarios were suggested. Drilling new horizontal wells were one of them. Typically horizontal wells increase oil and gas recovery by exposing a wider area of pay zone to production. However, the increase in recovery might not be economical and needs to be evaluated.

\subsection{RESEARCH OBJECTIVES}

The fundamental objective of this project and the associated research is expected to assess the horizontal wells' performance in one of the Iraqi naturally fractured carbonate reservoirs and to determine the optimum location and lateral length of these wells. The study's secondary objective is to find out the main reservoir parameters that influence the production history matching process. The research area will focus on the Upper Qamchuqa carbonate formation (Lower Cretaceous) and the related geology in Khabbaz field northwestern Iraq.

To conduct this study a static model (geological model) built for the Upper Qamchuqa reservoir by using Petrel software. Then, a dynamic model (simulation model) developed and validated by history matching the production data through CMG software. 


\section{CHAPTER 2: Literature REVIEW}

\subsection{Naturally Fractured Carbonate Reservoirs}

A naturally fractured reservoir is defined as "a reservoir in which naturally occurring fractures either have, or are predicted to have, a significant effect on reservoir fluid flow either in the form of increased reservoir permeability and/or reserves or increased permeability anisotropy" (Nelson, 2001, p. 4). Naturally fractured reservoirs are considered a production conundrum, with a small hydrocarbon recovery rate. They show high production potential at the beginning of development, but the production rate declines rapidly. Also, those reservoirs are widely known for having an early breakthrough for gas and water. However, naturally fractured reservoirs are one of the largest oil producers in the world. The complex and inconsistent nature of naturally fractured reservoirs pushes the industry to further their efforts to understand them more and create models with the best possible percentage of certainty (Bratton et al., 2006).

Nelson (2001) expanded into the four types of fractured reservoirs classification that was proposed by Hubbert and Willis (1955), taking into account the degree to which fractures have modified the porosity and permeability of the reservoir matrix. Type I fractures provide the necessary storage capacity (porosity) and permeability. Type II fractures provide the reservoir's intrinsic permeability while the matrix contains the critical porosity, and in Type III the matrix permeability is high enough for production, and fractures add more permeability to the system. In type IV fractured reservoirs, the fractures which filled with minerals form an impediment to fluid flow and splits the formation into small blocks. Also, these minerals prevent the fractures from providing any additional porosity or permeability to the reservoir. This classification constitutes the engineering classification of natural fractures.

Geological classification of naturally fractured reservoirs is distinct from the engineering classification. Prospects such as fracture patterns and strain distribution are the keys behind 
these geological classifications. Therefore, Stearns and Friedman (1972) classified natural fractures into 1) shear fractures and 2) extension fractures. Also, Aguilera (2003) categorized natural fractures based on their geological condition into a) tectonic fractures (fold and/or fault related), b) regional fractures, c) contractional fractures and d) surface related fractures. The surface related fractures are the least important type of fractures from the hydrocarbon production perspective.

Ahr (2008) stated that both matrix and fracture components are necessary to form the total porosity and permeability values in fractured reservoirs. Also, to evaluate the effect of a fracture's porosity and permeability on the reservoir performance, it is crucial to compare it with the contribution of the matrix's porosity and permeability to the reservoir. Nelson (2001) defines the four petrophysical determinations that are most useful to evaluate on fractured reservoirs (in order of increasing difficulty of calculation) as 1- fracture permeability, 2-fracture porosity, 3-fluid saturations within the fractures, and 4- Fractured system's recovery factor. The necessary data for these determinations can be obtained from whole-core analysis and well tests while well log analysis data are less reliable and less accurate for such studies according to Nelson (2001). Also, Nelson adds that well logs provide variable and incorrect results for quantitative measurements of fracture porosity and fracture permeability, particularly when not correlated to core data from the selected fractured zones. However, according to Ahr (2008) well logs provided by the Schlumberger company such as FMI ® (formation micro-resistivity imaging log) and FMS ( ) (formation microscanning $\log$ ) are widely prevalent for fracture identification and defining fractures' orientations.

Fracture morphology of the fracture planes is a significant factor that influences the fracture porosity and permeability. According to Nelson (2001), fracture morphology can be indicated in core and outcrop, and it can be concluded from well logs. Also, he has ranked four types of natural fracture morphology as (a) open fractures, (b) deformed fractures, (c) mineral filled fractures and (c) vuggy fractures.

Lorenz, Farrell, Hanks, Rizer, \& Sonnenfeld (1997) mention that "natural fractures are present in carbonates in settings that vary from undeformed, near horizontal beds to fold 
and thrust belts." They also point out that most fractures in the carbonates have an extensional origin. Furthermore, lithology significantly influences fracturing in carbonates. Therefore, dolomite and dolomitic mudstone are more fractured compared to limestone, and shale breaks usually limit fractures vertically. On the other hand, the structural position also has a great effect on fracture character. For instance, more fractures form along hinges of folds (high-stress area) than along limbs. Lorenz et al. (1997) also concluded that more than one generation of fracturing may occur in highly deformed strata where younger fractures may overprint older ones. The younger fractures are more likely to stay open and to be arranged parallel to in situ stresses so that they may control reservoirs' behavior.

Van Golf-Racht (1996) determined a carbonate reservoir be fractured if it has a continuous network of different levels of fracturing spread throughout it. The continuous fracture network in carbonate reservoirs is designated by: (1) notable mud losses during drilling processes, (2) unique behavior of pressure transient analysis, (3) cores examination. These features of fractured carbonate reservoirs can be indicated in the early period of field discovery or during the field development and production stage. 


\subsection{Dual Porosity Concept and Applications}

Naturally fractured reservoirs are best characterized by having two discrete types of porous media: matrix blocks and fractures. The matrix blocks and fractures have different storage and conductivity characteristics. Therefore, naturally fractured reservoirs are often called double-porosity reservoirs.

Barenblatt, Zheltov, \& Kochina. (1960) first proposed the concept of dual porosity. Fissure rocks consist of two distinct porous systems with two different porosities and permeabilities. The more permeable systems (fissure system) produce hydrocarbons into the well, and the less permeable (the matrix blocks) with high storage capacity act mostly as a source. Warren and Root (1963), introduced the dual porosity model based on the finding of Barenblatt et al. (1960). Their model described and handled the complexity of fluid flow through fractured porous media, and has been used widely in fractured reservoir simulations. Warren and Root presented the main characterization parameters that dominate the behavior of dual porosity systems. The first one was the storativity coefficient, which compares the volume of fracture storativity with the storativity of the entire reservoir. The second characterization was the interporosity flow coefficient, which defines the connectivity of natural fractures with rock matrix. However, the dual porosity concept was first integrated into a numerical model with fluid flow application on a large scale by Kazemi, Merrill, Porterfield, \& Zeman (1976). A three-dimensional (3D), threephase model, was developed by Thomas, Dixon, \& Pierson (1983) for simulating the flow of water, oil, and gas in a fractured reservoir.

There are two dual porosity systems in the fractured reservoirs depending on the fluid flow mechanism - dual porosity-single permeability and dual porosity-dual permeability. The dual porosity-single permeability occurs when the fluid flows from the matrix to the fracture cell and then to the wellbore. Thus, it assumes that the matrix has very low permeability and does not produce directly to the wellbore, and its permeability will be negligible. On the other hand, the dual porosity-dual permeability system would occur 
when the fluid flows from matrix cells to the fracture cells and from matrix cell to another (interblock flow) (Lu, 2009).

\subsection{HORIZONTAL WELLS TECHNOLOGY}

Horizontal drilling technology has inspired the petroleum industry in a way that no other recent invention has ever triggered. There were few attempts at horizontal drilling in the Soviet Union in the 1950's, China in the 1960's, Canada in the 1970's and Italy in the early 1980's (Burgess and Van de Slijke 1990). Nevertheless, according to (Mukherjee and Economides 1991) the most important production successes through horizontal wells were indicated in the early 1980's in offshore Italy. A considerable increase of production of not less than two to three times of equivalent vertical well's production was recorded in the Prudhoe Bay field and the Rospo Mare field. The producing formation type of the Rospo Mare field was a very helpful key behind the success of horizontal well drilling. Giger, Reiss, \& Jourdan (1984) reported that the Rospo Mare reservoir consists mainly of karsts (compact carbonate rock), which has a very low porosity. The low porosity feature of karsts prevents the oil from penetrating the matrix, so the oil resides in the fractures and vugs of the karstic system.

Novy (1995) indicates that horizontal wells are turning into a proven and reliable technique for hydrocarbon recovery. A horizontal well provides a larger contact area with reservoir's pay zones than a conventional well does, especially in reservoirs where fluids are trapped in horizontal or semi-horizontal layers. Exposing a larger contact area to production, induces lower drawdown pressure, which contributes to further oil and gas recovery and reduces the potential of water and gas coning. In addition, horizontal wells decrease the number of wells that are required to develop any field. For instance, Wilkirson, Smith, Stagg, \& Walters (1988) reported about three horizontal wells that drilled in the Prudhoe Bay, Alaska. As a result of the progress in well completion technology and the improvement of horizontal well drilling, the drilling cost per foot reduced by 40 percent. Likewise, the hydrocarbon production rate increased by 300 percent in horizontal wells 
compared to conventional wells' production. However, overall drilling cost of horizontal wells still higher than vertical wells cost by 1.3 to 2 times.

Burgess and Van de Slijke (1990) referenced that approximately one-half of horizontal wells was drilled in formations, where the main provider of their permeabilities are the fractures. Also, horizontal wells intersect more fractures than conventional wells as most fractures are nearly vertical. Moreover, approximately 20 percent of horizontal wells are completed in thin formation reservoirs: almost half of horizontal wells are completed in layers with less than 80 feet. Besides horizontal wells' application in fractured and thin bed formations other applications were found, as the technology advanced. According to (Pendleton, 1991) horizontal wells technology has been utilized in production improvement, reservoir management (such as in EOR and heavy oil projects), infrastructure cost reductions of offshore and remote exploration, and environmental protection tasks.

The productivity of a horizontal well depends on several components such as lateral length, reservoir thickness, anisotropy, porosity, permeability, compressibility, boundary conditions and the well's length, altitude and orientation. Zhang (1998) discussed a general solution to evaluate the well productivity of a horizontal well and determine an optimum production. Also, Zhang presented a new solution to estimate reservoir parameters that deliver the most impact on the well productivity prediction. Therefore, an assumption of an arbitrarily oriented well in an anisotropic reservoir has been made to apply the new solution.

The categorizing of horizontal wells is defined by the building rate of the radius of curvature. Therefore, there are three major types of horizontal wells according to Burgess and Van de Slijke (1990): short, medium and long. The short radius horizontal well has 1.5 degrees per 3 feet, the medium radius well has 8 to 50 degrees per each 100 feet and the long radius well type has 2 to 6 degrees per each 100 feet. Every single case of a horizontal well is dedicated to a certain utilization depending on the reservoir requirement and drilling 
conditions. Figure 3 displays a trajectory of a typical horizontal well with two build-up rates, long and medium respectively.

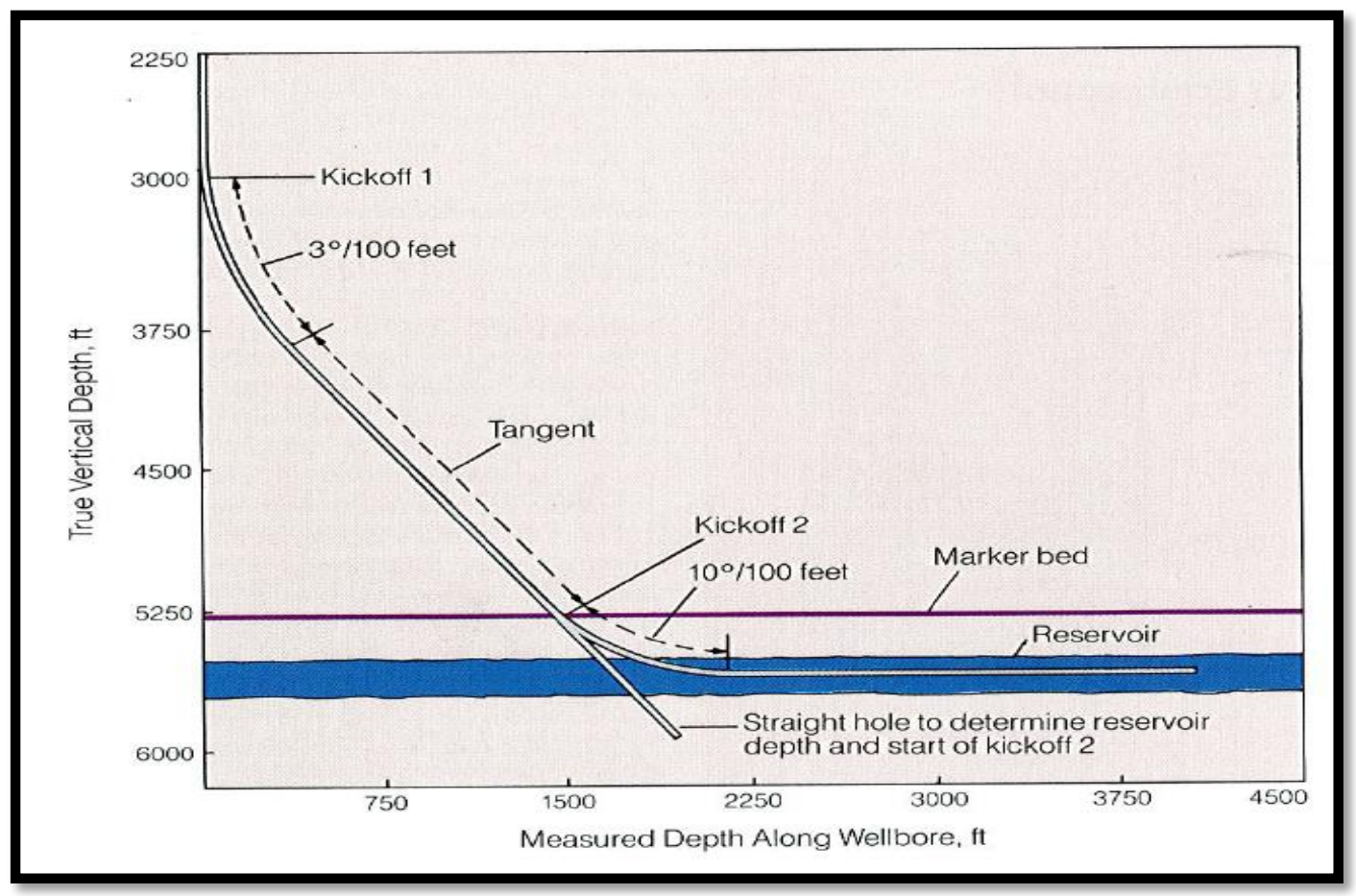

Figure 3: Typical Horizontal Well by Burgess and Van de Slijke (1988)

\subsection{RESERVOIR SIMULATION}

Reservoir simulation is a process of establishing and operating a model that reflects the behavior of an actual reservoir. The model can be either physical (laboratory sand pack) or mathematical. The mathematical model is a set of equations that are founded on a certain assumption and describes the fluid flow within the reservoir and from the reservoir to the wellbore (Coats, 1987). The main purpose of reservoir simulation according to (Odeh, 1969) is to predict the recovery rate of hydrocarbon fluids for various field operations. Also, the accuracy of reservoirs' performance depends on adequate field data availability. While according to Coats (1987) the purpose of the simulation is the estimation of field performance under various production scenarios and selecting the optimal plan for the field's future development. 
The perspective of reservoir simulation was gradually perceived in the late 1940's and early 1950's. The high cost of early simulation was acceptable considering the large size of the reservoirs that were studied. Watts (1997) studied the history of reservoir simulation and its development along each decade. A single-phase flow in one direction was first modeled by a reservoir simulator. Today, a model of three-phase flow in three directions with an enormous number of grid blocks is broadly utilized. In 1954, reservoir simulation began utilizing the radial gas flow calculations of Aronofsky and Jenkins. However, Watts mentions that Peaceman and Rachford's (1955) development of the alternating-direction implicit (ADI) procedure was the first work to get noticed outside the field of reservoir engineering. In the 1960's, solving the matrix equations was one of the main difficulties. Nevertheless, the first truly general-purpose simulators had appeared. Also, a mathematical breakthrough took place in that decade regarding the advance of reservoir simulation; the development of implicit-in-time methods made it easier to solve high-flow velocity issues, which helped to resolve well coning problems.

The 1970's witnessed several remarkable innovations in the path of reservoir simulation's development. The first innovation was a three-phase relative permeability model by Stone (1970), followed by the two-point upstream method by Todd, O'Dell, \& Hirasaki (1972). Finally, Peaceman's method of utilizing gridblock pressure and well flow rate to determine the bottom-hole pressure is still widely used today. In the early 1980's, nested factorization was developed as a new matrix solver method and the most significant advance at that time. Also, development of corner point geometry and a new formulation for compositional simulation was proposed. In the late 1980's and 1990's the efforts more focused on geological modeling, geostatistics, upselling, flexible grids, and parallelization. Table 1 summarizes Watts's timeline for reservoir simulation development. 
Table 1: State of the reservoir simulation capabilities (Watts, 199)

\begin{tabular}{|ll|}
\hline Decade & Capabilities \\
\hline 1950 & Two dimensions \\
& Two incompressible phases \\
& Simple geometry \\
& Three dimensions \\
& Three phases \\
& Black-oil fluid model \\
& Multiple wells \\
& Realistic geometry \\
& Well coning \\
1970 & Compositional \\
& Miscible \\
& Chemical \\
& Thermal \\
& Complex well management \\
& Fractured reservoirs \\
& Special gridding at faults \\
& GUl's \\
Improved ease of use \\
Geologic models and upscaling \\
Local grid refinement \\
Complex geometry \\
Integration with nonreservoir computations \\
\hline
\end{tabular}

Furthermore, Wang (2007) emphasizes the simulation software development from the user perspective. In the 1980 's, a complex software with interactive data perpetration and display on a graphical friendly user interface (GUI) was developed, and modeling fractured reservoirs become a possibility. Additionally, in the 1990's, the efforts were emphasized on making simulators easier to use. Therefore, automatic gridding packages were presented and local grid refinement developed to simulate more complex geometries.

There are several types of reservoir simulators. The selection of the proper simulator to represent a particular reservoir requires an adequate understanding of the reservoir and a deliberate examination of the available data. Odeh (1969) classifies simulators "according to the type of reservoir or process they are intended to simulate. There are, for example, gas, black oil, gas condensate, and miscible displacement reservoir simulators" (p. 1384). He further classifies the reservoirs according to the number of fluid phases that occur, resulting in one, two and three phase reservoir models. Moreover, Odeh classified simulators based on the number of dimensions. The most common model is two 
dimensional. The two-dimensional models have several geometries and the most predominant one is the horizontal (x-y) geometry. However, the radial (r-z) and the vertical $(\mathrm{x}-\mathrm{z})$ geometries are used frequently. Consequently, Odeh notes that these simulators may or may not take gravitational or capillary forces into account. Therefore, researchers need to understand that choosing proper simulator does not just depend on dimensionality. The type of hydrocarbon and fluid phases too must be represented, in selecting the proper simulator.

Ertekin, Abou-Kassem, \& King (2001) discussed the traditional methods of predicting a reservoir performance. They divided the methods into three categories: analogical, experimental and mathematical (numerical) methods. The analogical methods involve making a correlation of the properties of a mature reservoir with a target reservoir that shares the same geographical or petrophysical features. Then, using the correlation results to forecast the performance of the target reservoir. Therefore, this method can be applied to estimate well spacing, initial production rates, recovery factors, recovery mechanisms and decline rates. The experimental methods include creating laboratory models to measure physical flow properties in porous media such as flow rates, pressures, and fluid saturations. Accordingly, the results of these experiments scaled up to interpret the entire hydrocarbon accumulation and reservoir performance. However, scaling up all reservoir physical characteristics is not practically possible, so the application of the scaled up models is very limited. Lastly, the mathematical models which are based on using mathematical equations are the most commonly used methods today. These models can be generated by hand calculation or graphical techniques. Also, several software in personal computers can perform these calculations much faster. The mathematical equations that are used in these model consist of material balance equations, decline curve analysis, statistical (empirical correlations) and analytical (exact solutions) methods.

Reservoir simulation is becoming a standard tool for prediction and forecasting in the oil and gas industry. At that point, there are several developments that can be given credit of its widespread acknowledgment. For instance: advances in numerical methods of solving the partial differential equations (PDE), advances of computer technology (especially 
computing speed and storage capacity (memory)), progresses in reservoir characterization technique, advances in simulation software and the simplification incorporated within them that makes it easier to model field cases and the development of oil recovery techniques that made complicated cases possible to analyze. According to Belyadi (2011) (as cited in Ertekin et al., 2001), reservoir simulation is a type of numerical modeling that is employed to interpret a physical phenomenon and utilize it to forecast future performance. The procedure includes dividing the reservoir into a number of cells in three dimensions and modeling the changes of reservoir and fluid characteristics along time and location, in a sequence of discrete stages. Material balance equation incorporating with Darcy's law are utilized to solve for every cell and time step. Therefore, Ertekin et al. (2001) derived the fundamental flow equation for single phase flow in three dimensions and in the following section a summary of the main equations used is noted.

Darcy's law describes the relation between the fluid flow through a porous medium and the potential gradient in an empirical equation. For a single phase flow in three dimensions, the law can be expressed in the following equation:

\section{Equation 1: Darcy law for single phase flow in three dimensions}

$$
\vec{u}=-\beta_{c} \frac{k}{\mu}(\vec{\nabla} p-\gamma \vec{\nabla} Z) \text {. }
$$

However, equation (1) has several implicit assumptions and limitations listed by Ertekin et al. 2001 (p. 13).

The material balance equation in term of mass conversation law is written as following:

\section{Equation 2: Material equation in terms of mass conversation law}

$$
\left(m_{i}-m_{o}\right)+\left(m_{s}\right)=m_{a}
$$

The mass conservation equation for single phase flow in multi-dimensions can be written as below:

Equation 3: Mass conversation equation single phase flow in multi-dimensions

$$
-\frac{\partial}{\partial x}\left(A_{x} \frac{u_{I x}}{B_{I}}\right) \Delta x-\frac{\partial}{\partial y}\left(A_{y} \frac{u_{I y}}{B_{I}}\right) \Delta y-\frac{\partial}{\partial z}\left(A_{z} \frac{u_{I z}}{B_{I}}\right) \Delta z=\frac{V_{b}}{\alpha_{c}} \frac{\partial}{\partial t}\left(\frac{\emptyset}{B_{I}}\right)-q_{I S C}
$$


Where (I) is either oil, gas or water.

Therefore, the flow equation for single phase flow can be obtained by combing Darcy's law, Eq. 1, and the mass conservation equation (material balance ), Eq. 3. As following:

\section{Equation 4: Flow equation for single phase flow}

$\frac{\partial}{\partial_{x}}\left[\beta_{c} \frac{k_{x} A_{x}}{\mu_{I} B_{I}}\left(\frac{\partial_{p}}{\partial_{x}}-\gamma_{I} \frac{\partial Z}{\partial X}\right)\right] \Delta X+\frac{\partial}{\partial_{y}}\left[\beta_{c} \frac{k_{y} A_{y}}{\mu_{I} B_{I}}\left(\frac{\partial_{p}}{\partial_{y}}-\gamma_{I} \frac{\partial Z}{\partial y}\right)\right] \Delta y+$

$\frac{\partial}{\partial_{z}}\left[\beta_{c} \frac{k_{z} A_{z}}{\mu_{I} B_{I}}\left(\frac{\partial_{p}}{\partial_{z}}-\gamma_{I} \frac{\partial Z}{\partial z}\right)\right] \Delta z=\frac{V_{b}}{\alpha_{c}} \frac{\partial}{\partial_{t}}\left(\frac{\emptyset}{B_{I}}\right)-q_{I s c}$

Where (I) is either oil, gas or water.

Moreover, Eq. 4 is the most essential equation in reservoir simulation for single phase flow where no assumptions are made for compressible or non-compressible fluid.

Finally, reservoir simulation applied by high speed computers through utilizing a set of numerical solutions to interpret and predict the dynamic behavior of the reservoir. The numerical solution would give the values of pressure and saturation at discrete points in the reservoir. So, it uses the discretization concept, which involves transforming the partial differential equations into algebraic equations. Meanwhile, the analytical solution is continuous and gives the pressure, saturation and flow rate as a function of time and location. However, the nonlinear nature of the analytical solutions' equations makes it impossible to use them. Furthermore, the numerical solutions provide approximate results to exact problems, while the analytical solutions produce exact solutions to approximate (simplified) problems (Ertekin et al., 2001). 


\section{ChAPTER 3: METHOdOLOGY}

\subsection{DATABASE DEVELOPMENT}

The data for this project has been provided by the North Oil Company, which is a national Iraqi Oil company located in the city of Kirkuk in northern Iraq. There are 16 vertical wells which have been completed and are producing from Upper Qamchuqa reservoir in the Khabbaz oil field. Another four wells are penetrating the Upper Qamchuqa but producing from a different reservoir in the Khabbaz field. Information on the well tops, well logs, structure map, well trajectory, production history, and core analysis data are available for the reservoir. The core analysis data is available only for wells KZ_16 and KZ_11. Well logs are available for all 16 wells in the reservoir, and most of them contain Sonic, Gamma Ray, Neutron Density, Micro-Spherically Focused Log and Deep Later Log. 


\subsection{Geological Model Development}

Schlumberger's Petrel software was used to build the static model (geological model). Engauge Digitizer software was used to digitize the structure map as illustrated in Figure 4. Neuralog software is used to digitize the well logs. A Cartesian coordinates system was used to present the data with base geographic coordinate system WGS 84 and projection of UTM zone $38 \mathrm{~N}$ to provide accurate location of the wells in the model.

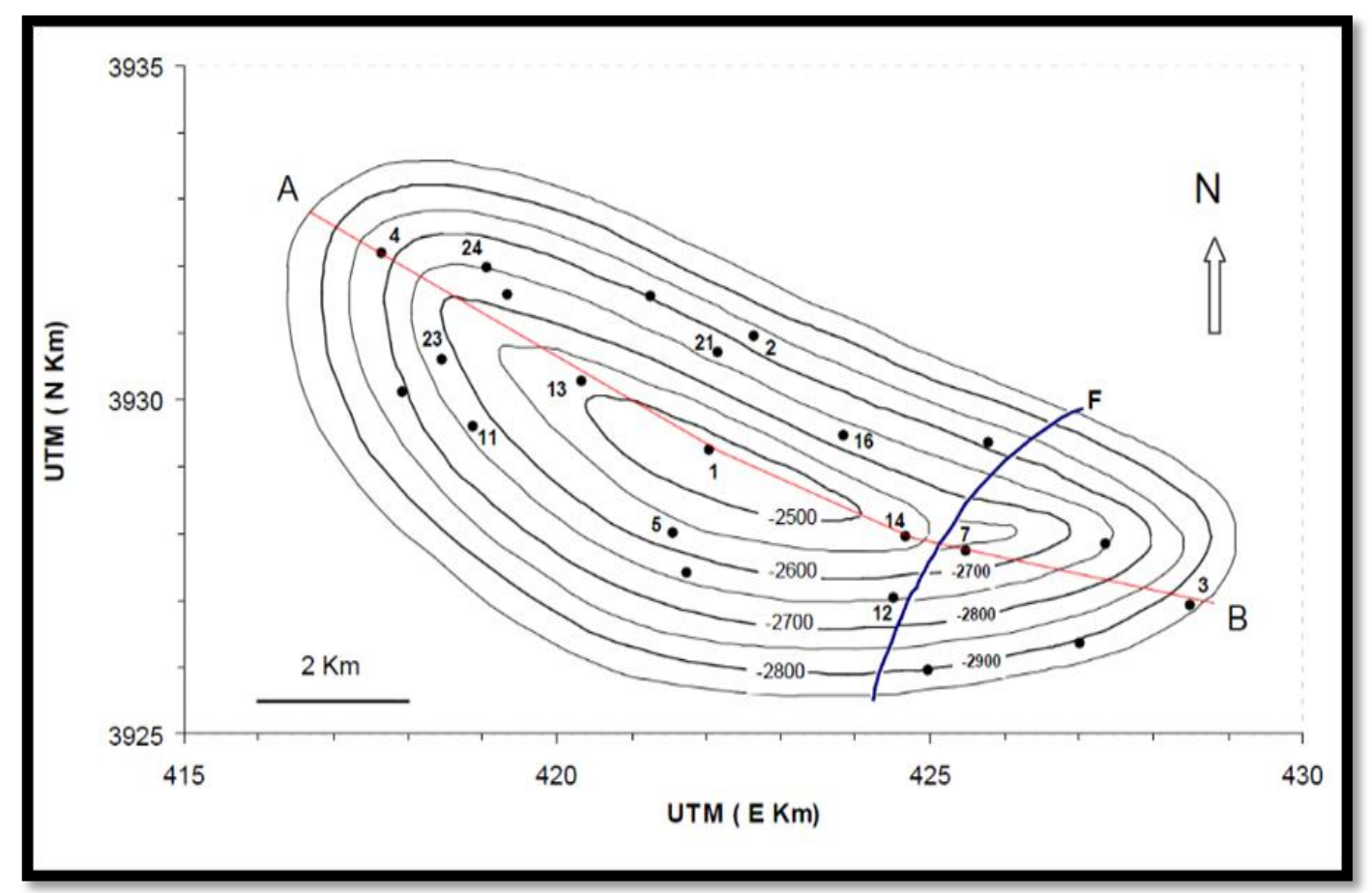

Figure 4: Structural contour map of the Upper Qamchuqa reservoir in the Khabbaz field. (Qadir, 2008)

The Static Model (Geological Model) was generated by using Petrel Software. However, to be able to use the available raw data in Petrel, several techniques were needed to prepare the data for utilization. The following steps were made to organize the data and then to build the Static model: 


\subsubsection{Wellheads Preparation}

Wellhead coordinates provided by the North Oil Company along with the well trajectory information (Table 2).

Table 2: Wellhead coordinates data

\begin{tabular}{|c|c|c|c|c|}
\hline $\begin{array}{c}\text { Well } \\
\text { names }\end{array}$ & $\begin{array}{c}\text { MD(FT } \\
\text { KB) }\end{array}$ & $\begin{array}{c}\text { Easting } \\
\mathbf{X}(\mathbf{m})\end{array}$ & $\begin{array}{c}\text { Northing } \\
\mathbf{Y}(\mathbf{m})\end{array}$ & $\begin{array}{c}\text { Production } \\
\text { Formation }\end{array}$ \\
\hline KZ_1 & 11289 & 422049 & 3929240 & Lower Qamchuqa \\
\hline KZ_2 & 11575 & 422645 & 3930946 & Tertiary \\
\hline KZ_3 & 10659 & 428298 & 3926910 & Tertiary \\
\hline KZ_4 & 10991 & 417650 & 3932200 & Upper Qamchuqa \\
\hline KZ_5 & 10827 & 421555 & 3927989 & Upper Qamchuqa \\
\hline KZ_7 & 10236 & 425502 & 3927731 & Upper Qamchuqa \\
\hline KZ_11 & 10000 & 418881 & 3929590 & Upper Qamchuqa \\
\hline KZ_12 & 10033 & 424514 & 3927037 & Upper Qamchuqa \\
\hline KZ_13 & 10531 & 420346 & 3930275 & Upper Qamchuqa \\
\hline KZ_14 & 10807 & 424685 & 3927939 & Lower Qamchuqa \\
\hline KZ_16 & 10170 & 423851 & 3929471 & Upper Qamchuqa \\
\hline KZ_21 & 9816 & 422167 & 3930713 & Upper Qamchuqa \\
\hline KZ_23 & 9701 & 418457 & 3930597 & Upper Qamchuqa \\
\hline KZ_24 & 9711 & 419356 & 3931580 & Upper Qamchuqa \\
\hline KZ_29 & 11296 & 421260 & 3931541 & Upper Qamchuqa \\
\hline KZ_31 & 9839 & 420641 & 3931468 & Upper Qamchuqa \\
\hline KZ_35 & 9757 & 419386 & 3930498 & Upper Qamchuqa \\
\hline KZ_36 & 9796 & 421550 & 3930115 & Upper Qamchuqa \\
\hline KZ_38 & 9826 & 418465 & 3931480 & Upper Qamchuqa \\
\hline KZ_40 & 10180 & 417772 & 3930557 & Upper Qamchuqa \\
\hline
\end{tabular}

Then, well heads are generated for each well in the Petrel software and the depth units are converted from meters to feet to coincide with the coordinate system setting (Table 3) 
Table 3: Well manager file

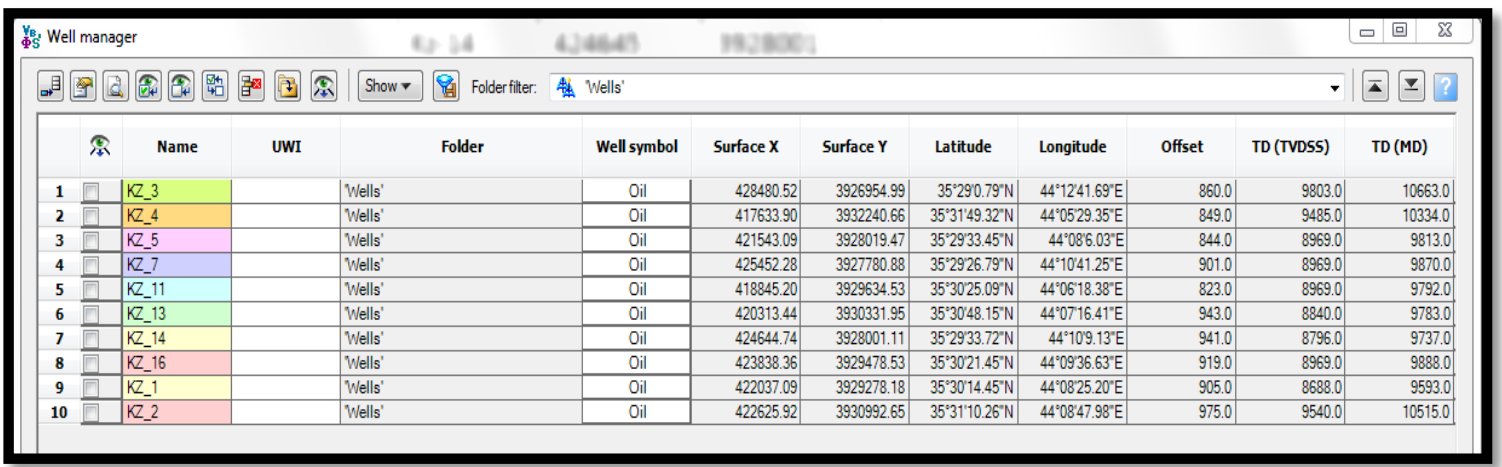

\subsubsection{Well TOPS SETting}

Well tops were available for the top and the base of the reservoir from geological survey and well logs measurements (Table 4). Some wells are partially penetrating the Upper Qamchuqa reservoir. Also, wells KZ_1, KZ_2, KZ_3, and KZ_14 are completed in a different reservoir, although they are penetrating the Upper Qamchuqa reservoir. Those wells are going to be used to help build the static model; then they will be deleted in the dynamic model.

Table 4: the Upper Qamchuqa well tops and thickness data

\begin{tabular}{|c|c|c|c|c|c|c|c|c|c|c|c|c|c|c|c|c|c|c|c|c|}
\hline Wells & KZ_1 & KZ_2 & KZ_3 & KZ_4 & KZ_5 & KZ_7 & KZ_11 & KZ_12 & KZ_13 & KZ_14 & KZ_16 & KZ_21 & KZ_23 & KZ_24 & KZ_29 & KZ_31 & KZ_35 & KZ_36 & KZ_38 & KZ_40 \\
\hline Upper Qamchuqa Top ft & 9029 & 9928 & 10505 & 9774 & 9288 & 9616 & 9465 & 9626 & 9203 & 9222 & 9534 & 9619 & 9468 & 9521 & 9790 & 9593 & 9334 & 9186 & 9524 & 9603 \\
\hline Sarmurd Top ft & 9593 & 10462 & 10659 & 10335 & 9813 & 9875 & 10029 & 10033 & 9783 & 9737 & 10043 & 9816 & 9701 & 9711 & 10367 & 9839 & 9757 & 9742 & 9826 & 10169 \\
\hline Gross Thick.ft & 564 & 535 & 154 & 561 & 525 & 259 & 564 & 407 & 581 & 515 & 509 & 197 & 233 & 190 & 577 & 246 & 423 & 556 & 302 & 566 \\
\hline
\end{tabular}

The well top data from the table (3) are used to generate well tops spreadsheets for both the Upper Qamchuqa and the underlying Upper Sarmord formation in Petrel (Table 5). 
Table 5: Well tops spreadsheets for the Upper Qamchuqa and Upper Sarmord formation

\begin{tabular}{|c|c|c|c|c|c|c|c|c|c|c|c|c|}
\hline \multicolumn{10}{|c|}{ Well top spreadsheet for 'WellTops' } & \multicolumn{3}{|c|}{ ( } \\
\hline 目 & 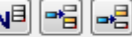 & 通田 & 国監 & Well filter: & \multicolumn{2}{|c|}{ 出 All wells } & - Edit $\mathrm{p}$ & Nor & $\checkmark$ & 量 & $\boldsymbol{-}$ & 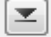 \\
\hline & $\begin{array}{c}\text { Well } \\
\text { identifier }\end{array}$ & & Surface & $\mathbf{x}$ & $\mathbf{Y}$ & $\mathbf{Z}$ & MD & $\begin{array}{l}\text { TWT } \\
\text { picked }\end{array}$ & $\begin{array}{l}\text { TWT } \\
\text { auto }\end{array}$ & $\begin{array}{c}\text { Geological } \\
\text { age }\end{array}$ & & TV \\
\hline 2 & $K Z \_1$ & & Sarmord & 422037.09 & 3929278.18 & -8688.00 & 9593.00 & & & & & \\
\hline 11 & $K Z \_1$ & & Up_Qam & 422037.09 & 3929278.18 & -8125.00 & 9030.00 & & & & & \\
\hline 8 & $K Z \_11$ & & Sarmord & 418845.20 & 3929634.53 & -9206.00 & 10029.00 & & & & & \\
\hline 17 & $K Z \_11$ & & Up_Qam & 418845.20 & 3929634.53 & -8644.00 & 9467.00 & & & & & \\
\hline 5 & $K Z \_13$ & & Sarmord & 420313.44 & 3930331.95 & -8840.00 & 9783.00 & & & & & \\
\hline 18 & $K Z \_13$ & & Up_Qam & 420313.44 & 3930331.95 & -8261.00 & 9204.00 & & & & & \\
\hline 9 & KZ_14 & & Sarmord & 424644.74 & 3928001.11 & -8796.00 & 9737.00 & & & & & \\
\hline 19 & $K Z$ __14 & & Up_Qam & 424644.74 & 3928001.11 & -8283.00 & 9224.00 & & & & & \\
\hline 10 & $K Z \_16$ & & Sarmord & 423838.36 & 3929478.53 & -9123.00 & 10042.00 & & & & & \\
\hline 20 & $K Z \_16$ & & Up_Qam & 423838.36 & 3929478.53 & -8612.00 & 9531.00 & & & & & \\
\hline 6 & $K Z \_2$ & & Sarmord & 422625.92 & 3930992.65 & -9540.00 & 10515.00 & & & & & \\
\hline 13 & $K Z \_2$ & & Up_Qam & 422625.92 & 3930992.65 & -8951.00 & 9926.00 & & & & & \\
\hline 1 & $K Z \_3$ & & Sarmord & 428480.52 & 3926954.99 & -9803.00 & 10663.00 & & & & & \\
\hline 12 & $K Z \_3$ & & Up_Qam & 428480.52 & 3926954.99 & -9645.00 & 10505.00 & & & & & \\
\hline 3 & KZ_4 & & Sarmord & 417633.90 & 3932240.66 & -9485.00 & 10334.00 & & & & & \\
\hline 14 & $K Z_{-} 4$ & & Up_Qam & 417633.90 & 3932240.66 & -8925.00 & 9774.00 & & & & & \\
\hline 7 & $K Z \_5$ & & Sarmord & 421543.09 & 3928019.47 & -8969.00 & 9813.00 & & & & & \\
\hline 15 & $K Z \_5$ & & Up_Qam & 421543.09 & 3928019.47 & -8447.00 & 9291.00 & & & & & \\
\hline 4 & $K Z \_7$ & & Sarmord & 425452.28 & 3927780.88 & -8974.00 & 9875.00 & & & & & \\
\hline 16 & $K Z_{-} 7$ & & Up_Qam & 425452.28 & 3927780.88 & -8715.00 & 9616.00 & & & & & \\
\hline
\end{tabular}

\subsubsection{SuRFACES CONSTRUCTION}

It is very significant to create surfaces from the digitized structure contour maps, especially if seismic data is not available. Therefore, the structure contour map is used as an input data to create the surface of the Upper Qamchuqa reservoir (Figure 5).

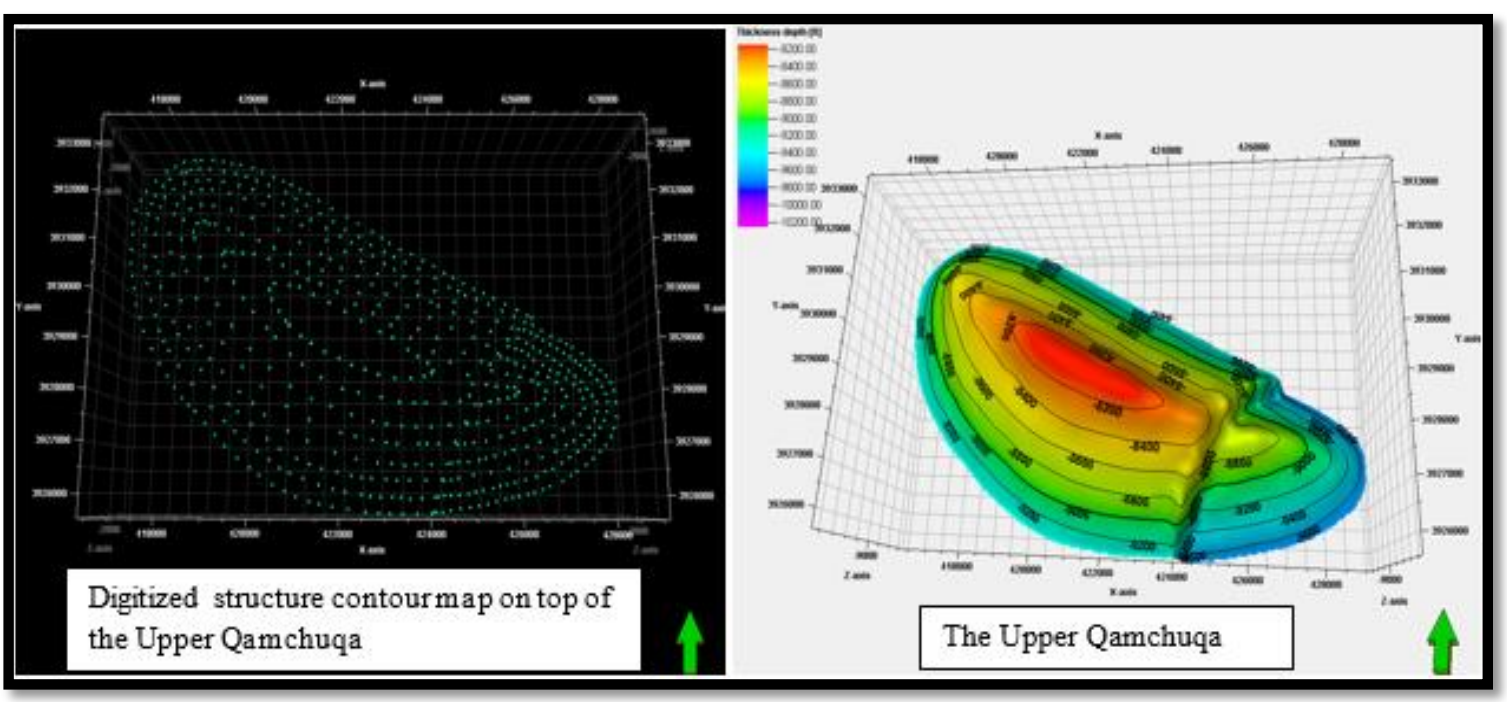

Figure 5: Digitized structure contour map and surface of the Upper Qamchuqa reservoir 
Also, surface for the Upper Sarmord formation (bottom of the Upper Qamchuqa) is created from the well tops data (Table 4) and depends upon the trend of the Upper Qamchuqa surface (Figure 6).

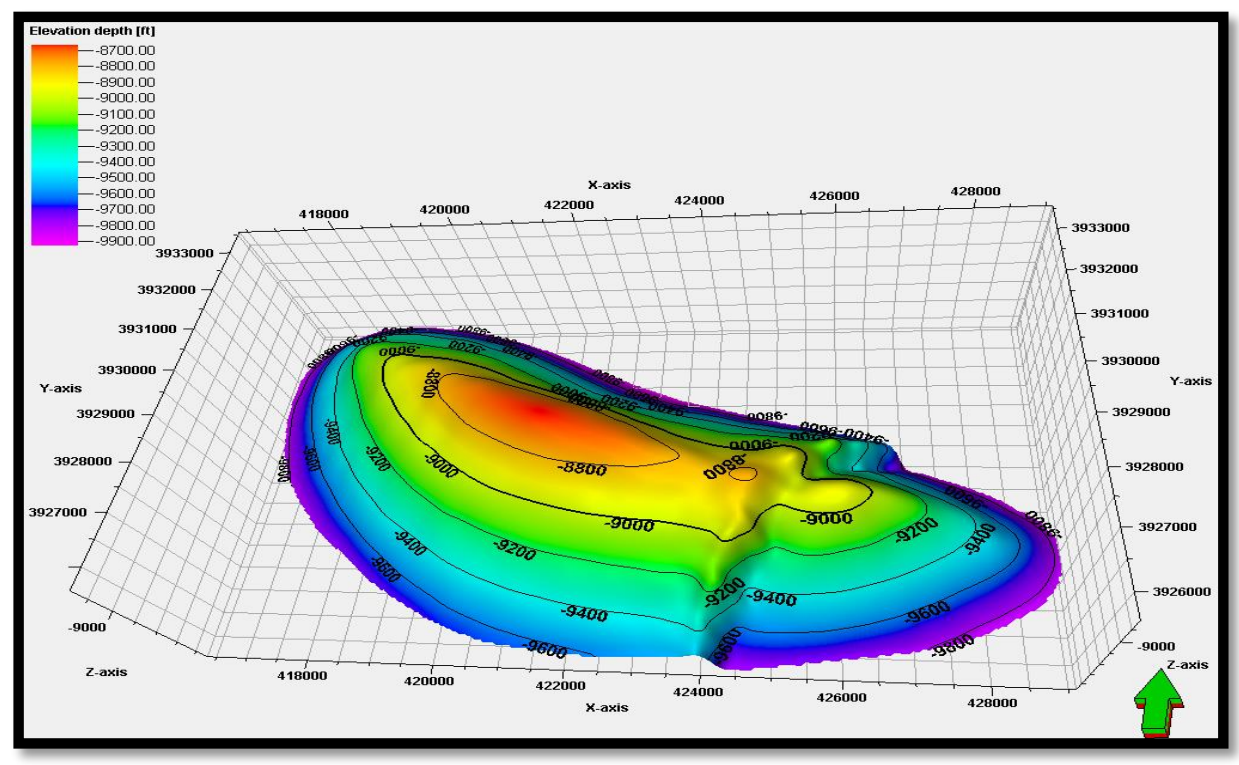

Figure 6: The Upper Sarmord formation surface (base of Upper Qamchuqa reservoir)

\subsubsection{Well Logs Digitization AND UPLOADING}

The available well logs for the reservoir were from 14 wells, which are KZ-1, KZ-2, KZ3, KZ-4, KZ-5, KZ-7, KZ-11, KZ-13, KZ-14, KZ-16, KZ-21, KZ-23, KZ-24, and KZ-29. For most wells there are Gamma Ray, Sonic, Neutron, Density, Micro Spherical Focused Log and Deep Lateral Log. Since the well logs have to be in LAS format to be able to upload them into Petrel software, they were digitized by using Neuralog Digitizing Software (Figure 7). 


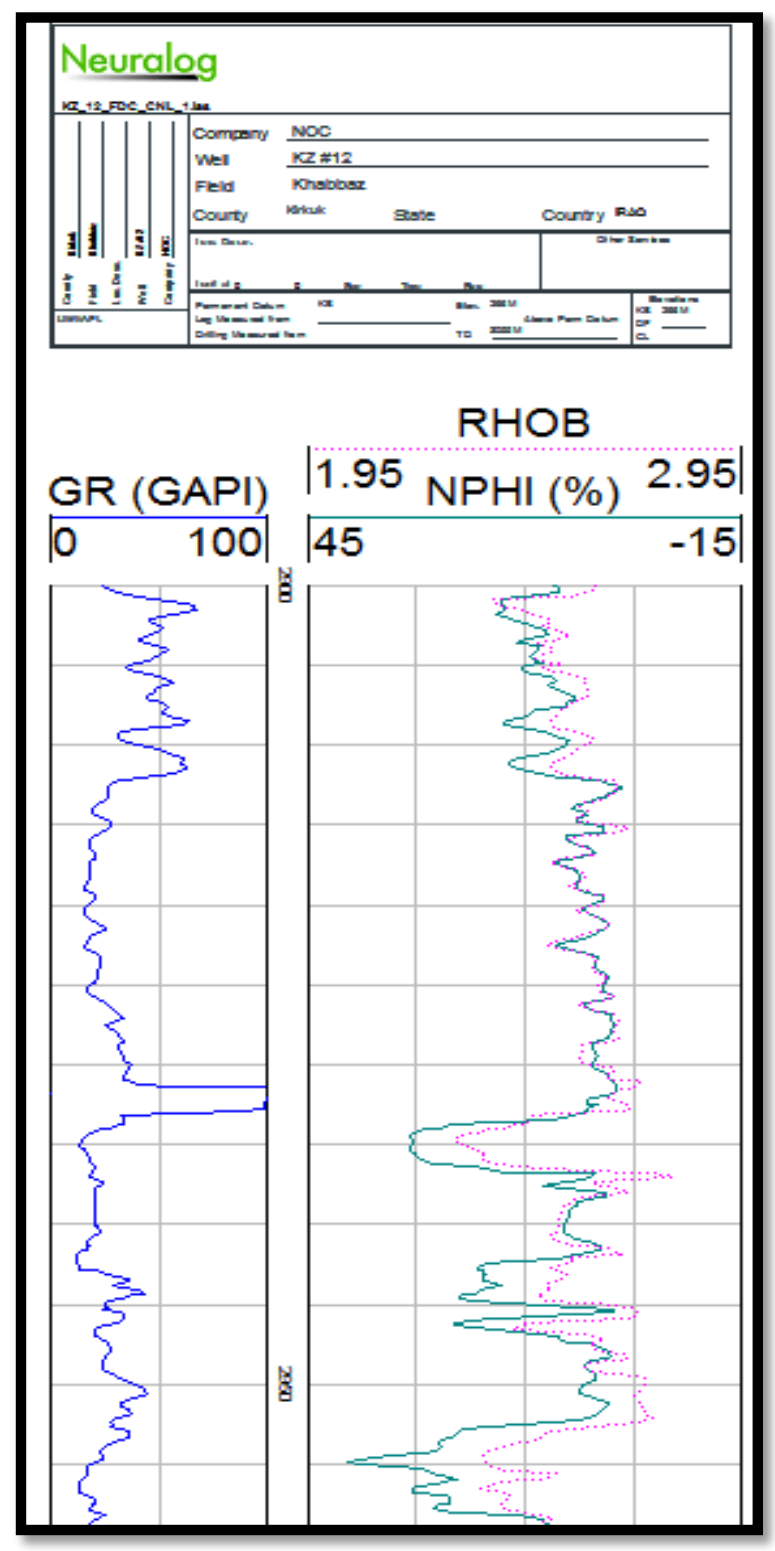

Figure 7: Neuralog Digitizer Results for the well KZ-12

After digitizing all well logs, the resulting LAS files were uploaded to Petrel. Then, a new Wells section generated for the logs and flattened on the top of the Upper Qamchuqa reservoir to check the tops picking for the Upper Qamchuqa reservoir (Figure 8). 


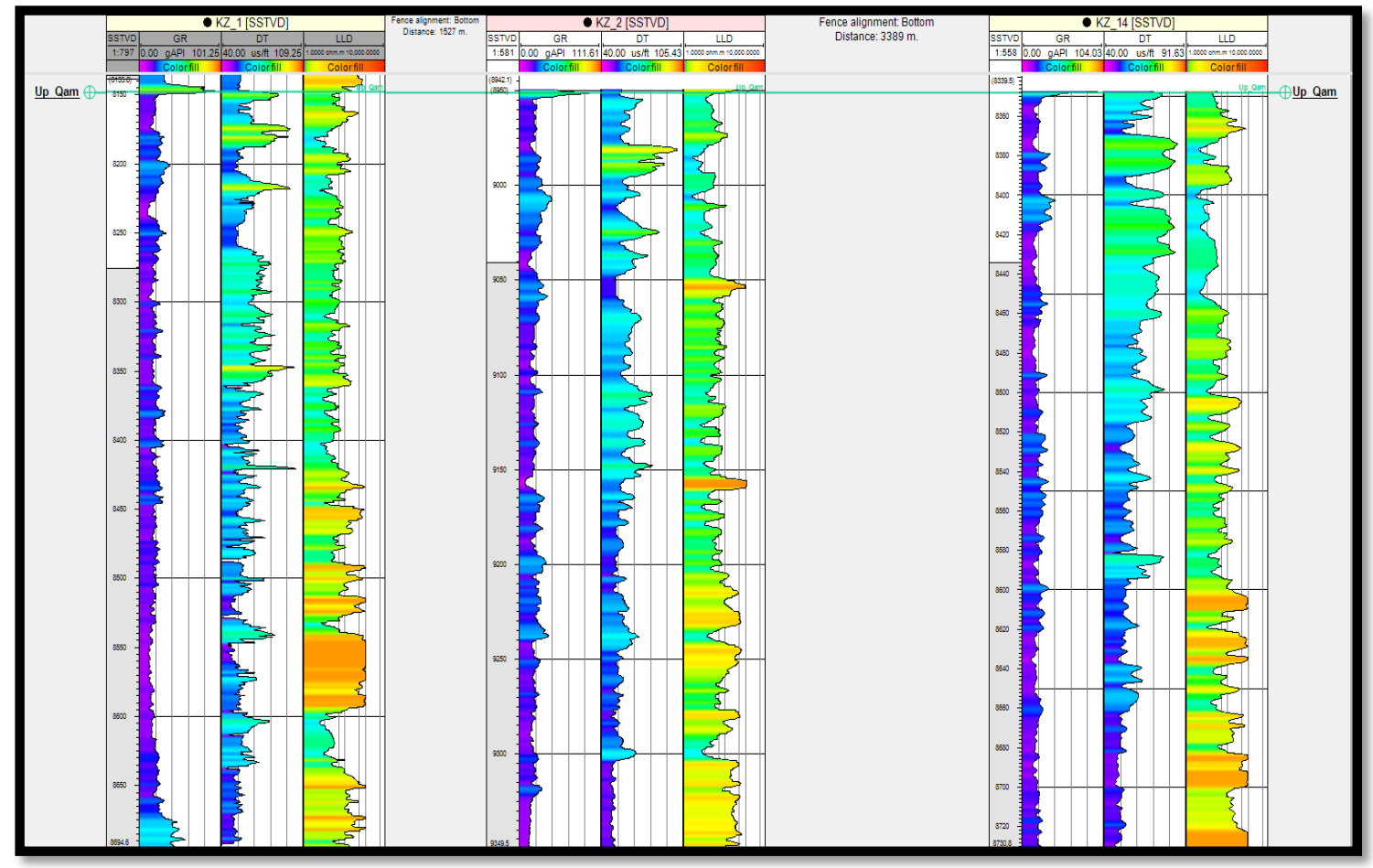

Figure 8: An example of well section flattened on the top of the Upper Qamchuqa.

The well logs that were generated in this step will be the input data for Scale Up process in property modeling to distribute the properties within each layer. Meanwhile, Scale Up is a significant part of geological modeling in the Petrel software.

\subsubsection{Corner Point Gridding}

Corner point gridding was used to make grids for the reservoir to be able to apply the fluid flow equations in the simulation model. First of all, fault modeling is generated depending on the two surfaces we created earlier (Upper Qamchuqa and Upper Sarmord surfaces), (Figure 9). However, the Fault modeling process will define the faults in the model that in turn will form the basis for creating the 3D grid. (Petrel manual, 2012). 


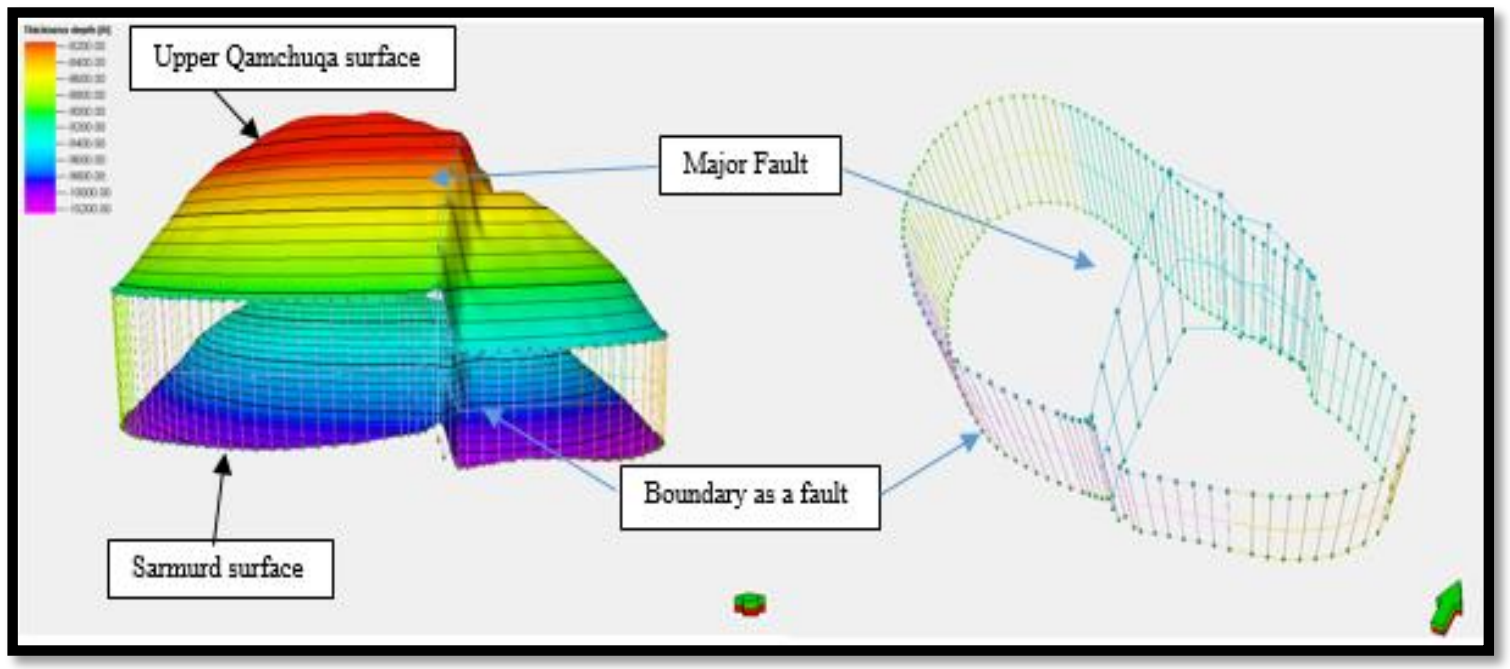

Figure 9: Fault modeling by using two surfaces.

Also, to generate a corner point 3D grid from the fault model, the next step was Pillar gridding. 'Pillar gridding is the process of making the 'Skeleton Framework.' The skeleton is a grid consisting of a Top, Mid and a Base skeleton grid, each attached to the Top, the mid and the base points of the key pillars (the fault model)" (Petrel manual, 2012). To perform Pillar gridding the direction and trends of faults and grid cell are set (Figure 10).

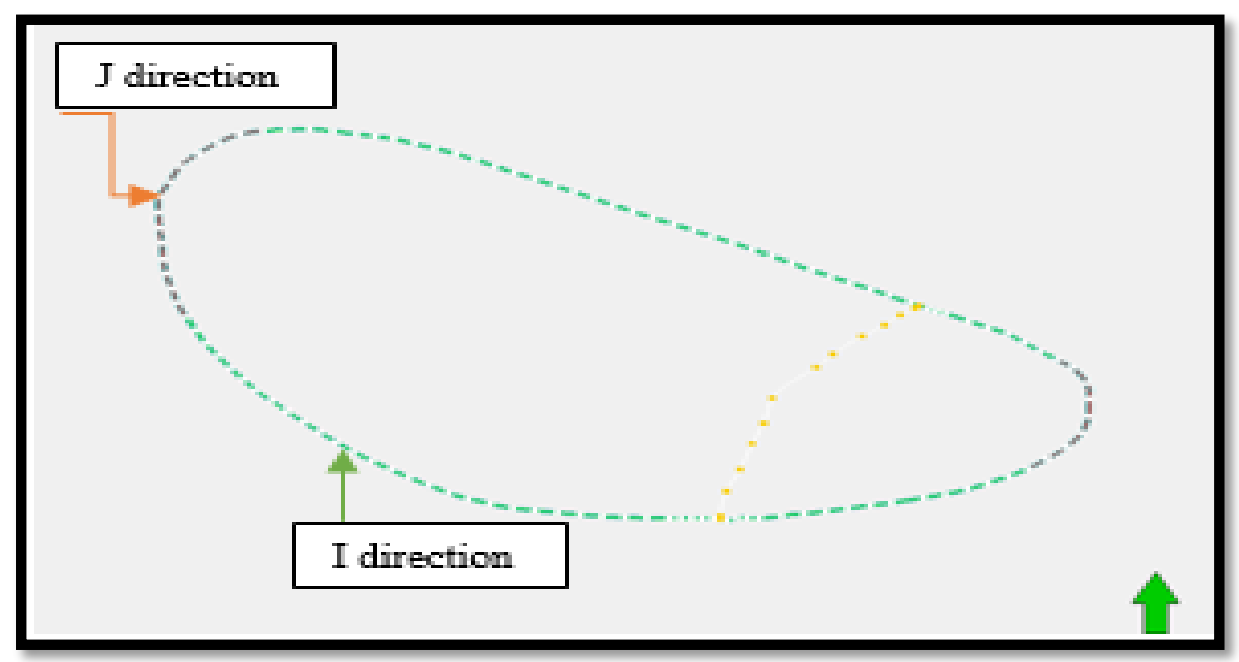

Figure 10 Selecting direction for grid cells 
As a result, Skeletons and a 3D grid are generated for the reservoir. (Figure 11).

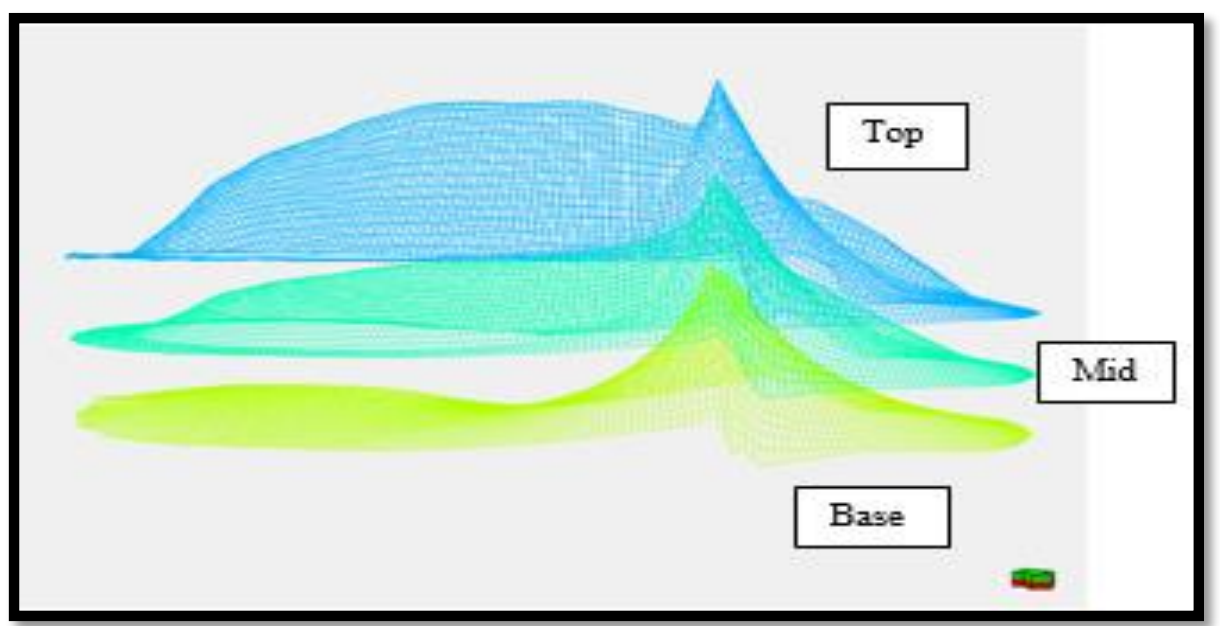

Figure 11: Produced skeletons from pillar gridding process

Once the skeleton is constructed, by inserting the input surfaces, its new horizons are built for the 3D grid system. The last step of corner point gridding was vertical layering. According to the reservoir characterization for the Upper Qamchuqa reservoir, there are three lithological units (A, B, and C) (Qadir, 2008), so the reservoir is divided into three layers (Figure 12).

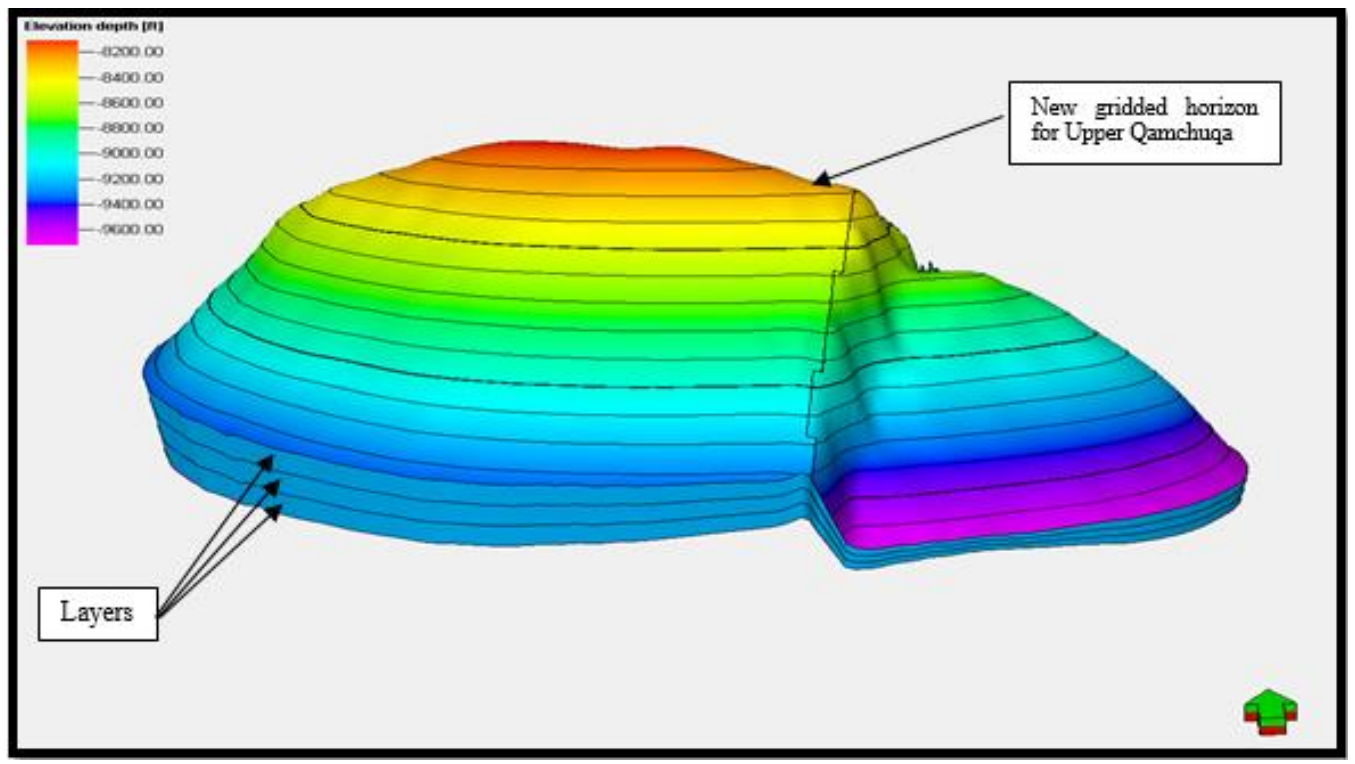

Figure 12: New gridded horizon and layers of the Upper Qamchuqa reservoir 


\subsubsection{PROPERTY MODELING}

The objective of property modeling is to distribute reservoir properties between the available wells. The two primary processes in it are Scale-Up well logs and Petrophysics modeling.The key features of the geological model are porosity and permeability. Therefore, the first thing was to prepare the porosity and permeability from well logs and core analysis data. Core analysis data were available for well KZ-16 and used as a reference to calibrate and examine the well $\log$ data.

Thus, to get a better approach for porosity utilization in the scale-up process, Neutron Porosity and Density porosity from well logs was compared with the porosity from core analysis. The best approach was Neutron porosity when comparing for well KZ_16 (See figure 13).

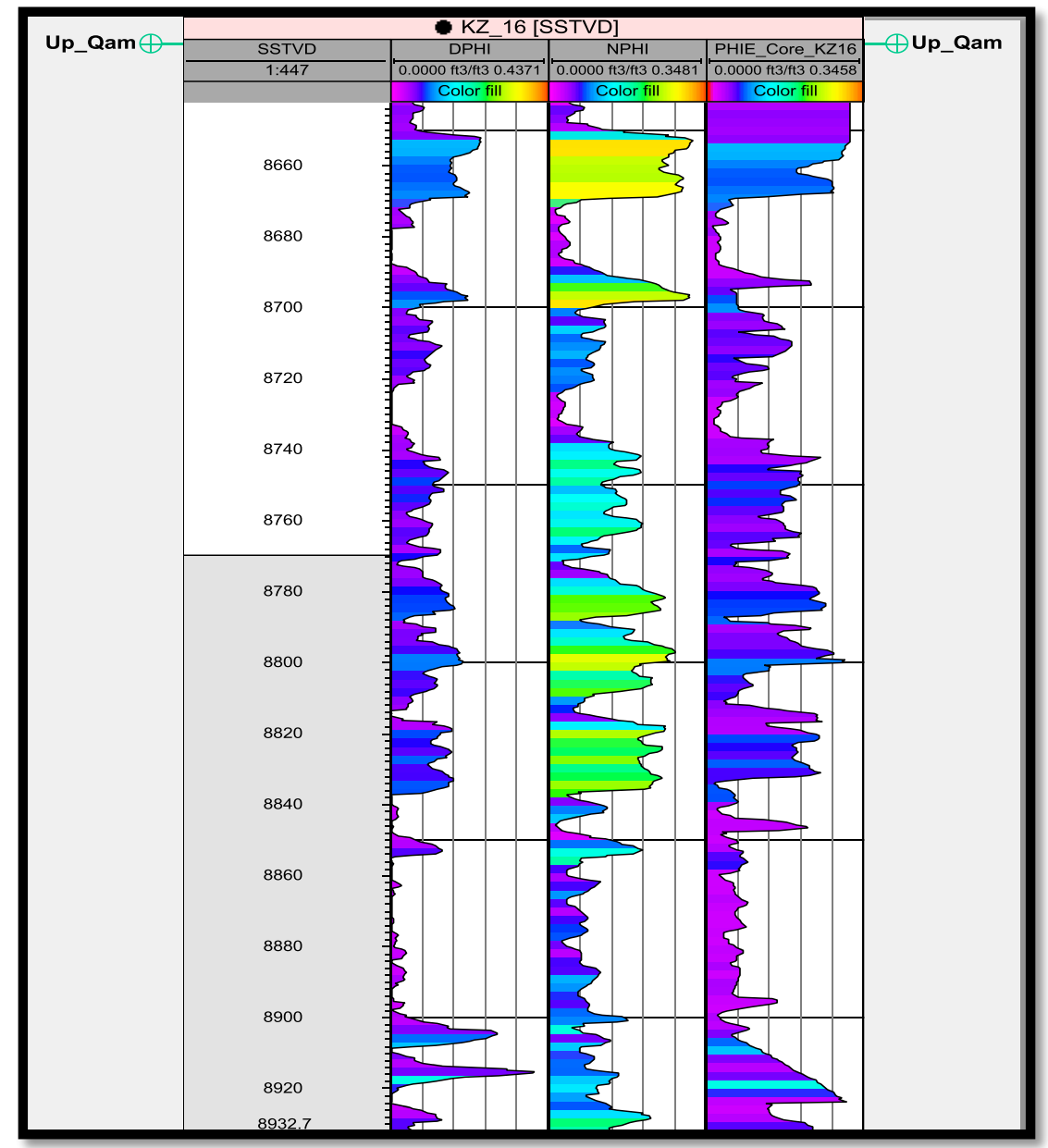

Figure 13: Comparison of well logs porosity with core analysis porosity for well KZ-16 
Several methods were used to predict the permeability from porosity and compare them with permeability from core data analysis for well KZ-16. Permeability in Carbonate Rocks does not just depend on porosity, it also depends on pore throat, sorting and grain size. So it was challenging to predict a reliable value. However, the multilinear regression (MLR) method has been used to predict permeability from well logs to consider other factors that are affecting the permeability of carbonate reservoir (Taghavi, 2005). The multilinear regression method is extracted from regression analysis concept, which connects independent values to predict a dependent value. In this case, the dependent value is log permeability, and the independent values are the average of well log data (Taghavi, 2005):

$$
\log (\mathrm{K})=(-2.488-0.0073 * \mathrm{GR}-0.619 * \text { Den }+11.128 * \mathrm{Neut}+0.050 * \Delta \mathrm{t}
$$

Where:

$\mathrm{K}=$ Permeability

GR $=$ Gamma Ray

Den $=$ Density Porosity

Neut $=$ Neutron Porosity

$\Delta \mathrm{t}=$ Sonic travel time

Therefore, the calculated permeability from the multilinear regression method is compared to the permeability from core data for well KZ-16 (See figure 14). Then, the method was utilized to predict the permeability in all wells in the Upper Qamchuqa reservoir. 


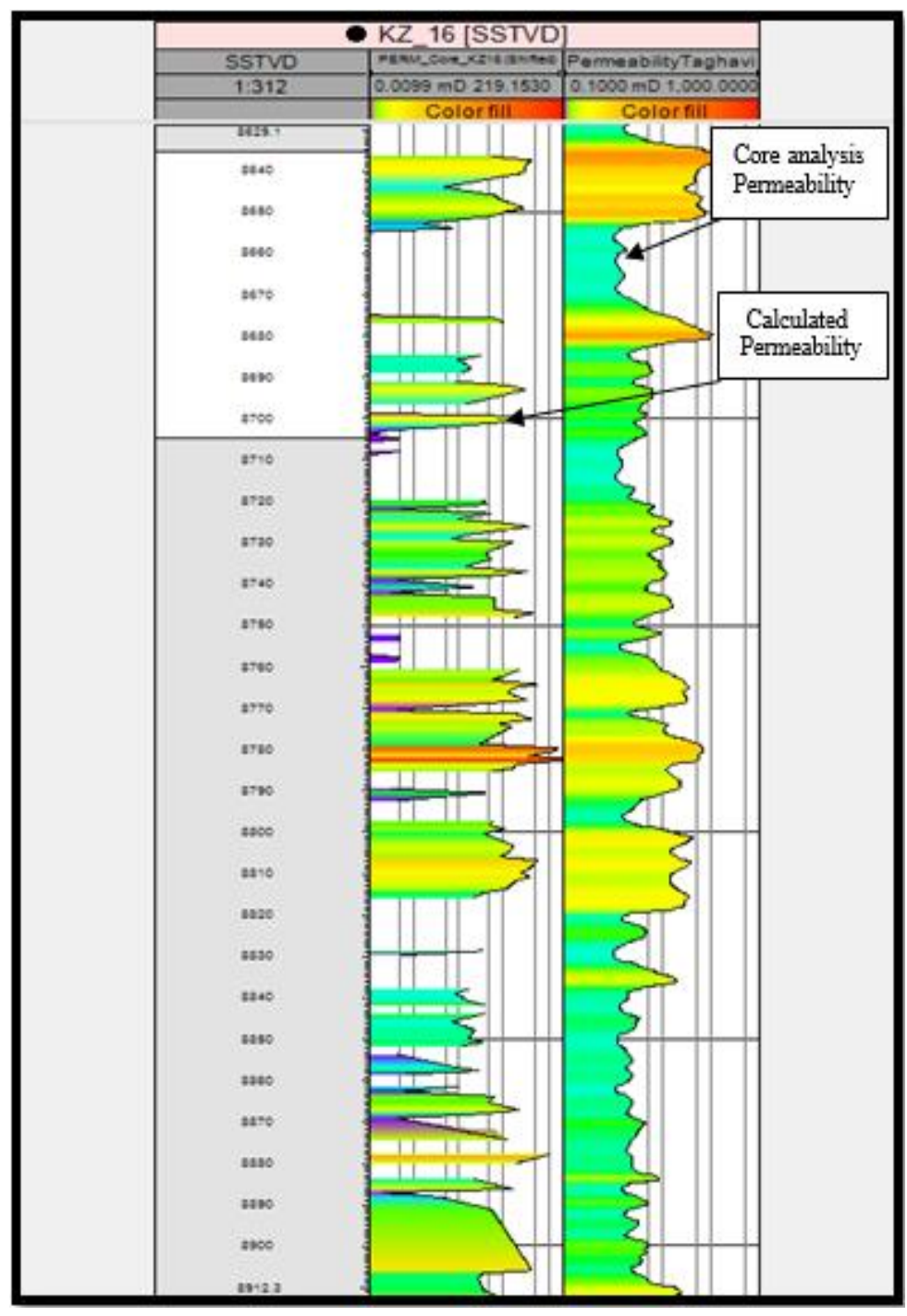

Figure 14 Comparison of calculated permeability with core analysis permeability for well KZ-16

After preparing the porosity and permeability for all 20 wells in the reservoir, and since the sampling of well logs are usually smaller than the simulation grid cells, well log data will need to be scaled up. The scale-up process requires that all log values found in a grid cell will be averaged to one value. An averaging algorithm will be automatically used by Petrel to perform the scale-up. Also, in this respect, there were three lithological layers (Units) in the reservoir (Qadir, 2008), so the resulting 3D grid will average the log values located in each layer separately (See figure 15). 


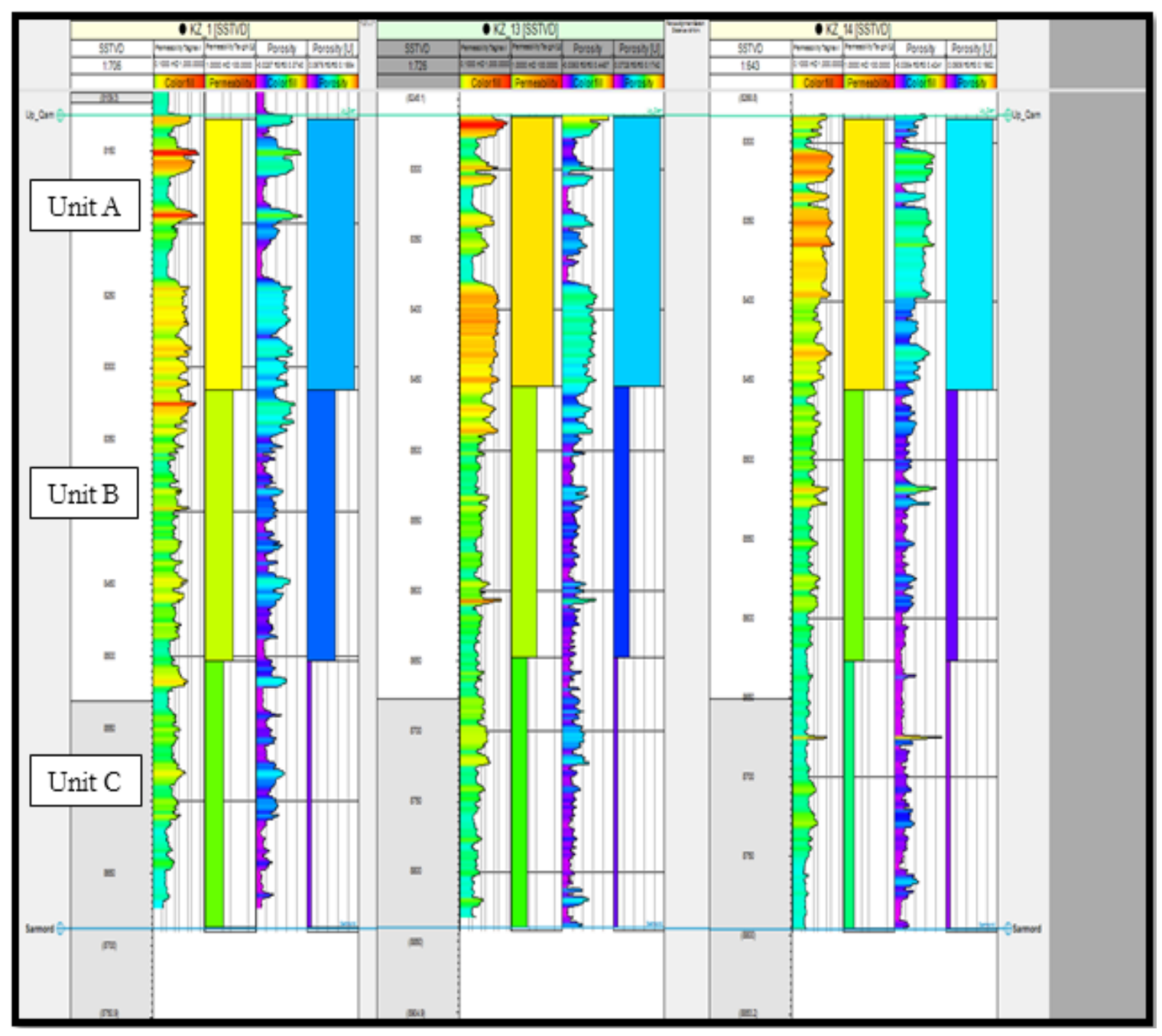

Figure 15: Scale-Up process for Porosity and Permeability, wells KZ-1, KZ-13 and KZ14

The last step in the property modeling is Petrophysics modeling. The petrophysical modeling process makes interpolation of porosity and permeability scaled up data throughout the model grid. The same algorithms used to make surfaces are also used to make interpolation in the petrophysics model; the only difference is that the interpolation is done in 3D (Petrel manual, 2012). Therefore, the Gaussian random function simulation algorithm was used to interpolate porosity and permeability data along the reservoir.

A porosity model was built for the reservoir depending on the scaled up porosity and interpolation algorithm mentioned earlier, (Figure 16). 


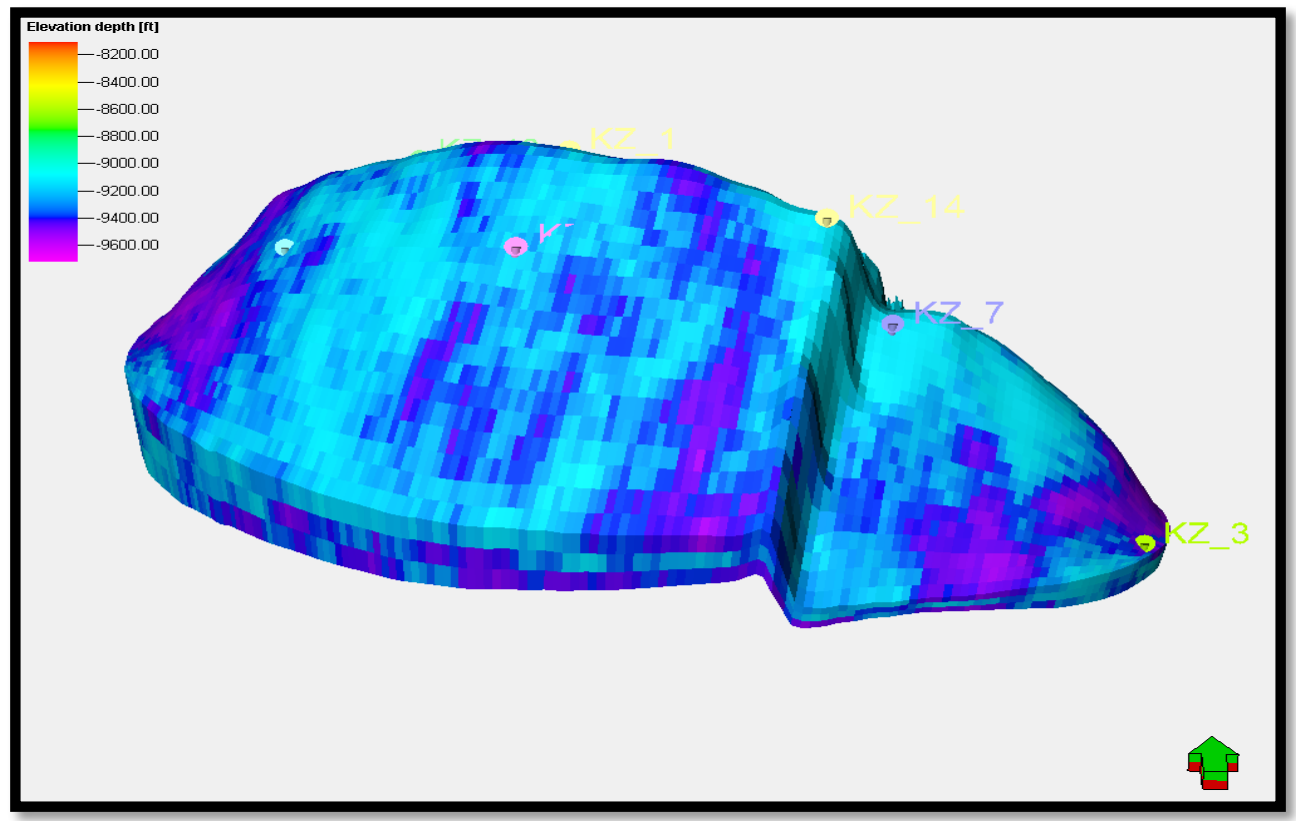

Figure 16: Porosity Model for the Upper Qamchuqa reservoir

Also, a permeability model was built for the reservoir from the scaled up permeability (Figure 17). However, the accuracy is lower than the one in porosity modeling because permeability has not been obtained directly from the well logs.

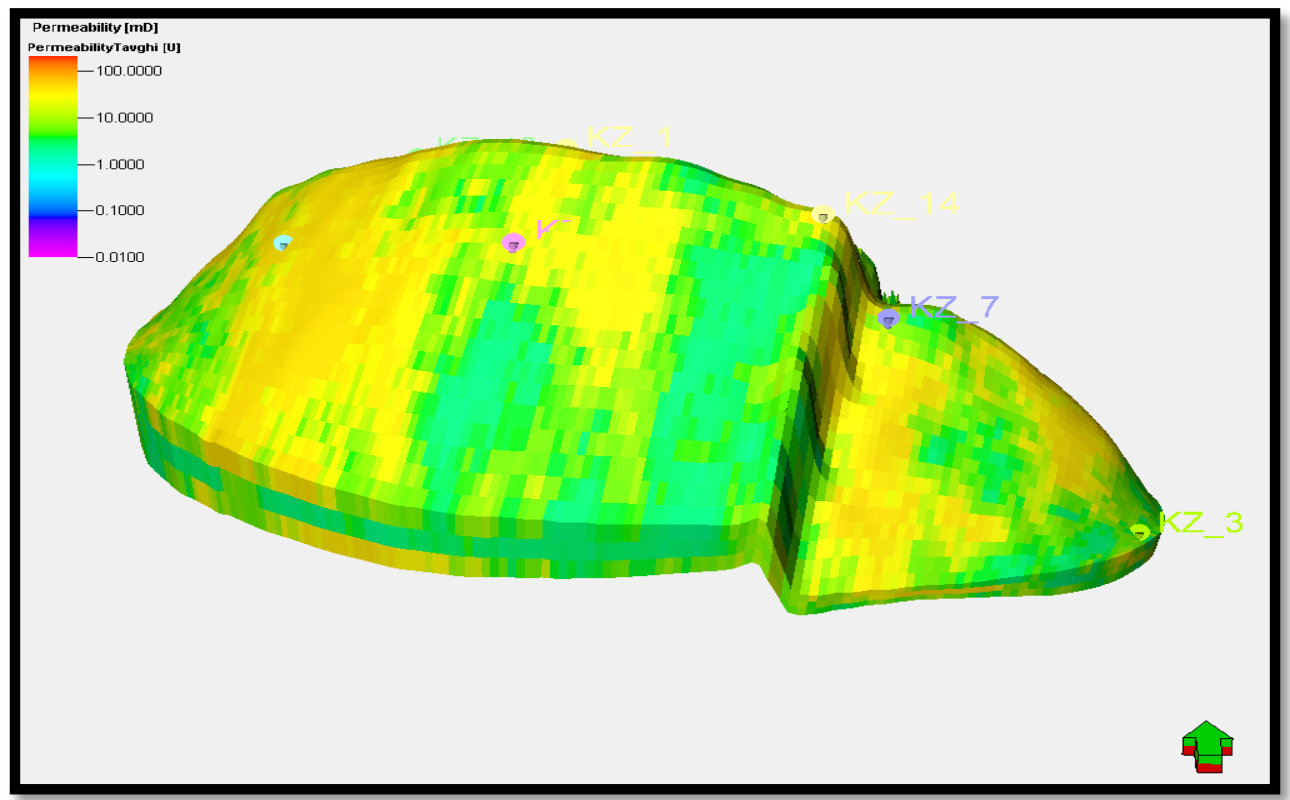

Figure 17: Permeability Model for the Upper Qamchuqa reservoir 


\subsection{Simulation Model Development}

Reservoir simulation is used by oil and gas companies to help make investment decisions, to maximize productivity, estimate reserves, and improve the performance of producing reservoirs. The evolution of computing hardware, software design and the advance in the use of numerical algorithm formulas, gave a boost to Reservoir Simulation and modeling software and lowered the time required to build up a model (Yaghi, 2013).

There are many simulation software in the industry right now, and the most common software are Petrel, Eclipse, and CMG (Computer Modelling Group). In this research, we are using the commercial CMG simulator software. The company offers three simulators, IMEX, which is a black oil simulator, GEM (compositional simulator) and STARS (thermal, compositional simulator). According to the production data and PVT data, the hydrocarbon in Upper Qamchuqa reservoir has three phases (Oil, Water, and Gas). Therefore, the black oil simulator (IMEX) utilized to develop a history matched model for the reservoir. Also, the generated simulator will be used to predict the future performance of the reservoir, to be able to make the most economical decisions regarding the development of the Khabbaz Oil Field.

\subsubsection{Dual Porosity Model.}

Since naturally fractured reservoirs have two distinct porosities, a dual porosity model will best describe and represent the heterogeneity of the reservoir. The dual porosity model was first presented by Warren and Root (1963) based on the findings of Barenblatt et al. (1960). The dual porosity models have been employed to manage the complexity of the fluid flow and transport in naturally fractured reservoirs (Hadad at El, 2012).

Therefore, a dual porosity model has been set for the Qamchuqa reservoir in CMG simulator. The start date of the simulation was January 1990 as the field began producing for the very first time. 


\subsubsection{Importing The Geological Model into the SIMULATOR.}

The previous geological model exported from Petrel as a rescue file. It consisted of three parts: 3D grid, Porosity model, and Permeability model. The rescue file was then uploaded to the CMG and provided the simulator with information about reservoir boundary, gird tops and dimension, porosity maps, permeability maps, thickness data and wells trajectory. For instance: permeability data imported with the rescue file and uploaded to CMG (Figure $18)$.

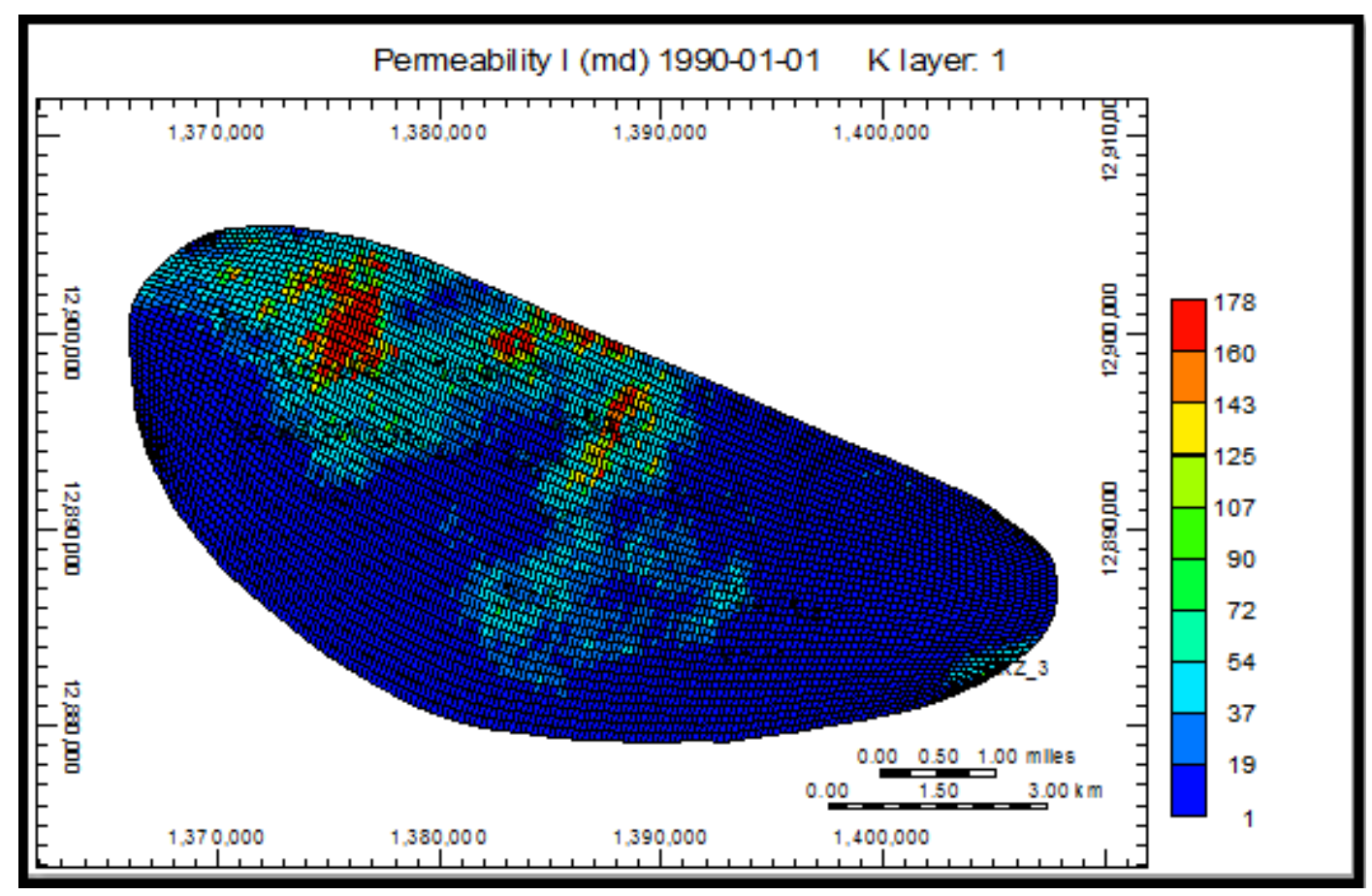

Figure 18: Permeability data imported from Petrel to $\mathrm{CMG}$

Other necessary data required for the fracture part of the reservoir, such as fracture permeability, fracture porosity, and fracture spacing was not available; there was not any date regarding the fractures provided for the research.Therefore, initial values were suggested for each of the properties mentioned above. 
For fracture porosity, the initial guess was $5 \%$ and for fracture permeability, the first estimate was $100 \mathrm{md}$. Meanwhile, an initial estimate of fracture spacing was one foot. All these values are an initial estimate and are going to be varied in history matching process.

\subsubsection{RESERVOIR INITIAL CONDITIONS.}

The initial condition data for the Upper Qamchuqa reservoir and hydrocarbon properties were available from PVT, core analysis, and other measurements. Most data collected from well KZ_4 and KZ_11.

- Reservoir Temperature $=210^{\circ} \mathrm{F}$

- Bubble Point Pressure =3815 psi

- Reference Pressure $=4364 \mathrm{psi}$

- Reference Depth $=8809 \mathrm{ft}$.

- Gas-Oil contact $=8440 \mathrm{ft}$.

- Oil-Water contact $=9160 \mathrm{ft}$.

- $\quad$ Oil API $=30.5$

- Gas gravity $=0.65$

- Rock Compressibility is set to be $2 \mathrm{E}-6$ (1/psi).

Available fluid contacts were the original contacts, which measured at the very beginning of reservoir development. Moreover, in that position, there were no new measurements to use in the simulator. Thus, the fluid contacts will be considered as a variable in the next history matching process.

\subsubsection{Relative Permeability}

Laboratory data of relative permeability obtained from core samples of well KZ_11are shown below in (Figure 19) and (Figure 20). An average of data was utilized as an input for rock types and rock-fluid properties in CMG. Nevertheless, the data then manually 
tuned in history matching process to acquire the best approach to the actual water and gas production.

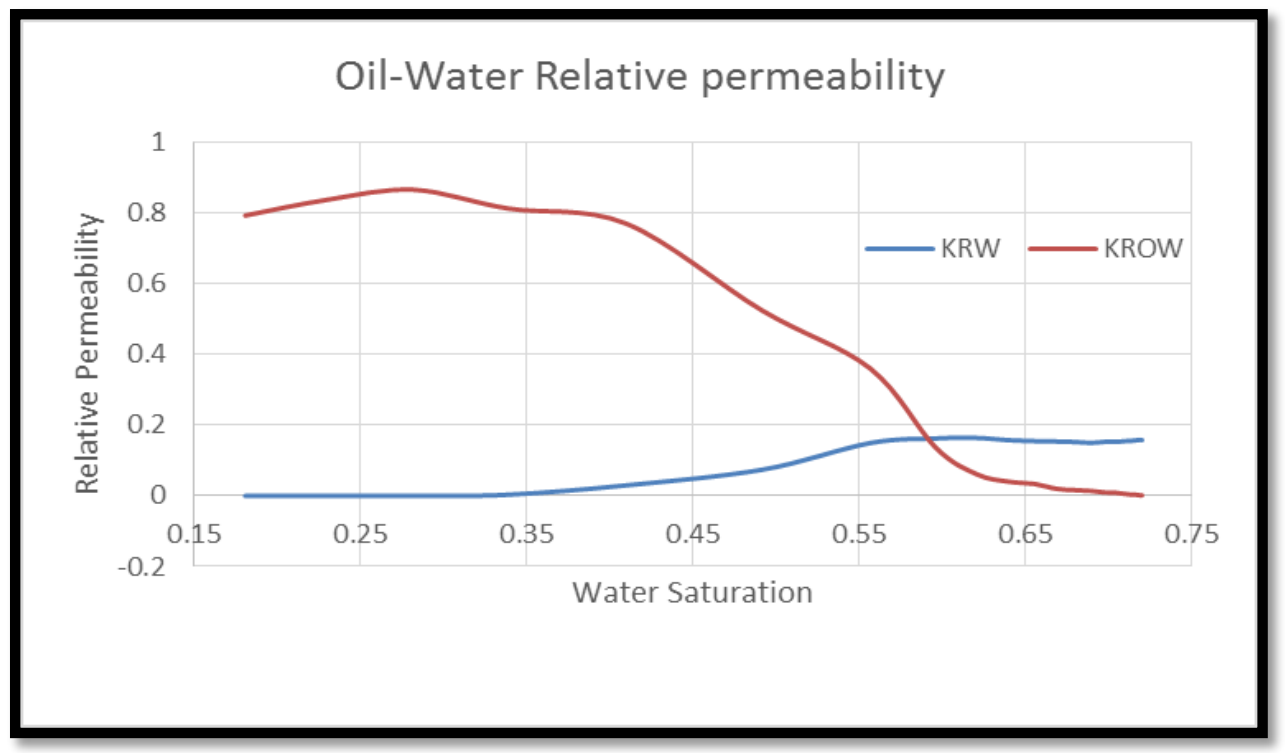

Figure 19: Relative permeability for oil and water well $\mathrm{KZ} \_11$

The curves were then smoothed by using the power law smoothing algorithm in CMG. Curves of gas-oil relative permeability were also modified by using the CMG Bulletin smoothing algorithm.

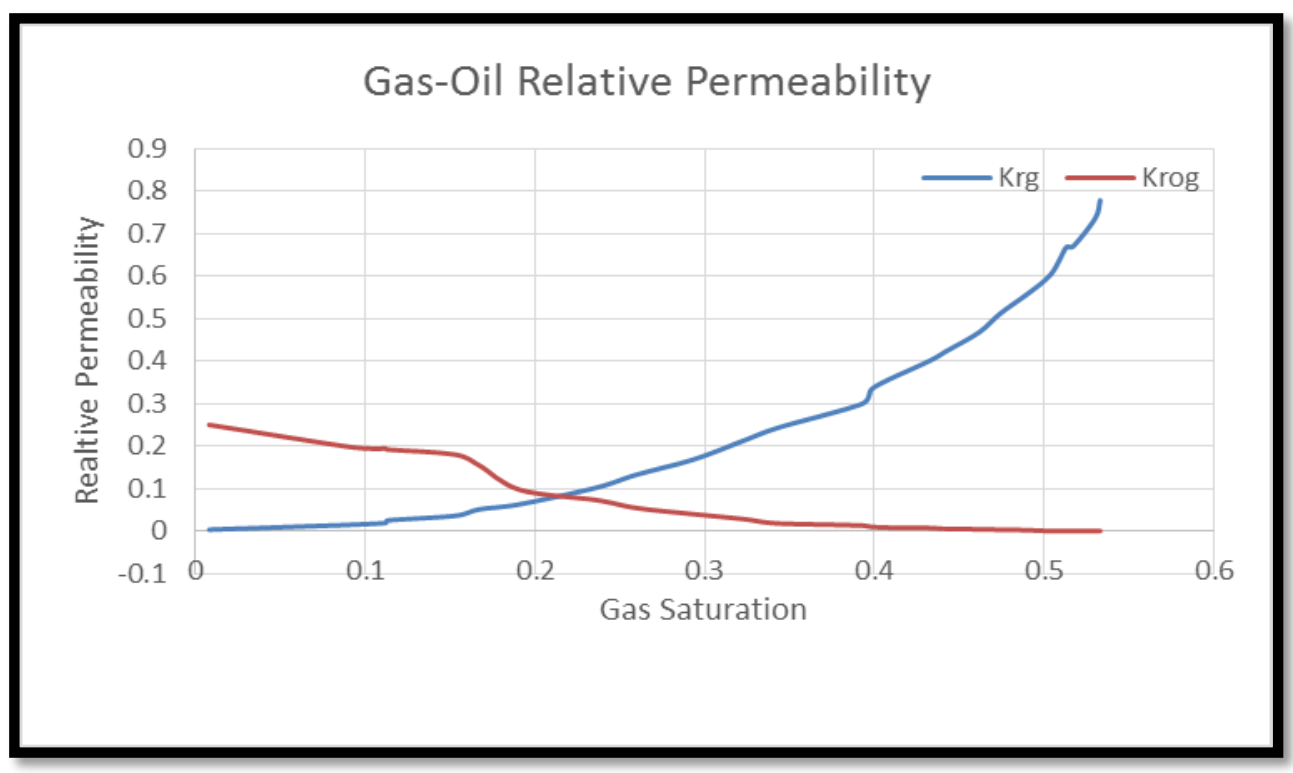

Figure 20: Relative permeability diagram for oil and gas well KZ_11 


\subsubsection{Wells Trajectories and Completion.}

Well trajectories were already set within the geological model in the Petrel software. Kelly bushing elevations measurement was reviewed for all wells (Figure 21).

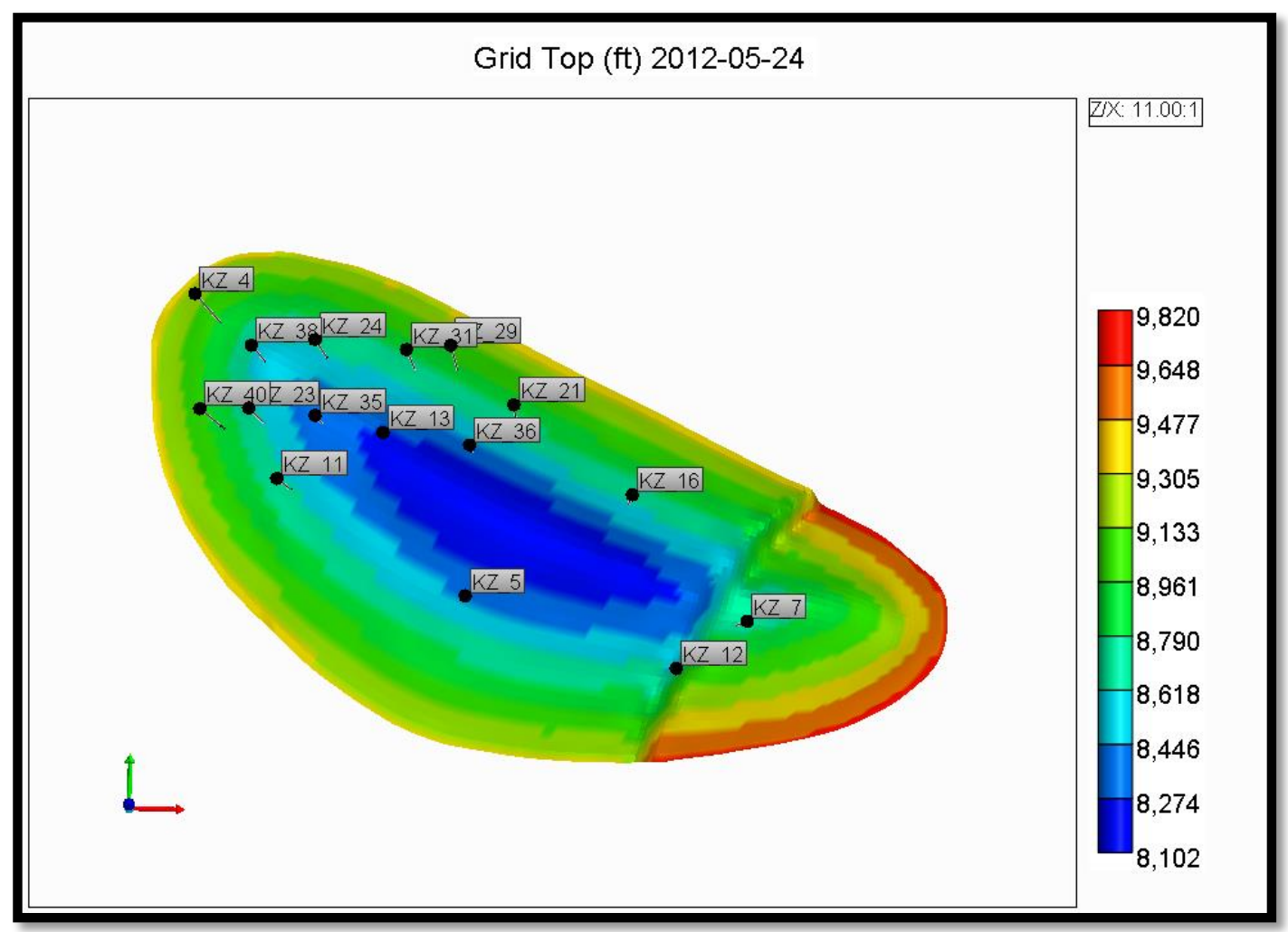

Figure 21: Wells trajectory of the Upper Qamchuqa reservoir

On the other hand, completion data needed to be set for each well in the reservoir. Some of the wells were perforated while others had openhole completion. So, completion date, type, and intervals were created for wells according to available data. 


\subsubsection{Production Dates and Well Constraints.}

Although many oil wells were drilled in Khabbaz oil field in the late 1970s and the 1980s, production from the field started in 1990. The oil production from the field (Figure 22) was delayed because of security concerns of Iraq-Iran war. The oil production was later halted again by the First Gulf War (1991) then by Iraq War (2003).

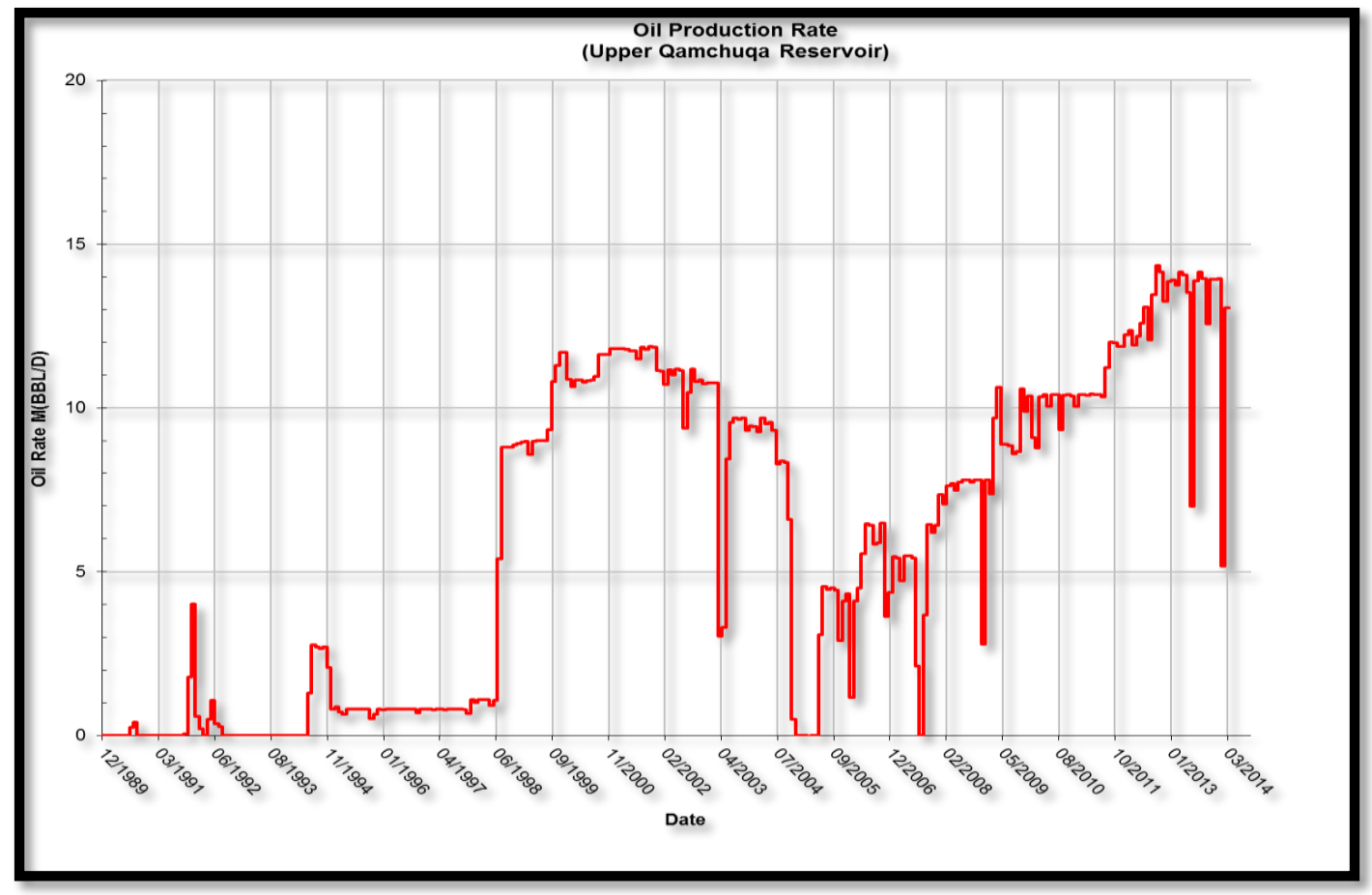

Figure 22: Daily oil production rate from Upper Qamchuqa reservoir

To set the production dates for the wells in the simulator, all 20 wells in the reservoir were identified as oil producer wells. Then, production dates were set for each well according to the actual production history. Furthermore, production constraints data were not available for the reservoir at this point. Other data, such as production tests were available and could be used to determine the production constraints. Therefore, an excel sheet developed by Guo-Ghalambor (2007) was utilized to calculate bottom hole flowing pressure (BHFP) for each well. The bottom hole flowing pressure will be used as a production constraint with a 
margin of uncertainty. The input data (Table 6) for Guo-Ghalambor method obtained from production tests and the well trajectories.

Table 6: Input data for Guo-Ghalambor method to calculate BHFP

\begin{tabular}{|c|c|c|}
\hline \multicolumn{3}{|l|}{ Input Data: } \\
\hline Total measured depth: & 9,645 & $\mathrm{ft}$ \\
\hline Average inclination angle: & 3 & deg \\
\hline Tubing I.D.: & 3.068 & in. \\
\hline Gas production rate: & $2,521,000$ & scfd \\
\hline Gas specific gravity: & 0.7 & air $=1$ \\
\hline Oil production rate: & 1900 & stb/d \\
\hline Oil specific gravity: & 0.85 & $\mathrm{H}_{2} \mathrm{O}=1$ \\
\hline Water production rate: & 0 & $\mathrm{bbl} / \mathrm{d}$ \\
\hline Water specific gravity: & 1 & $\mathrm{H}_{2} \mathrm{O}=1$ \\
\hline Solid production rate: & 1 & $\mathrm{ft}^{3} / \mathrm{d}$ \\
\hline Solid specific gravity: & 2.65 & $\mathrm{H}_{2} \mathrm{O}=1$ \\
\hline Tubing head temperature: & 80 & ${ }^{\circ} \mathrm{F}$ \\
\hline Bottom hole temperature: & 200 & ${ }^{\circ} \mathrm{F}$ \\
\hline Tubing head pressure: & 1550 & psia \\
\hline
\end{tabular}

As a result, production constraint has been calculated according to the numbers of production tests available for each well. However, some input data, such as gas production rate were not available after 2003. So, production constraints had to be assumed according to the previous information. Furthermore, few wells (KZ_1, 2, 3, and 14) had penetrated the Upper Qamchuqa reservoir, but completed in a different reservoir. Those wells were deleted from the model. In summary, a base model has been constructed for Upper Qamchuqa reservoir and ran successfully. 


\subsection{History MATChing}

\subsubsection{INTRODUCTION}

History matching is the process of modifying uncertain parameters of a reservoir to get a satisfactory match with the actual history data (flow rate, pressure, saturation). The history matching is a significant tool during the development and management phases of oil and gas reservoirs. Hence, history matched models are essential to guarantee reliable future forecasts and provide a broader understanding of the subject reservoir (Netto, Schiozer, Ligero, \& Maschio, 2003). However, history matching is an ill-posed problem (inverse) where different combinations of modified reservoir parameters can give almost the same behavior of the actual reservoir history data (Shahkarami, 2012).

An essential step in history matching procedure is distinguishing the uncertain parameters. Therefore, some parameters are known for their adequate reliability and do not need to be matched. These parameters are initial pressure, hydrocarbon PVT analysis, gross thickness, net to gross cutoff values, oil flow rates, and well locations (Cosentino, 2001). On the other hand, the most uncertain parameters that can be adjusted to get a matched model are reservoir permeability, porosity, thickness, relative permeability, capillary pressure, reservoir fluid properties, rock properties, water properties and fluid contacts (Mattax \& Dalton, 1990). Therefore, this uncertain reservoir parameter will be recognized by the following sensitivity analysis and calculated by history matching the reservoir behavior later.

Also, in this study, a commercial reservoir simulator (CMG) is utilized to simulate the Upper Qamchuqa reservoir of Khabbaz field, validated by the history match on the production rate. 


\subsubsection{Sensitivity Analysis}

"A Sensitivity Analysis Task is used for determining the overall variation of simulation results under different parameter values and/or which parameters have the greatest effect on simulation results" (CMG, 2012). Sensitivity analysis uses some simulation runs to check how sensitive the results are to various adjustable parameters. It helps to better comprehension of how different parameters impact the results. The obtained information from the sensitivity analysis can be used later in other tasks such as history matching (CMG, 2012).

Thus, performing sensitivity analysis as a pre-history matching process will provide ideas about the sensible parameters in the model and save time in the history matching process.

Therefore, a sensitivity analysis was performed to identify the parameters that have a significant impact on history matching of cumulative oil production. Therefore, a range of minimum and maximum values are assumed for the parameters (See Table 7).

\section{Table 7: Range of input parameters for sensitivity analysis process}

\begin{tabular}{|l|c|c|c|c|c|c|}
\hline Range & $\begin{array}{c}\text { Fracture Permeability } \\
\text { (VarPermFracture)(md) }\end{array}$ & $\begin{array}{c}\text { Fracture Porosity } \\
\text { (VarPorFracture) }\end{array}$ & $\begin{array}{c}\text { Water Oil Contact } \\
\text { (VarDWOC)(ft) }\end{array}$ & $\begin{array}{c}\text { Gas Oil Contact } \\
\text { (VarDGOC)(ft) }\end{array}$ & $\begin{array}{c}\text { Matrix Permeability } \\
\text { (VarMatrixFilePermeability.txt) }\end{array}$ & $\begin{array}{c}\text { Fracture Spacing } \\
\text { (VarFractureSpac)(ft) }\end{array}$ \\
\hline Lower & 40 & 0.025 & 9115 & 8438 & Permeability*1.txt & 1 \\
\hline Higher & 300 & 0.125 & 9153 & 8488 & Permeability*2.5.txt & 100 \\
\hline
\end{tabular}

The results of the sensitivity analysis indicated that, the fracture permeability and the fracture porosity have the greatest effect on the history matching process. While other parameters, such as water-oil contact and gas-oil contact has much less impact and the results were not sensitive to their adjustment (See Figure 23). 


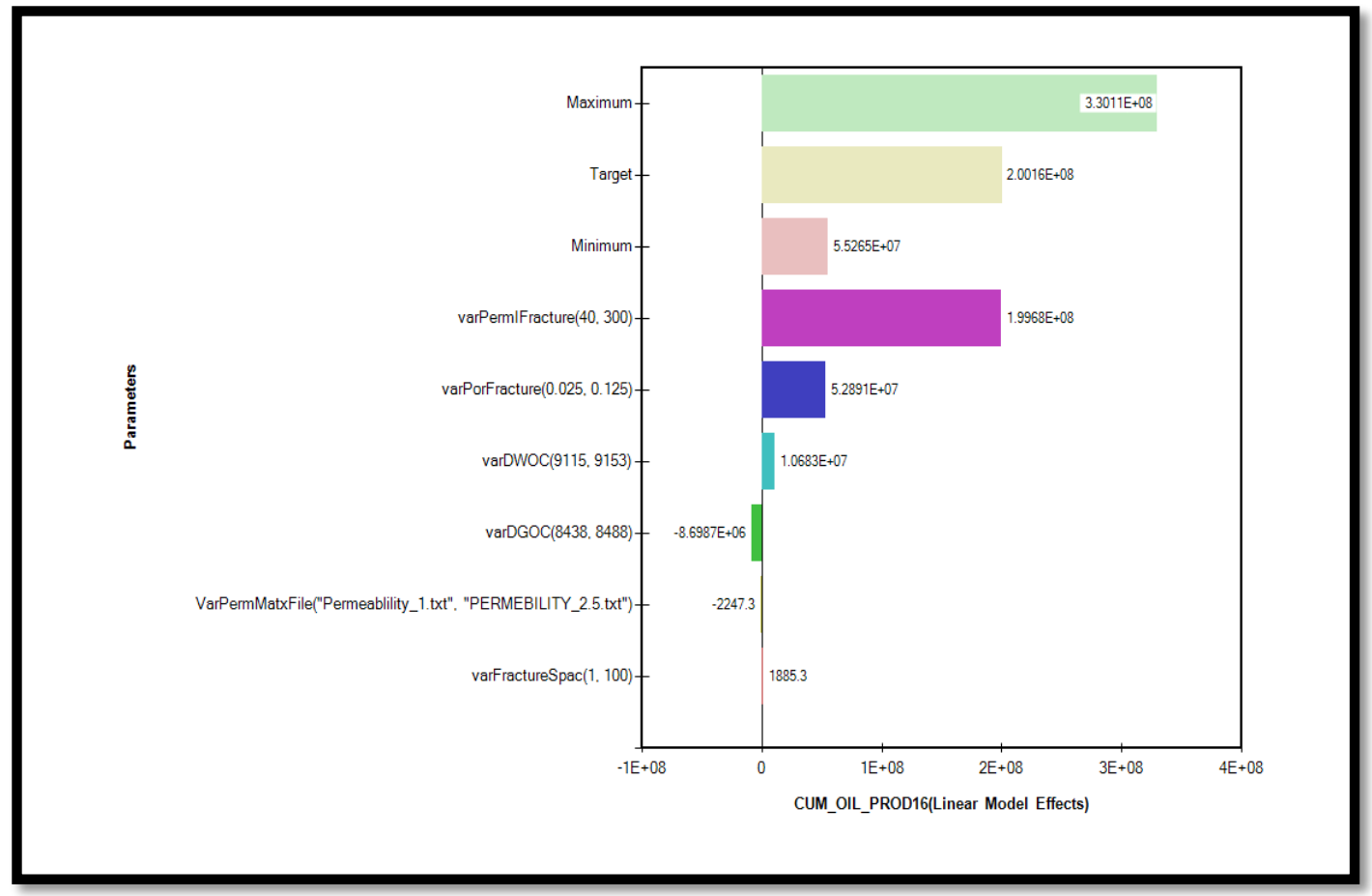

Figure 23: Sensitivity Analysis well KZ_11

In addition, the sensitivity analysis was performed by using CMOST software, which is a tool of the CMG simulation package. Nevertheless, it is important to mention that the data for fracture permeability, fracture porosity, and fracture spacing were not available. A constant value was assumed for each property for the entire reservoir in the base model. 


\subsubsection{Automated and Manual History Matching}

The historical data are very crucial for any history matching process. They consider as checking points in the matching process. So having a precise and reliable history data is the key to having a trustworthy model. Usually, oil production history data are more accurate than gas and water production data (Mattax \& Dalton, 1990). Therefore, cumulative oil production is used as primary production information in this simulation model.

Basically, automated history matching keeps the geological model credibility and estimates the input uncertain reservoir properties while attempting to match the actual field performance. The basic procedure is to begin with an initial parameter guess and improve it by incorporating field data in an automatic loop. The match will be evaluated between the measured and estimated data by using an objective function as mention earlier (Shahkarami, 2012).

Automated history matching process was performed by using CMOST software in CMG simulator. The history matching allowed varying the assumed reservoir properties and finding the best property value for each well in the reservoir. So, for the first run of history matching the following assumptions were made for the entire reservoir:

Fracture Permeability $=25,50,75,100,150,200 \mathrm{MD}$

Fracture Porosity $=0.025,0.05,0.075,0.1$

Fracture Spacing $=0.5,1,1.25,1.5,2 \mathrm{ft}$. 
Then, from the best match of each well, property values were picked, and new property maps were created for the reservoir. For example, fracture permeability property was selected from best match of each well and put together to form a fracture permeability map for the entire reservoir. (See Table 8).

Table 8: Property map created according to history matching data

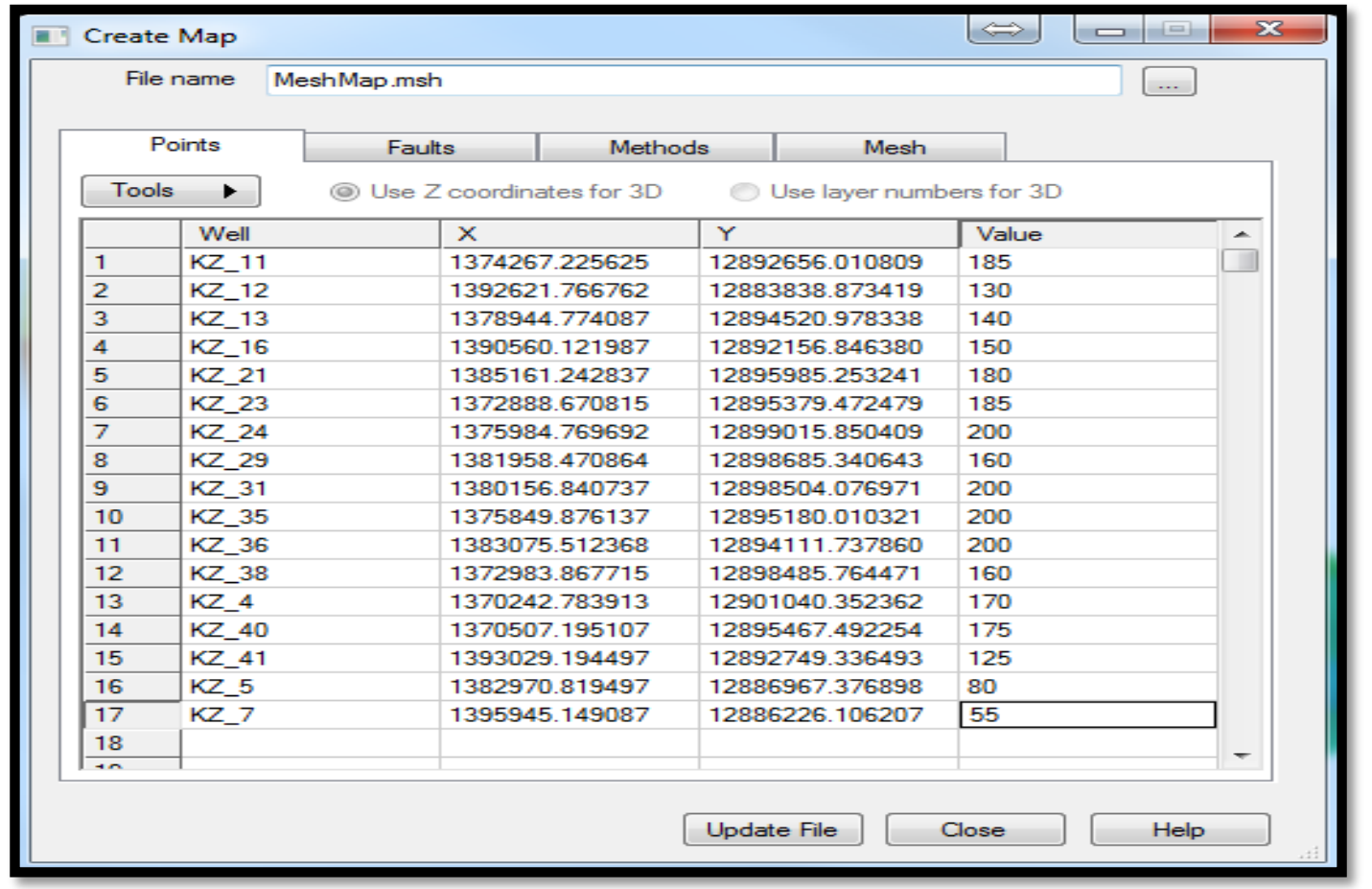

Default interpolation algorithm (inverse distance estimation) is used to create the maps for fracture permeability, fracture porosity, and fracture spacing. Thus, the next run gave better matching with production history data. However, to improve the matching, manually tuning the properties was required for each well separately. The manually history matching is a trial and error process where the error evaluated between the observed data and modeled data and the reservoir parameters adjusted manually to get a better match.

Furthermore, predicted cumulative oil production is used as an input parameter to compare with the actual production history and check the converging of each run (Figure 24). 


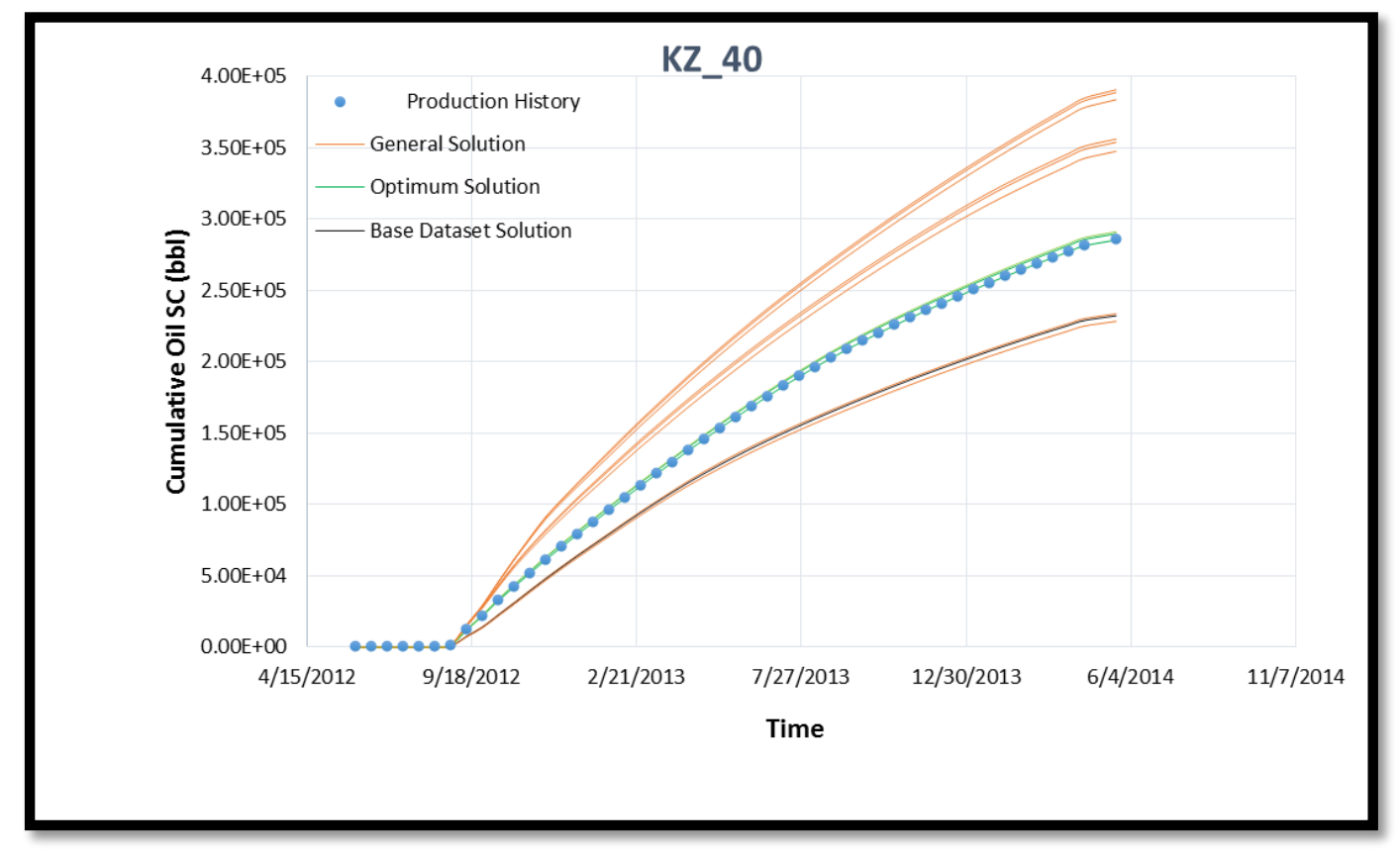

Figure 24: First History matching run well KZ_40

Consequently, series of simulation runs performed by manually adjusting the reservoir parameters for each well to get the best possible approach.

On the other hand, the predicted water production rate for some wells was much higher than actual water production. Consequently, the oil-water relative permeability data had to be revised. Fine-tuning the irreducible water saturation and lowering the entire water permeability curve helped to achieve a better match for water production. Therefore, improved results for history matching were gained.

Subsequently, the previous procedure was repeated until an adequate history matched model was obtained. The degree of acceptable match was achieved by determining the history matching error objective function for each run. The historic match Error objective function measures the relative difference between the simulation results and measured production data (CMG, 2012).

Finally, a satisfactory history matching of the cumulative oil production was achieved (Figure 25), and the model also validated by history matching the cumulative gas 
production (Figure 26). However, cumulative gas production field data were available until 2003 and obtained from production tests.

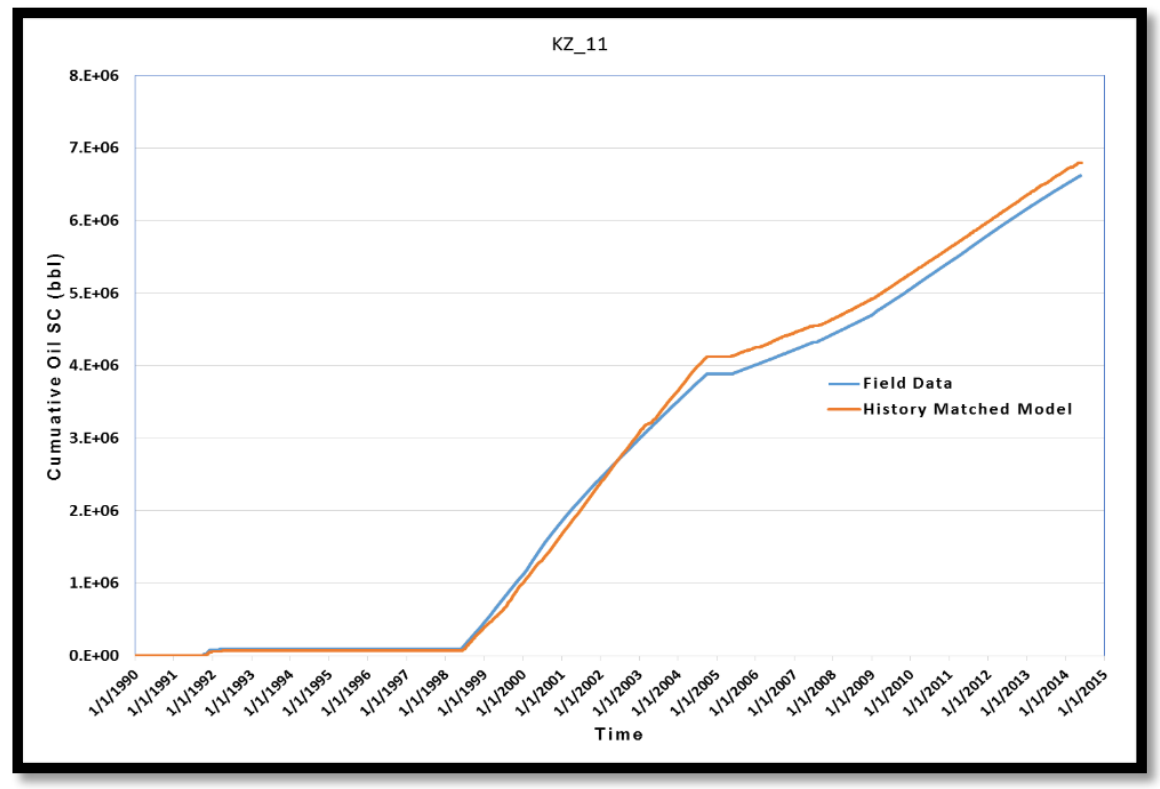

Figure 25: History matched model of cumulative oil production, well KZ_11

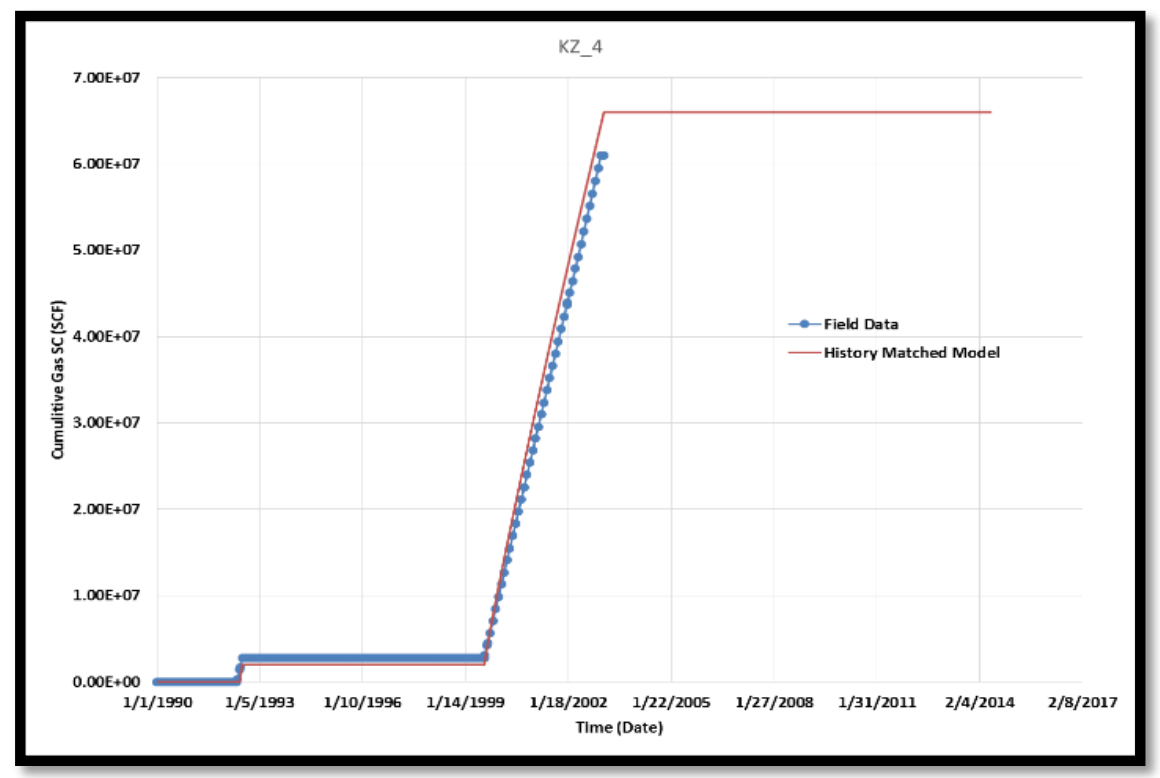

Figure 26: History matched model of cumulative gas production, well KZ_4 


\section{Chapter 4: Results AND Discussions}

\subsection{Natural Fractures Parameters' Impact on the HiSTORY MATCHING}

In this section, reservoir parameters that influence the history matching process has been investigated. A sensitivity analysis has been performed to analyze the parameters' impact on the history matching. Also, Tornado plots describes the sensitivity analysis results and are employed to distinguish the comparative importance of the variables (parameters). Moreover, the parameters in the tornado plots are ordered from having the greatest effect on the objective function to having the least effect. The objective function for this analysis was the cumulative oil production for each well (See Figure 27). Also, the maximum and minimum bars in tornado plots refers to the objective functions (cumulative oil production) values, while the target bar represents the objective function obtained from the field history file (CMG, 2012).

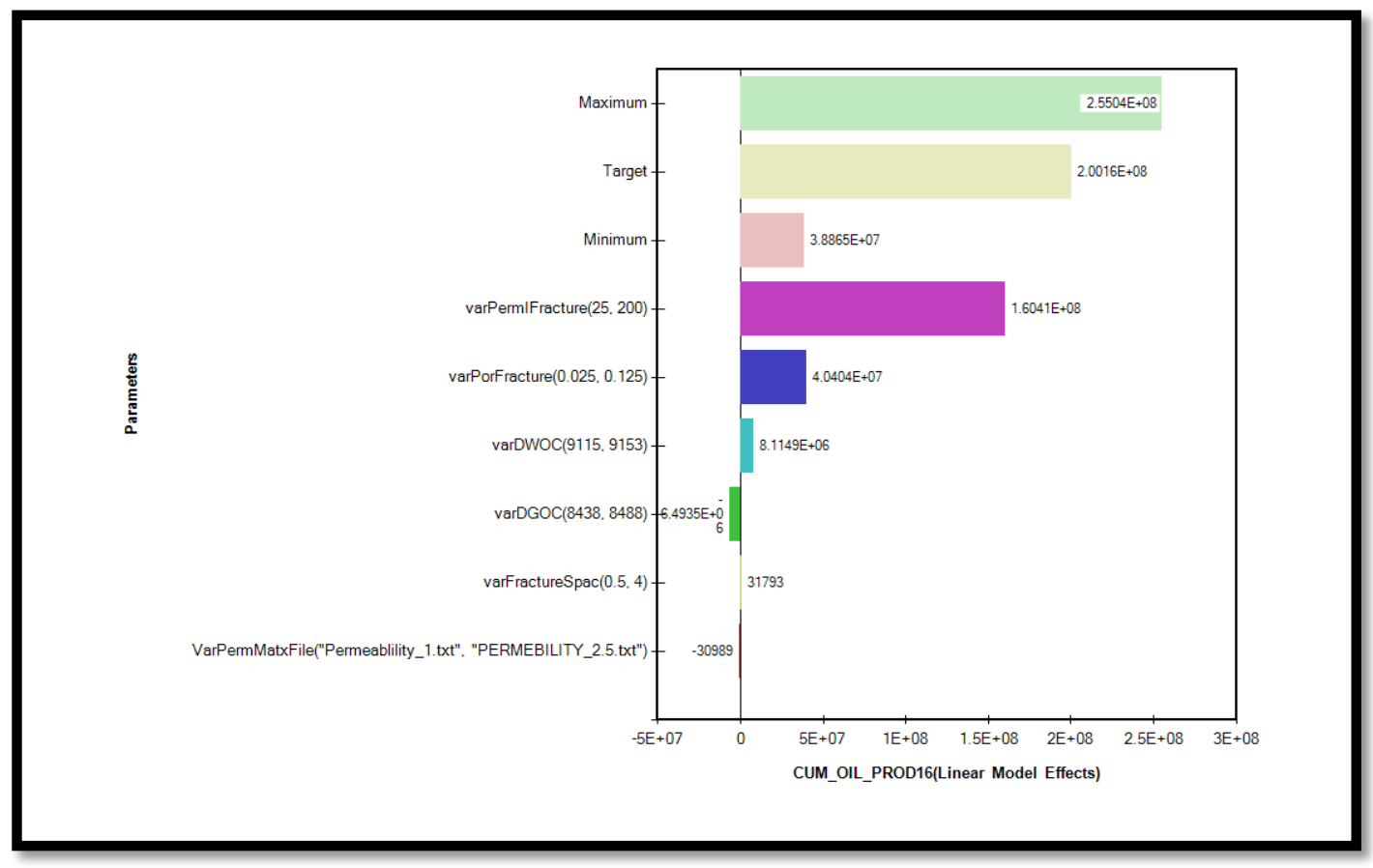

Figure 27: Tornado plot for cumulative oil production (objective function), KZ_16 


\subsubsection{Natural Fracture Permeability}

Natural fracture permeability has a significant impact on the history matching of the cumulative oil production. The fracture permeability (varPermFracture) is varied from 25$200 \mathrm{md}$. Figure 28 displays the effect of fracture permeability in a sensitivity analysis tornado chart of well KZ_16. As can be noted, increasing the fracture permeability has a positive impact on the history matching process.

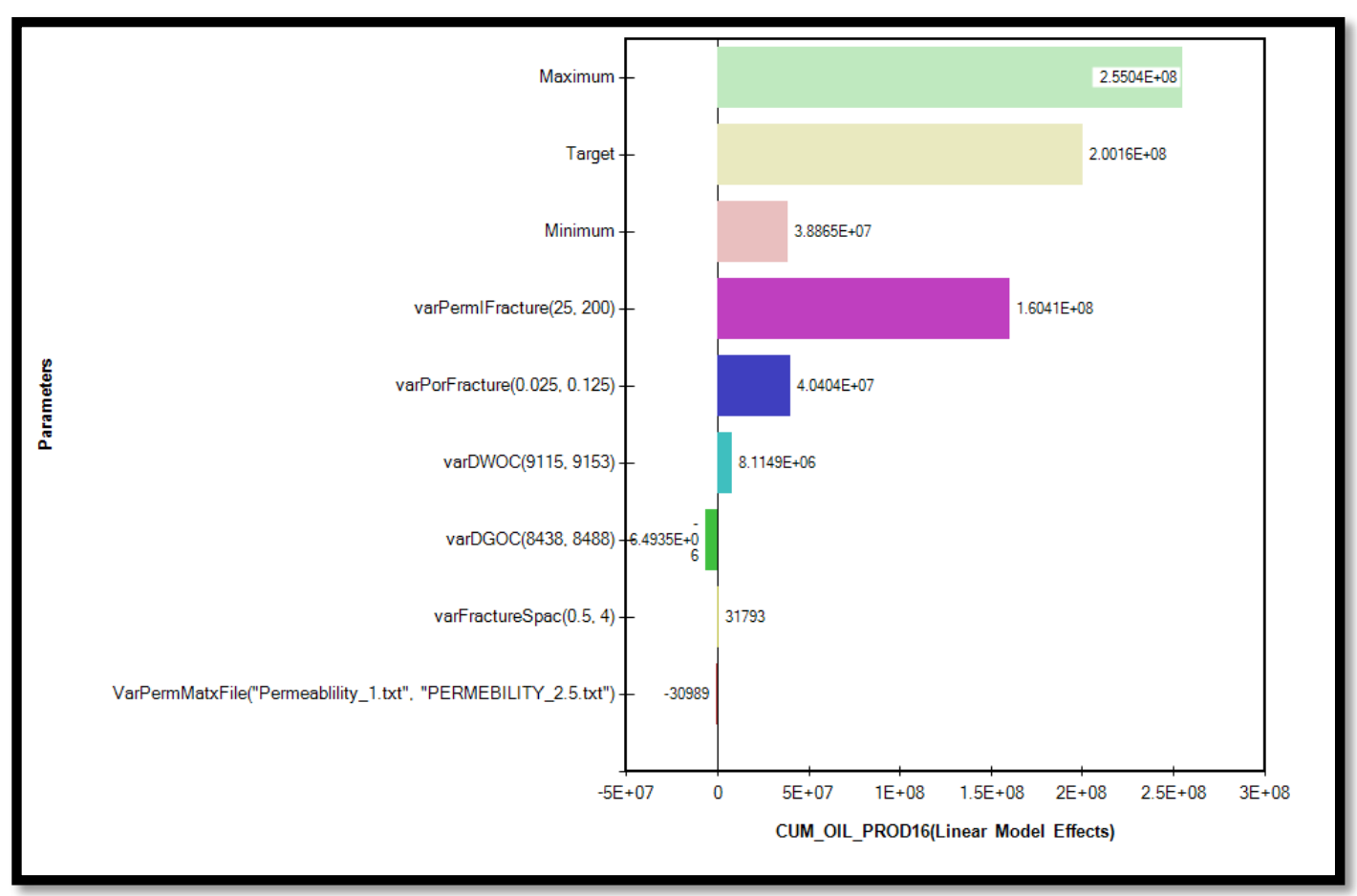

Figure 28: Fracture permeability impact on history matching process, KZ_16 


\subsubsection{NATURAL FRACTURE POROSITY}

Fracture porosity is varied from 5-10\% throughout the reservoir and appeared to have the second most significant impact on production. Figure 29 illustrates the effect of fracture porosity (varPorFracure) on the history matching of cumulative oil production for well KZ_31.

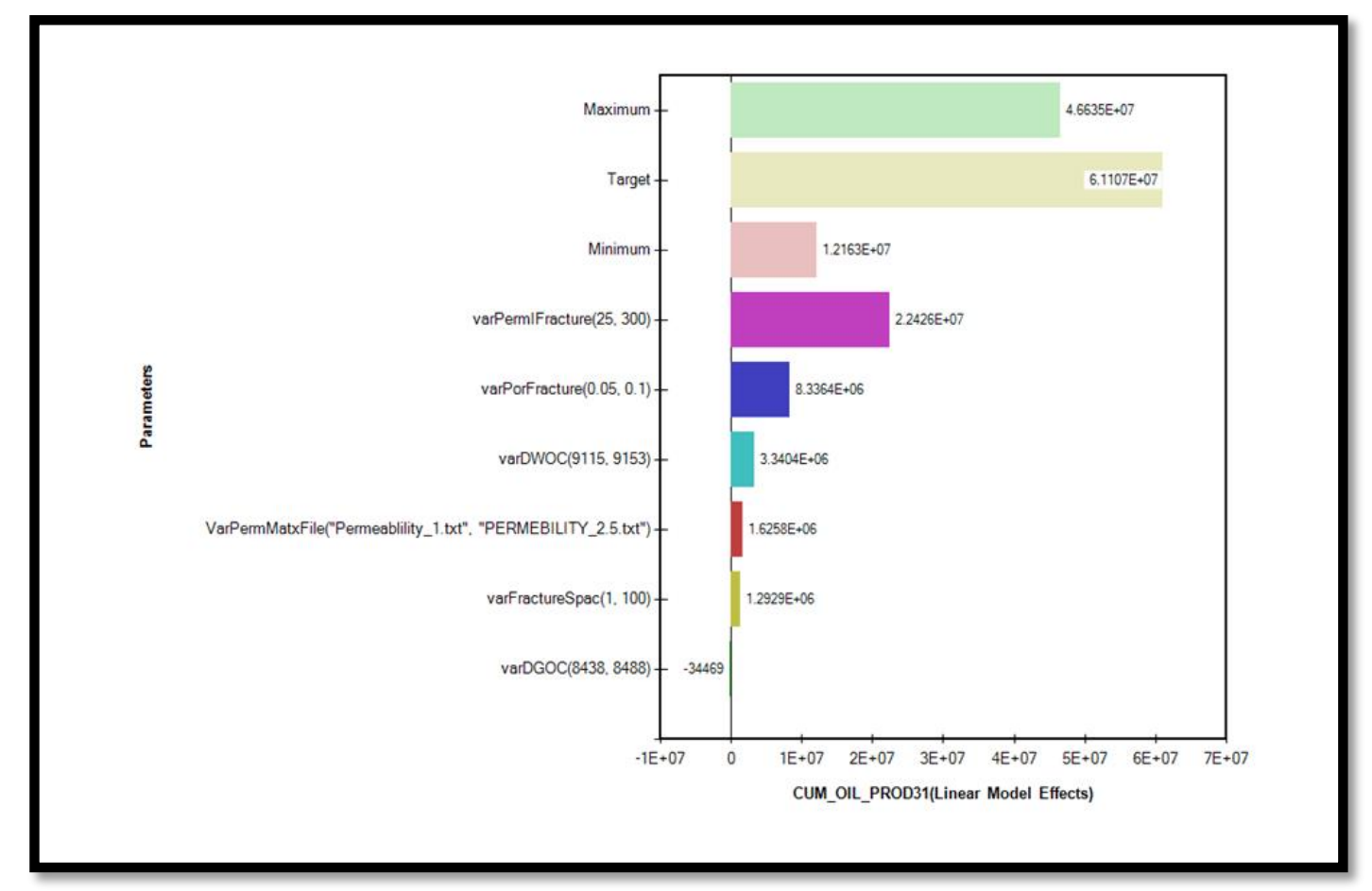

Figure 29: Sensitivity Analysis showing fracture porosity impact on production, KZ_31 


\subsubsection{Natural Fracture SPACING}

The natural fracture spacing impact on the production performance of current vertical wells and the new suggested horizontal well is studied. The natural fracture spacing (varFracureSpac) was varied from one 1-100 feet in the sensitivity analysis. Figure 30 indicates the impact of fracture spacing on the history matching of the cumulative production. As it is evident, natural fracture spacing has a minor effect on the vertical wells production performance.

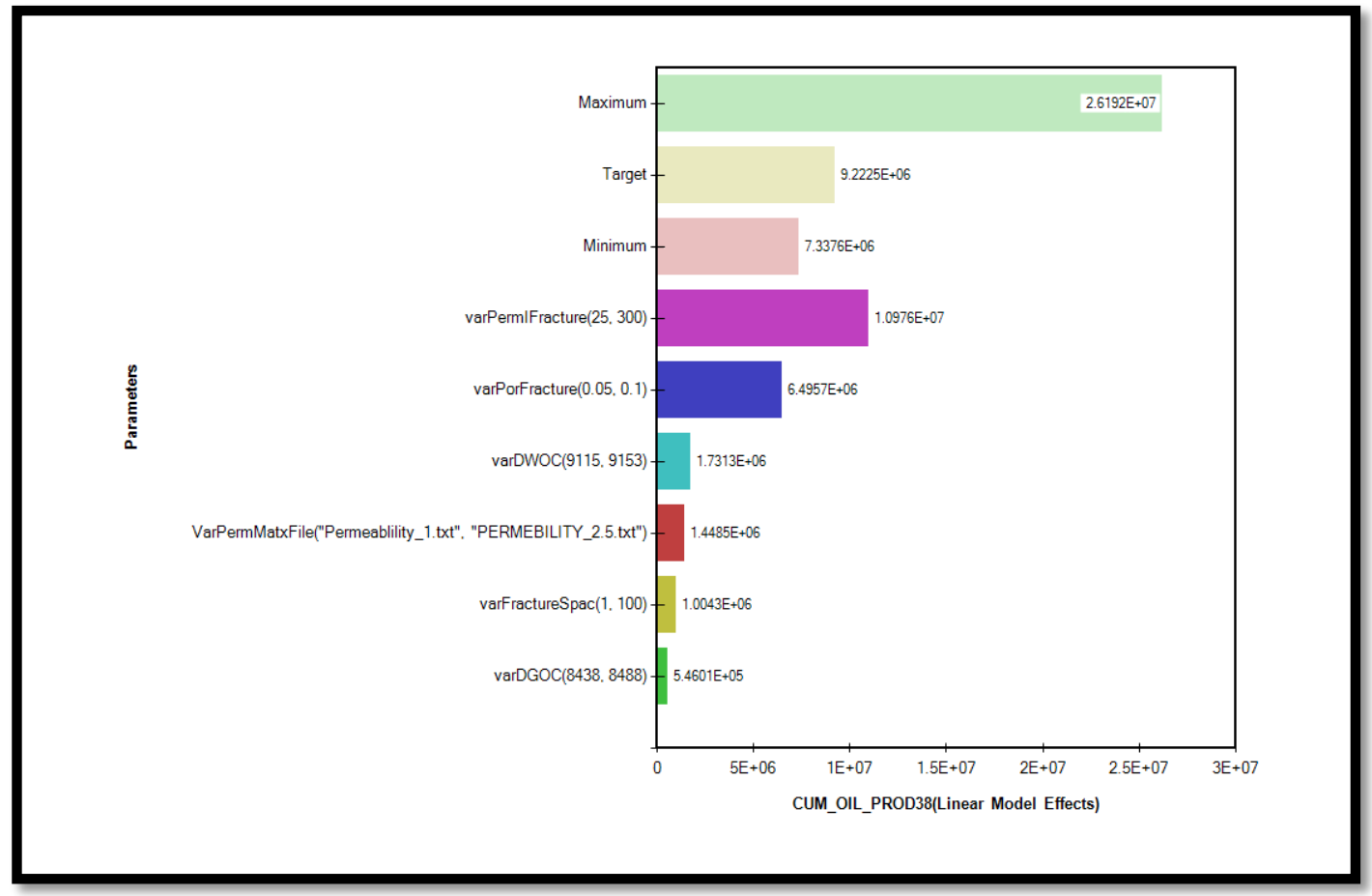

Figure 30: Sensitivity analysis highlighting the fracture spacing impact on production,

$$
\text { KZ_38 }
$$


Figure 31 compares the natural fracture spacing effect on the production of the proposed horizontal well. As displayed, the natural fracture spacing is varied from 10-100 feet, and natural fracture spacing does not affect the production profile.

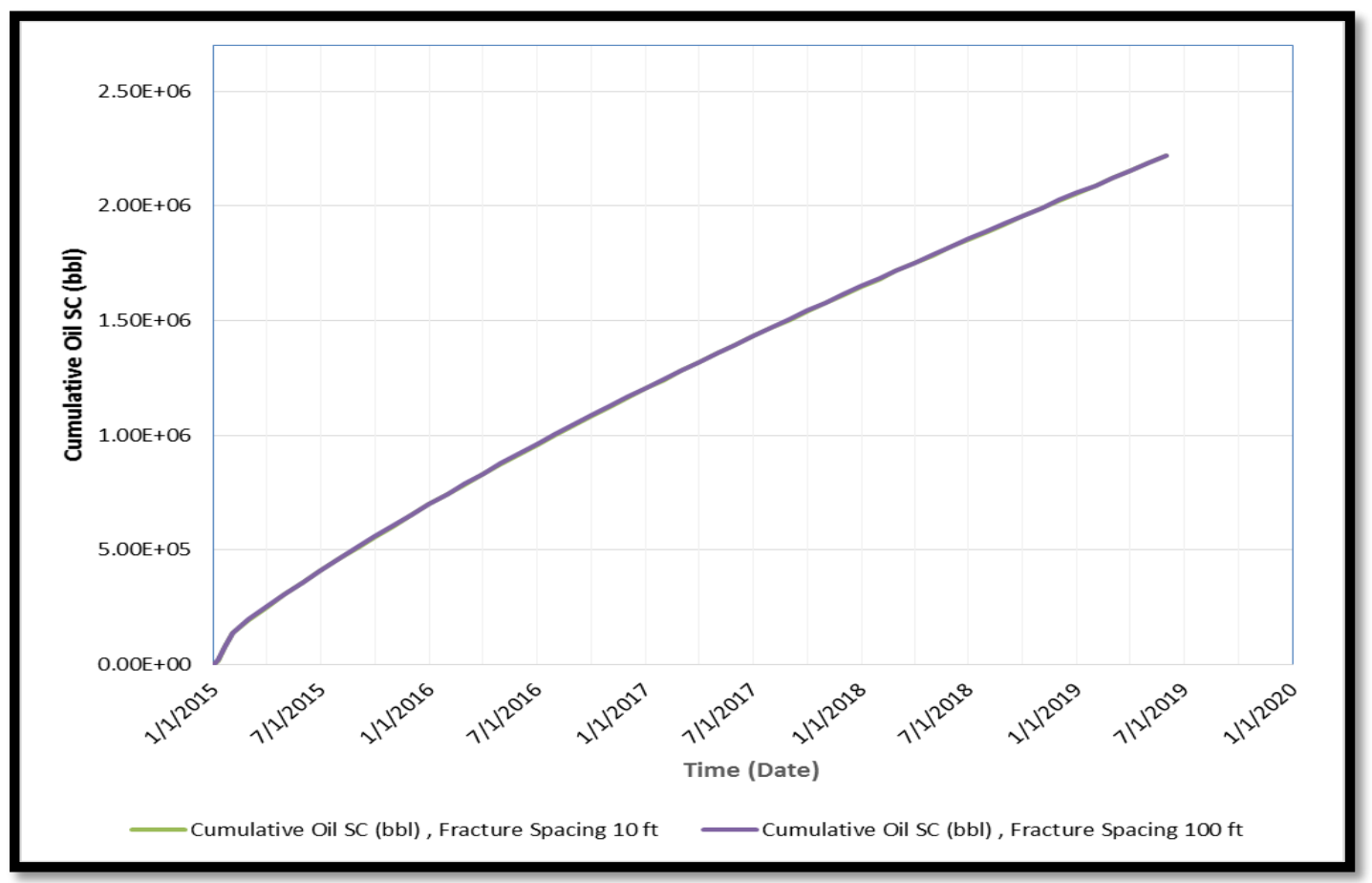

Figure 31: Compares two simulation runs with different fracture spacing for a horizontal well 


\subsection{The Impact of UnCERTAinty on The Predicted}

\section{Horizontal Well's Performance.}

History matching is the best available approach to simulate the performance of any hydrocarbon field. However, the process involves too many uncertain input data, which makes the output data highly doubted too. Therefore, to overcome the margin of uncertainty of the history matched model, two new models are generated for the reservoir. The first one is created by increasing the reservoir properties 20 percent. The second model is generated by decreasing the reservoir properties 20 percent.Figure 32 compares the cumulative oil production of a horizontal well in both previous models. As it can be seen, the uncertainty impact is proportional with the two generated models and has a relatively small effect on the proposed horizontal well.

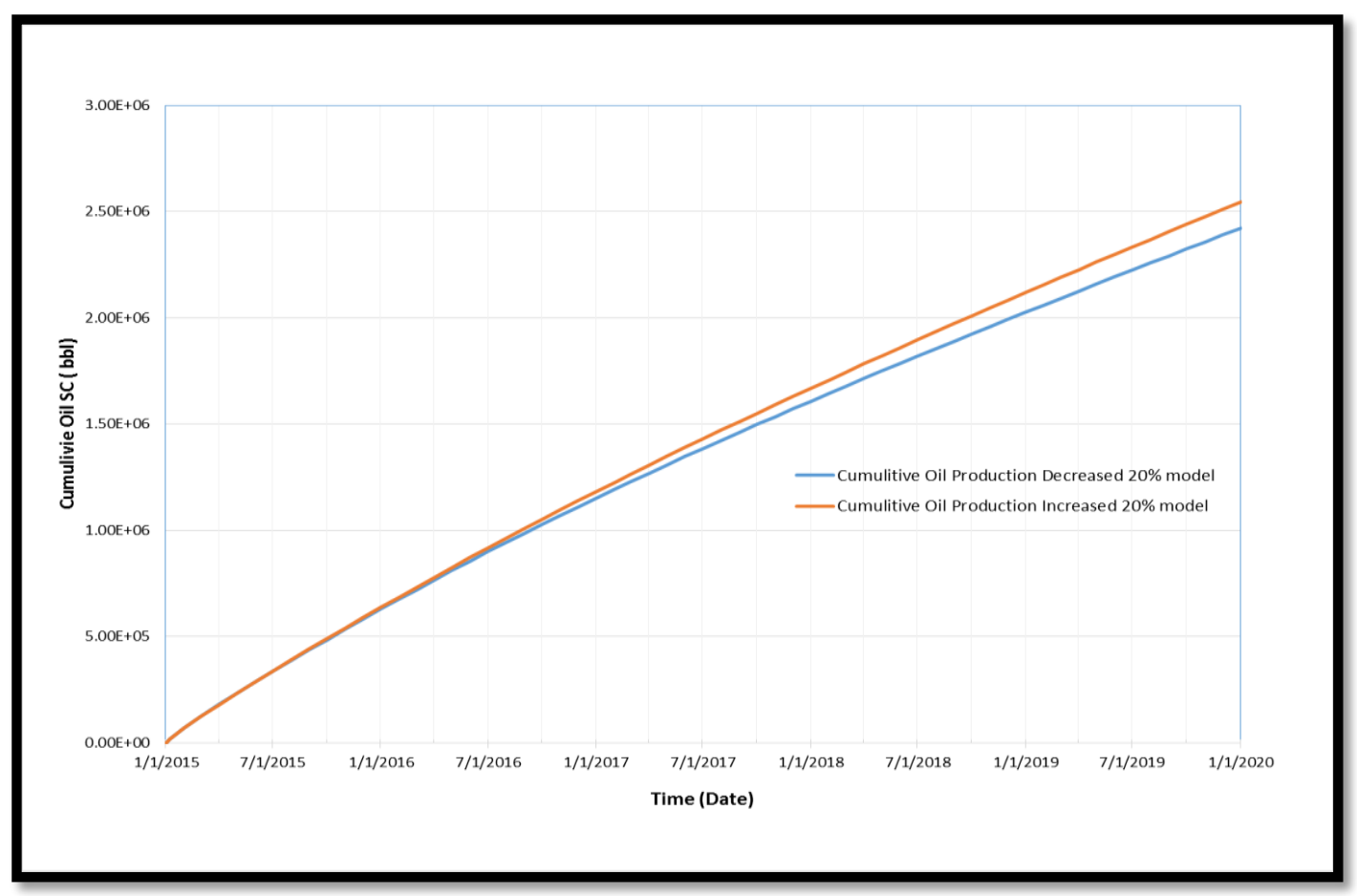

Figure 32: Impact of history matching uncertainty on the horizontal well performance 


\subsection{Horizontal Well Placement}

To determine the optimum placement of the new horizontal well, several combinations of parameters were investigated. The parameters were: the horizontal well's location, lateral length, and orientation. The targeted formation's layer (K1 or K2) also varied. Moreover, the lateral length ranged from 3500 feet to 6500 feet, and the new horizontal well is referred as well KZ_41.

Likewise, three regions were preferred in drilling the new horizontal wells, depending on the low well density and oil saturation in each region (Figure 33).

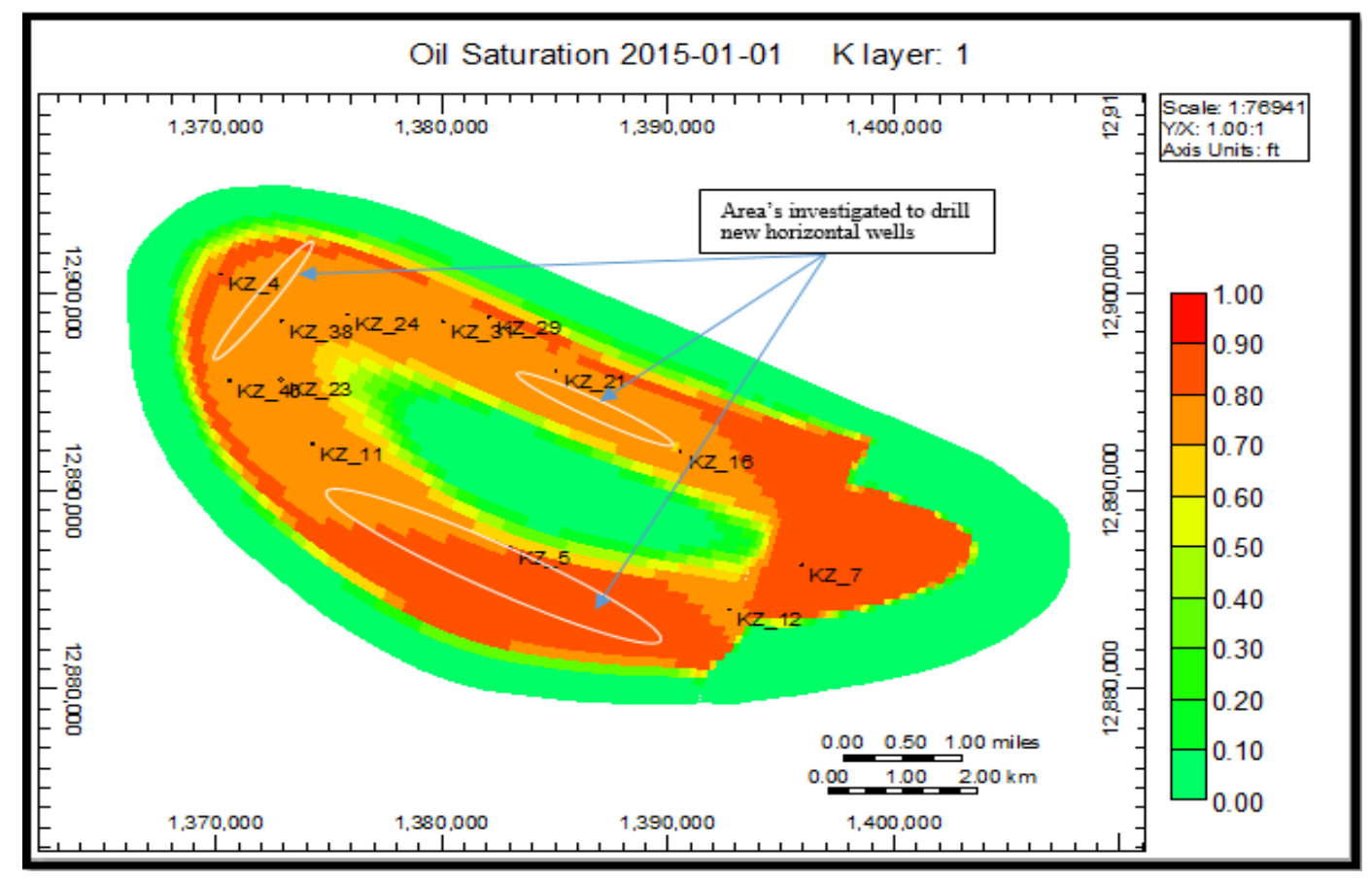

Figure 33: Suggested area to investigate for drilling the new horizontal well

In addition, the average daily oil production rate has been selected as a comparison criterion to find out if the new horizontal well is economical. Therefore, a presumption has been made to consider a new horizontal well economical if it replaces the oil production of 5 to 6 vertical wells. However, from a cost standpoint, other criteria might be considered when deciding the feasibility of a horizontal well. 
Assuming the same production rate for the other vertical producing wells for five years of productions, following scenarios are studied:

Scenario 1: Placing the new horizontal well (KZ_41) in the southeast of the reservoir (Figure 34). The proposed lateral length was 3500 feet and completed in the layer (K2) of Upper Qamchuqa formation.

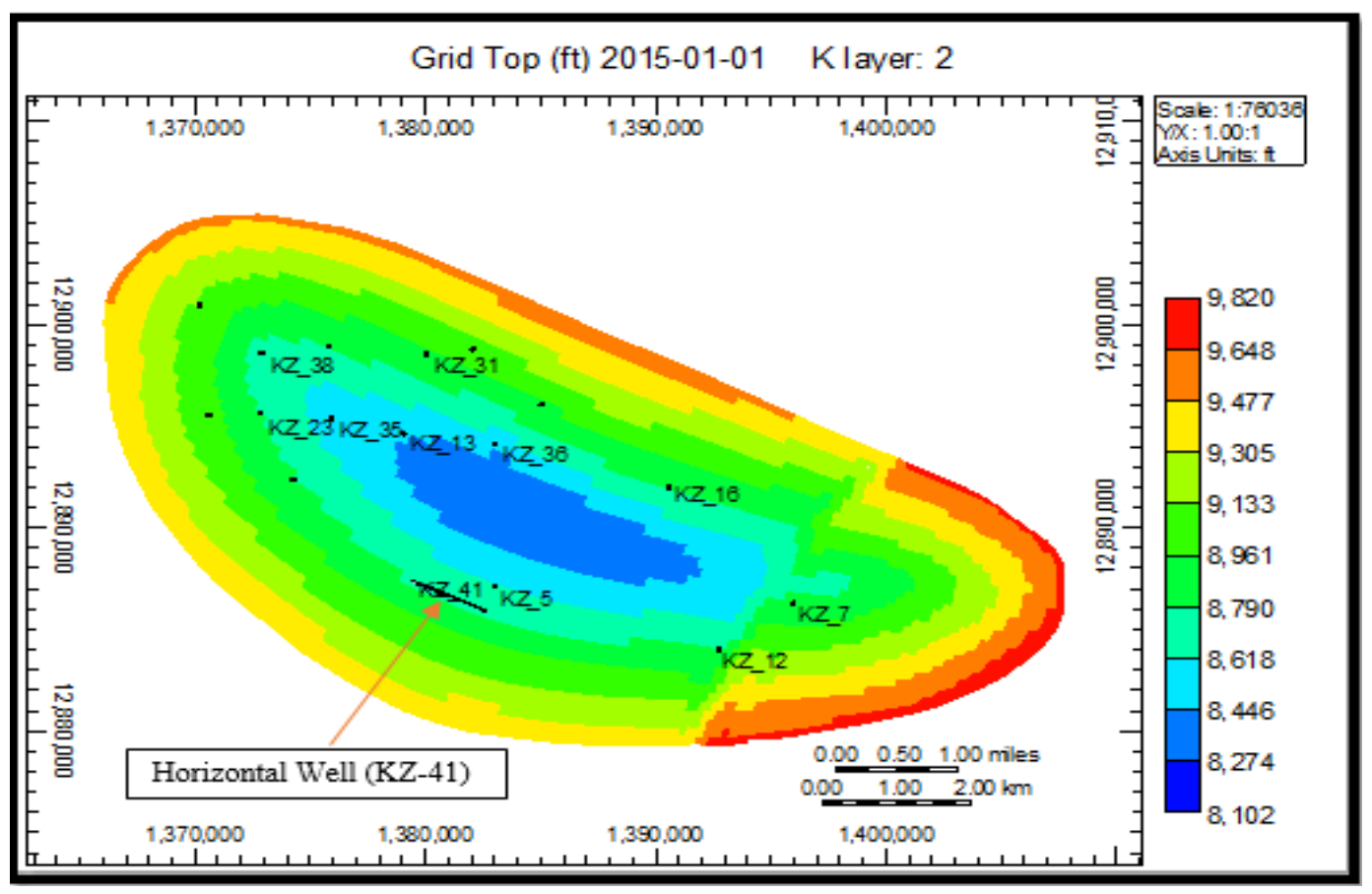

Figure 34: Scenario 1, the new horizontal well (KZ_41) location.

Figure 35 illustrates the monthly oil production rate for 3500 feet horizontal well for five years. The average daily production rate for this period is $1750 \mathrm{bbl}$, which if compared with the last two vertical wells (KZ_38 and KZ_40) production rates combined is three times higher. In other words, the new horizontal well in this location with $3500 \mathrm{ft}$ lateral is going to replace three vertical wells in the reservoir. However, it is not economical enough to be considered for future development. 


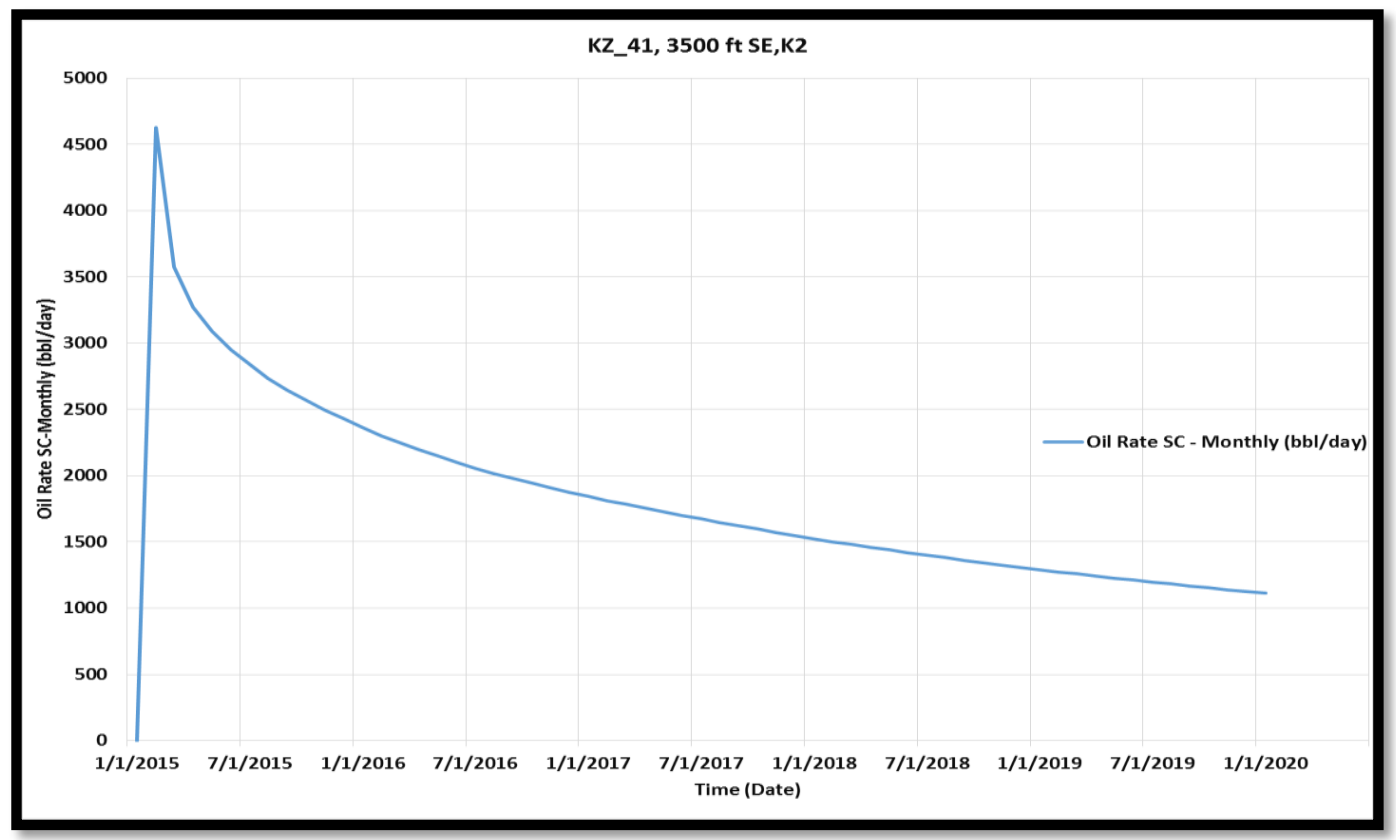

Figure 35: Scenario 1, monthly production rate for the new horizontal well (KZ_41)

Scenario 2: Placing 3500 feet horizontal well (KZ_41) in the southeast of the reservoirtargeting layer K1 of the Upper Qamchuqa formation (Figure 36).

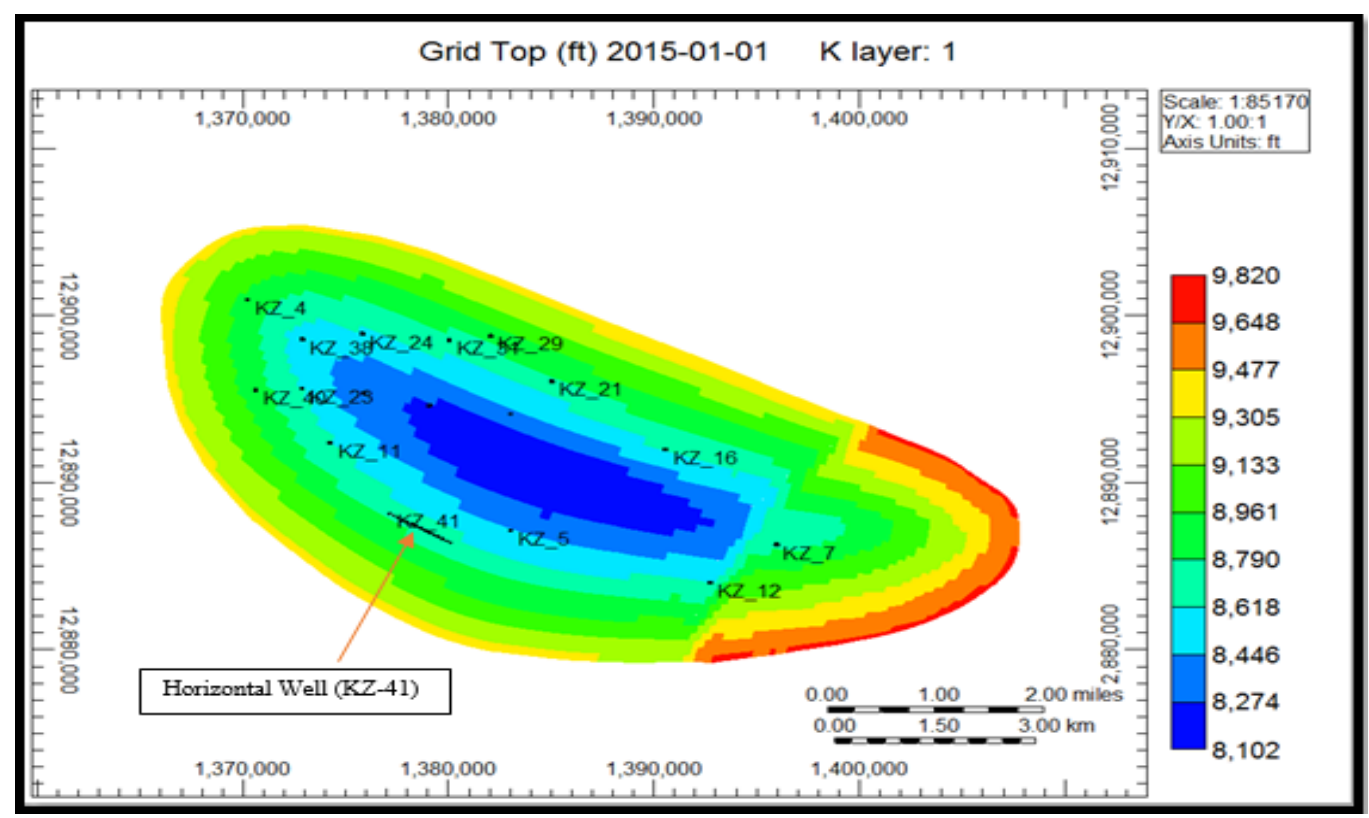

Figure 36: Scenario 2, new horizontal well (KZ-41) completed in layer K1 
Figure 37, compares the monthly production rate from 3500 feet horizontal well completed in two different layers of the reservoir ( $\mathrm{K} 1$ and $\mathrm{K} 2$ ). As can be seen, the monthly production rate has been insignificantly impacted with layer changing. However, the production rate of layer K2 (scenario 1) is slightly higher.

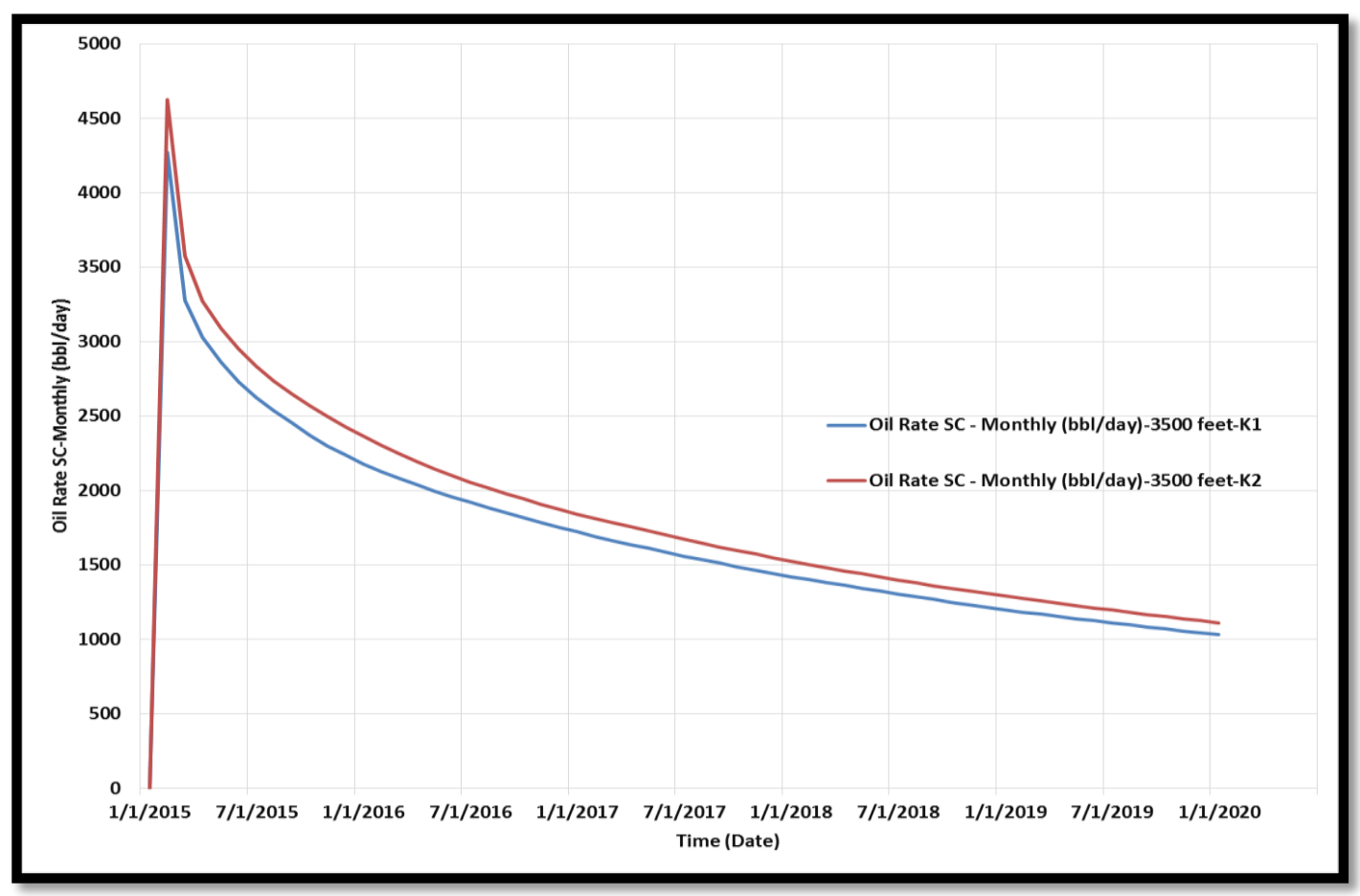

Figure 37: Comparison of monthly oil rate for scenario 1 and 2

Scenario 3: is devised to increase the production from the new horizontal well and make it economical. The lateral length of the horizontal well mentioned in the scenario 1 risen to $5500 \mathrm{ft}$. Figure 38 compares the monthly production rate of two horizontal well in the same location with different lateral lengths (3500 feet and 5500 feet). As well, it indicates that the average daily oil production for scenario 3 is $2500 \mathrm{bbl}$. The production rate of 2500 bbl/day replaces five vertical wells if compared with wells $\mathrm{KZ} \_38$ and $\mathrm{KZ} \_40$ production, which considers a good scenario to be proposed for the future development. 


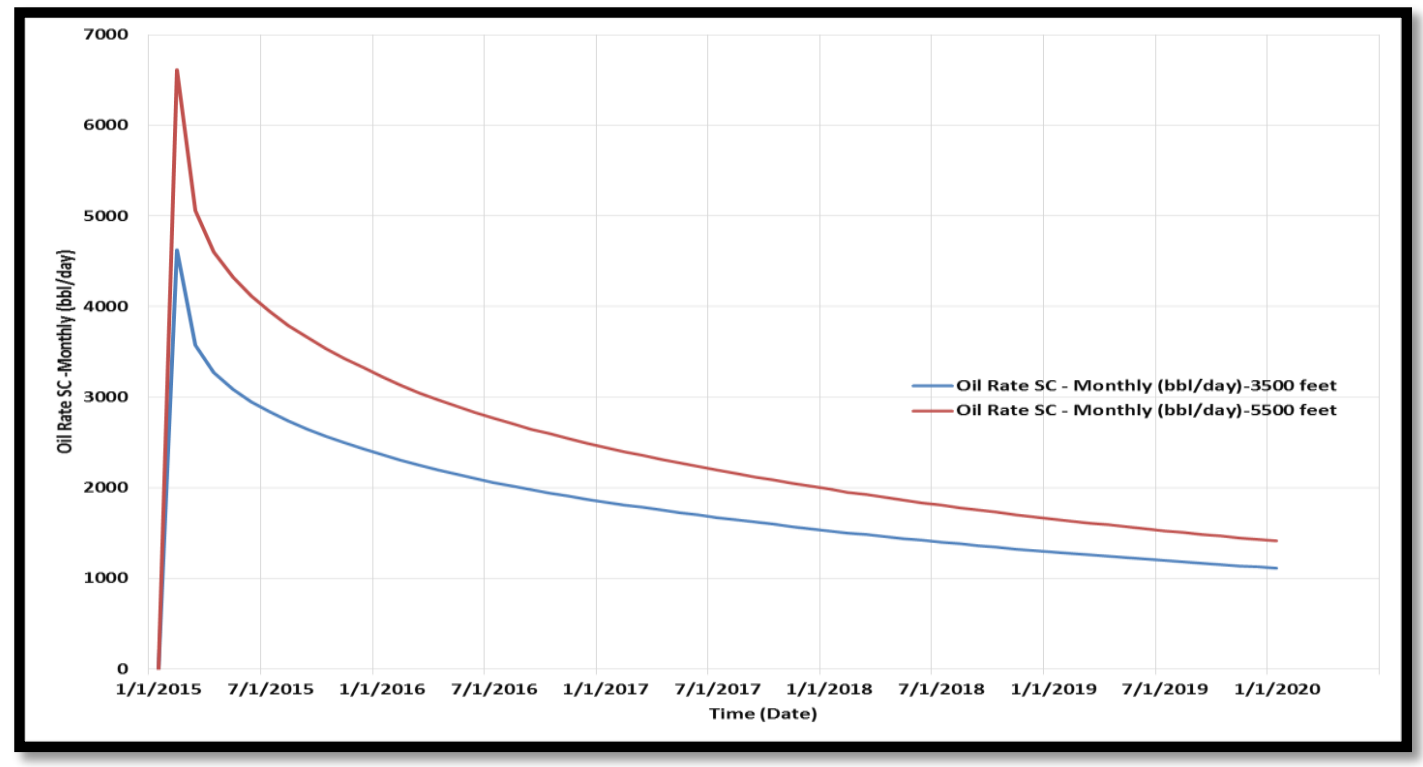

Figure 38: Comparison of monthly oil production of scenario 1 and 3

Figure 39 shows the difference between drilling 5500 feet horizontal well in the layer K1 and layer K2. As it can be noted, layer K2 is producing a slightly higher than layer K2. Therefore, for the next scenarios, the horizontal well will be completed only in the layer K2 without further comparison.

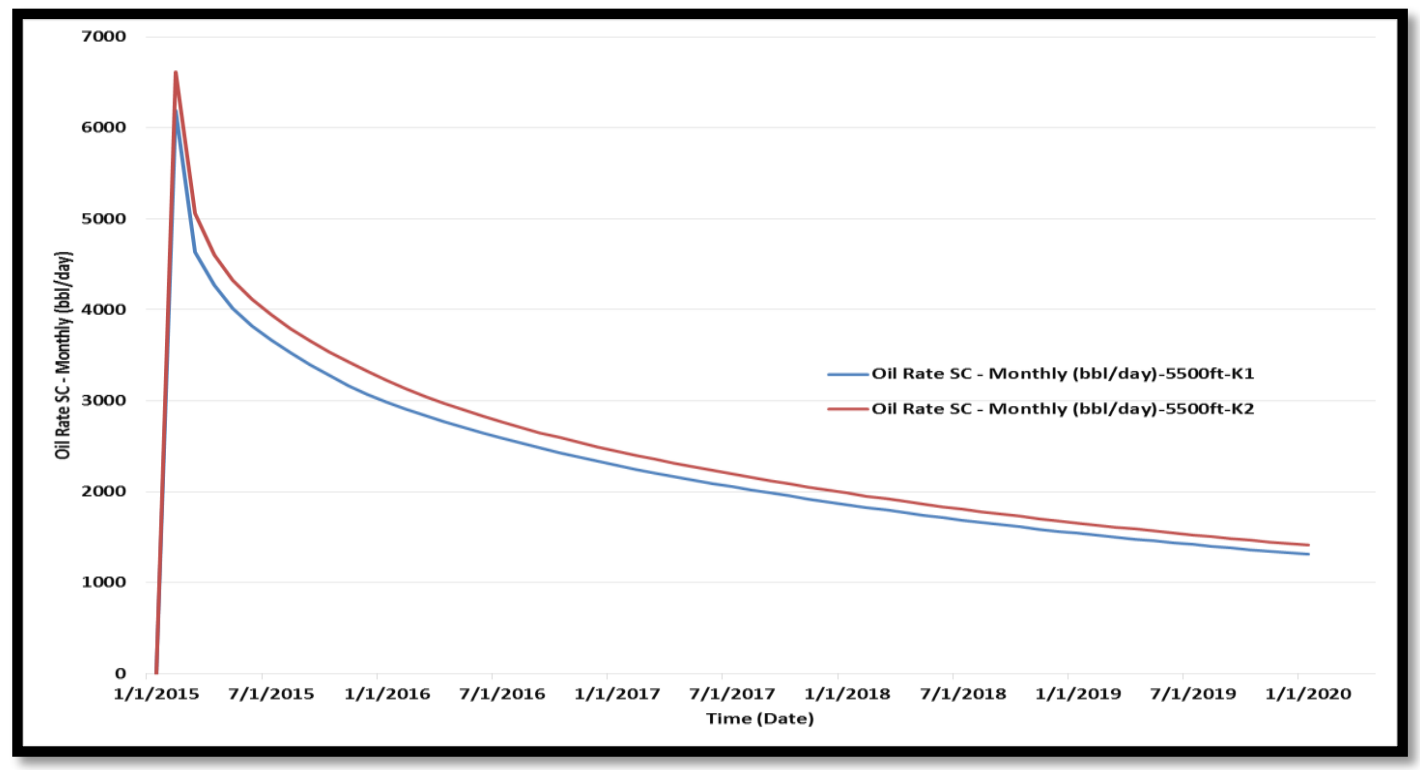

Figure 39: Comparison of monthly oil production of scenario 3 in different layers 
Scenario 4: in this scenario, the lateral length is increased further to determine the production increment per each 1000 feet. Figure 40 compares the monthly production rate of 6500 feet with 5500 feet horizontal well from scenario 3. As can be noted, there is an adequate increase in production with the extra 1000 feet lateral. The increase in the average daily production was about $300 \mathrm{bbl}$, which is almost equal to a vertical well's production. However, other considerations such as drilling problems and cost should be taken when deciding to extend the lateral length. Otherwise, scenario 4 is recommended from the oil production standpoint.

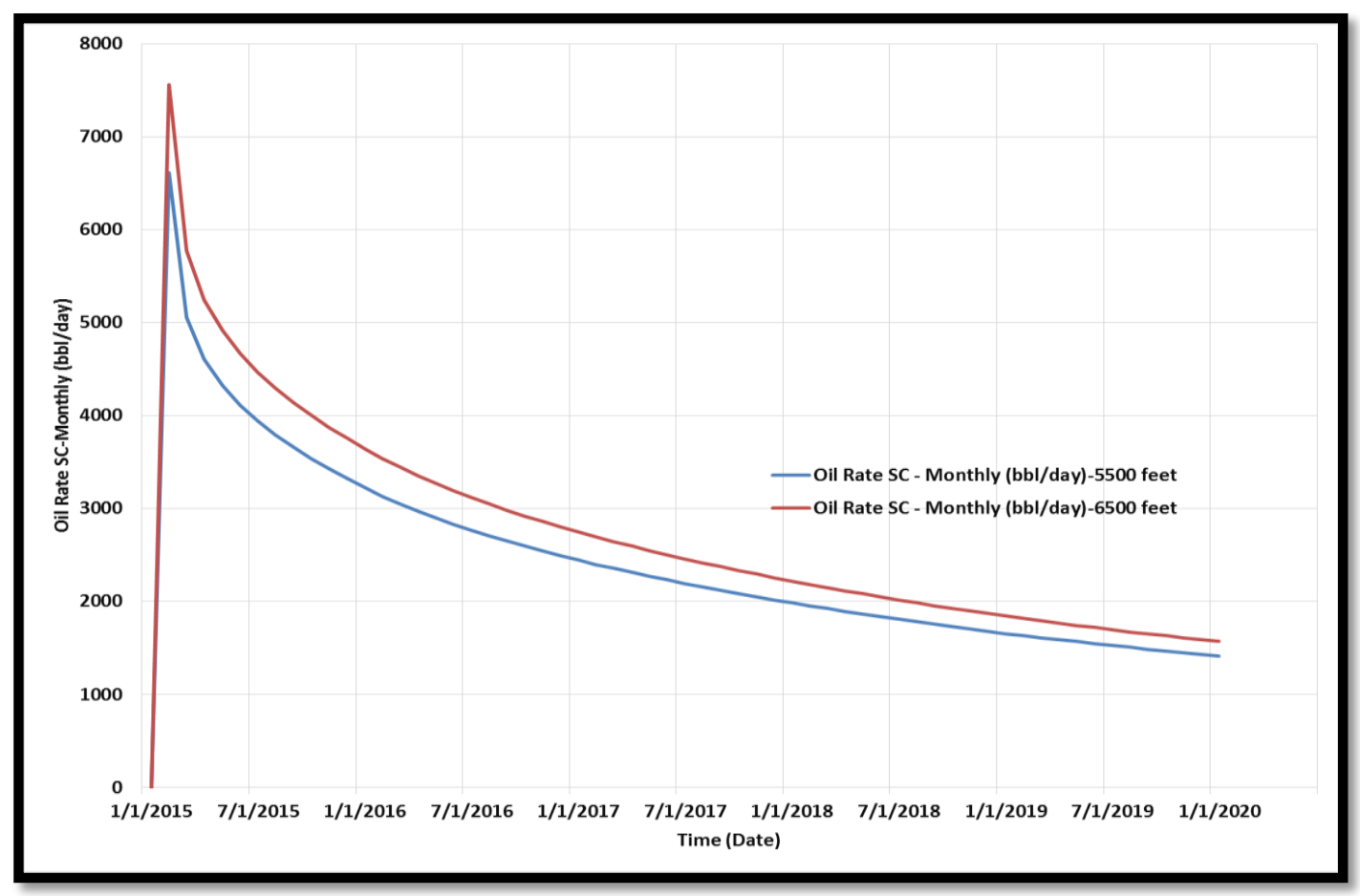

Figure 40: Scenario 4, comparison of horizontal wells with two different lateral length 
Scenario 5: drilling the new horizontal well in the northwest of the reservoir between wells KZ_4 and KZ_38 (Figure 41). The orientation of the horizontal was north-south and the lateral length proposed was 3500 feet and 5500 feet.

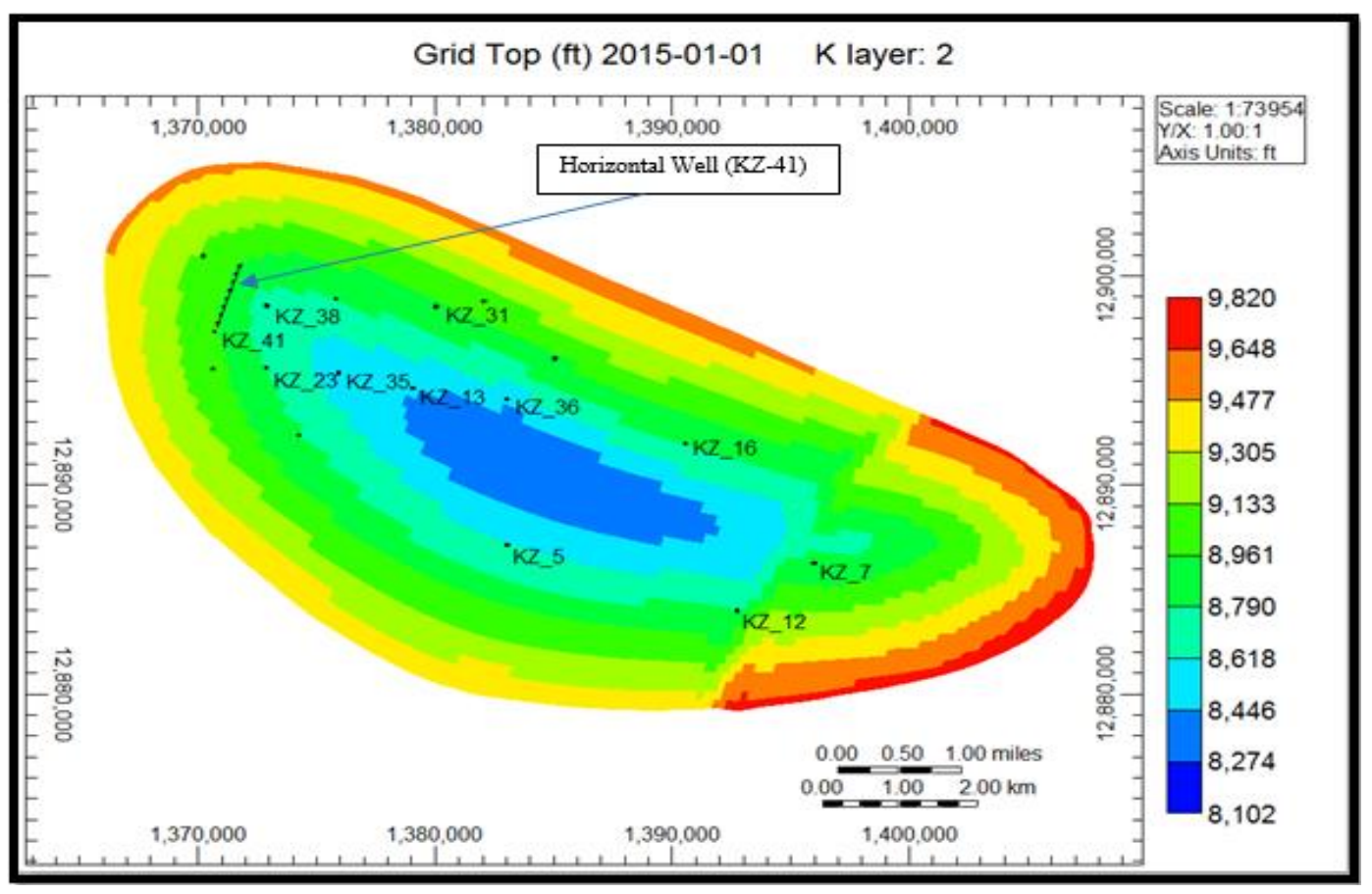

Figure 41: horizontal well placement in the north of the reservoir.

Figure 42 compares the monthly oil production from 3500 feet and 5500 feet horizontal well. As it can be observed, the production is very low and ultimately not economic. The reason of that is the orientation of horizontal wells are most likely parallel to the natural fractures and not intersecting them. Consequently, it is not recommended to drill horizontal wells in the north-south direction. 


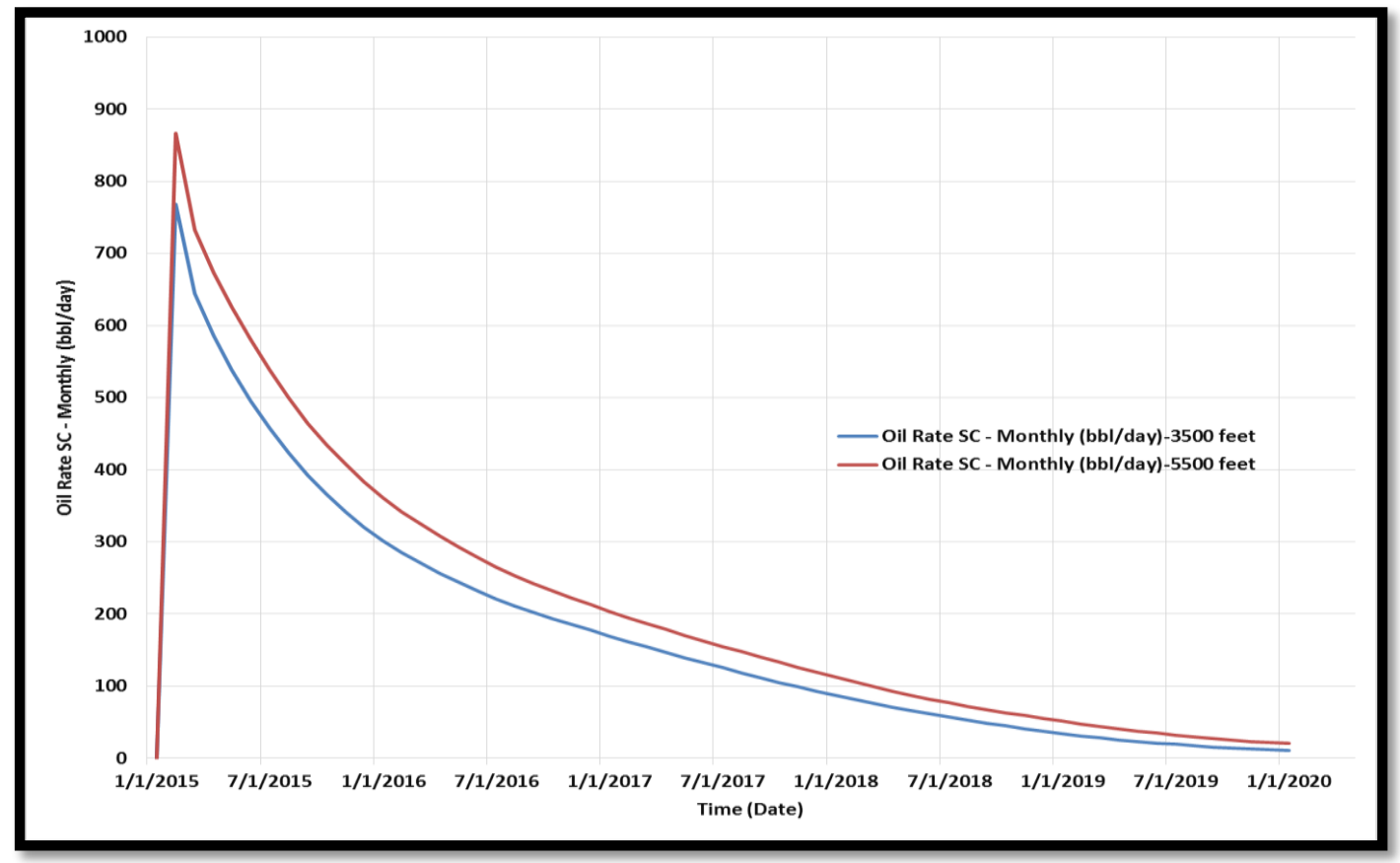

Figure 42: Comparison of horizontal wells in the North-South orientation

Scenario 6: Placing 3500 feet lateral horizontal well in the northeast of the reservoir with east- west direction. The new well is close to well KZ_16 and KZ_36 (Figure 43).

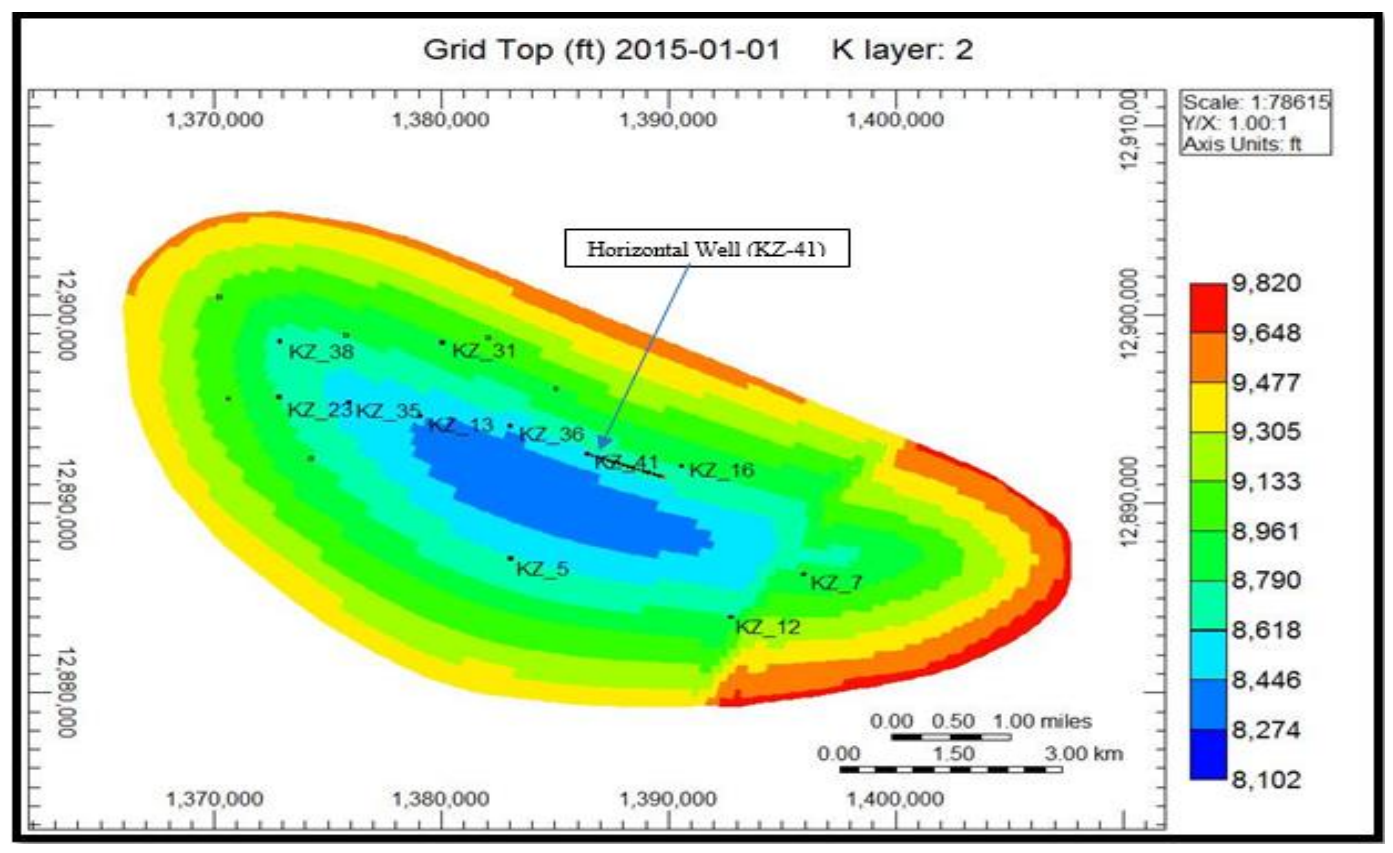

Figure 43: Scenario 6, horizontal well placement in the north-east of the reservoir 
Figure 44 demonstrates the monthly oil production of 3500 feet horizontal well in the northeast of the field. It is evident to see that slope of the monthly oil rate decline rapidly, and the average daily production rate for five-year prediction is $1100 \mathrm{bbl}$. Consequently, a horizontal well with that feature would replace only two vertical walls, which is not enough to be considered for future developments.

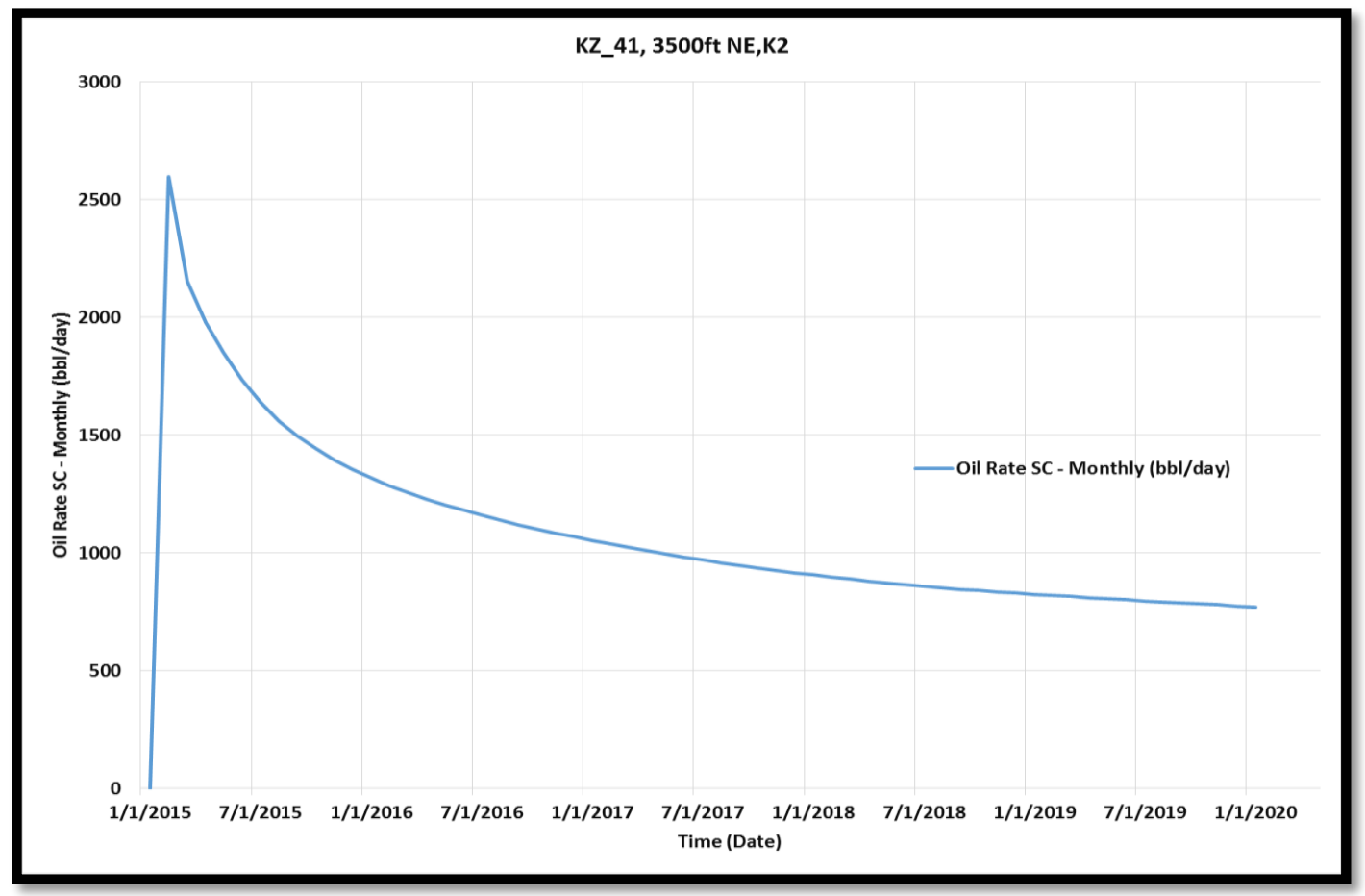

Figure 44: Scenario 6, monthly oil production from 3500 feet horizontal well in NE of the reservoir. 
Scenario 7: Extending the lateral length of the horizontal well in scenario 6 to 6500 feet. Figure 45 illustrates the differences in the monthly production rate of 3500 feet lateral (scenario 6) with 6500 feet lateral. As it can be observed, increasing the lateral length helped to improve the oil production at an economical rate. So, the average daily oil production for 6500 feet horizontal well is $2000 \mathrm{bbl}$ and replaces four vertical wells in the reservoir. Therefore, drilling a horizontal well in the northeast of the reservoir with long laterals is also an option to improve the recovery and develop the field.

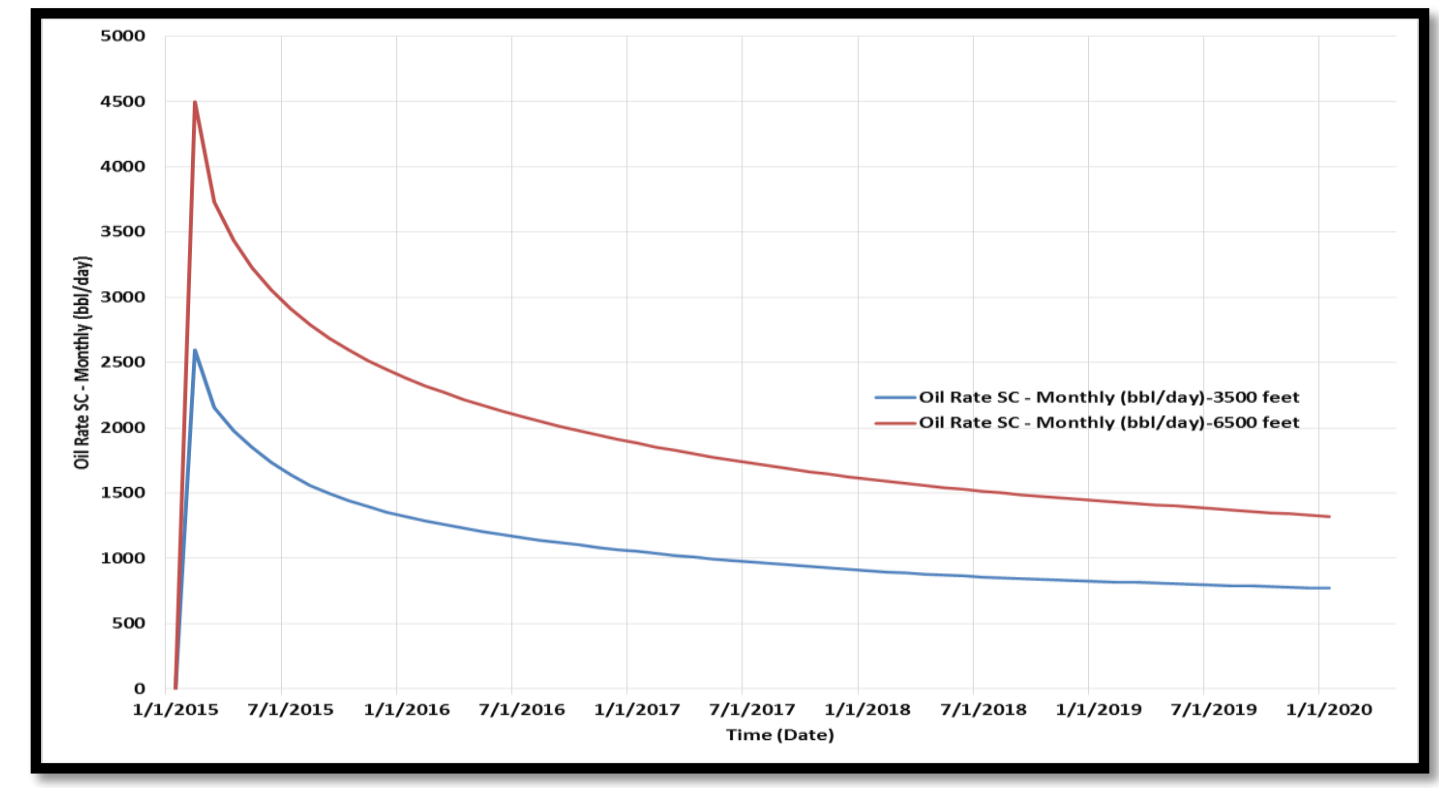

Figure 45: Scenario 7 monthly production rate comparison

In summary, scenario 2 with 5500 feet horizontal in the southeast of the reservoir (Figure 46) and scenario 7 with 6500 feet horizontal in the northeast of the reservoir (figure 47), are going to replace four to five vertical wells and contribute significantly to oil recovery improvement. Also, it is concluded that altering the layer number K1 or K2 (unit A and unit B) have a minor impact on the predicted production performance, and $\mathrm{K} 2$ has given a slight better production rate in the investigated parts of the reservoir. 


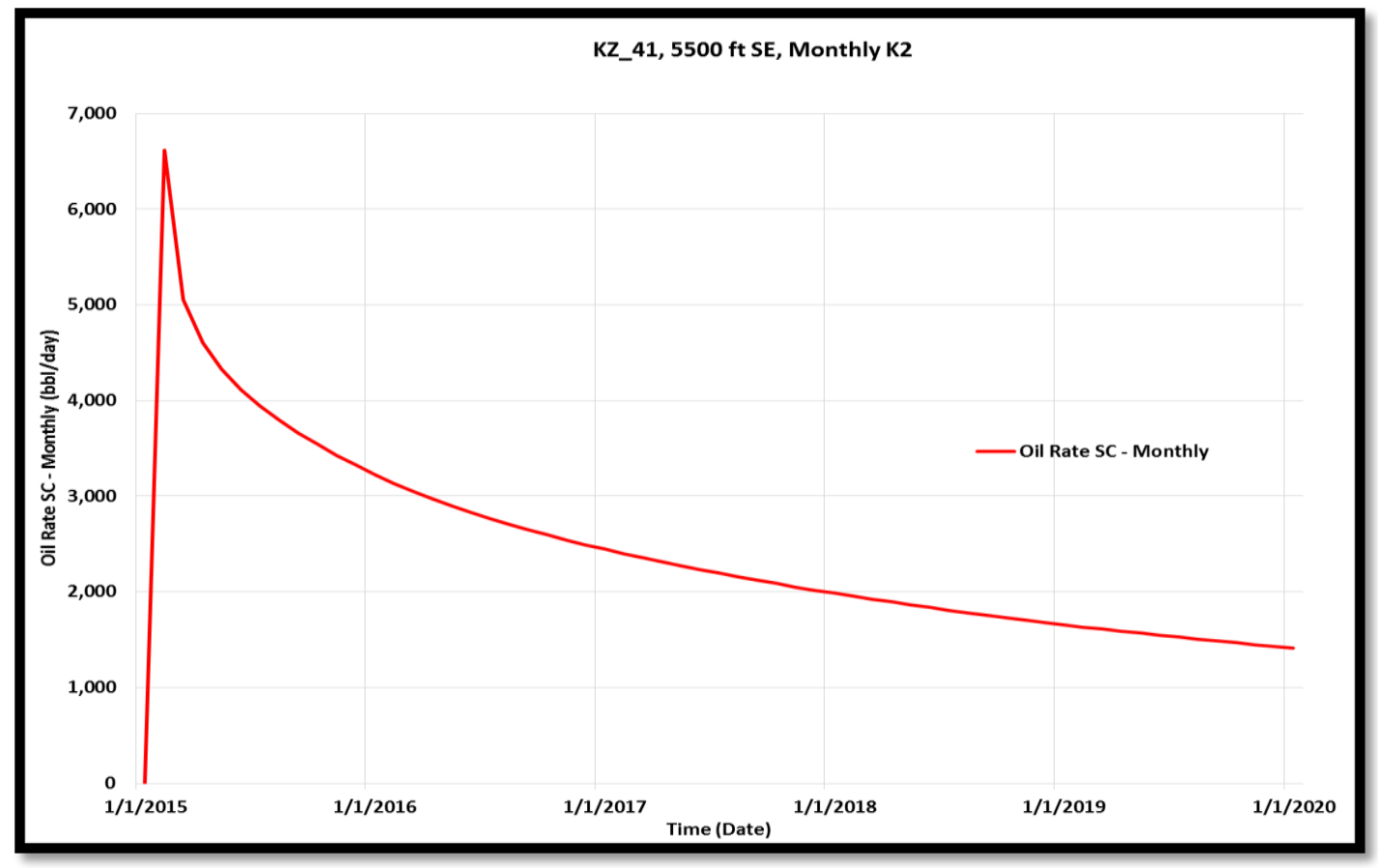

Figure 46: Optimal horizontal well's placement and lateral length in the southeast of the reservoir with average production rate of $2500 \mathrm{bbl} / \mathrm{day}$

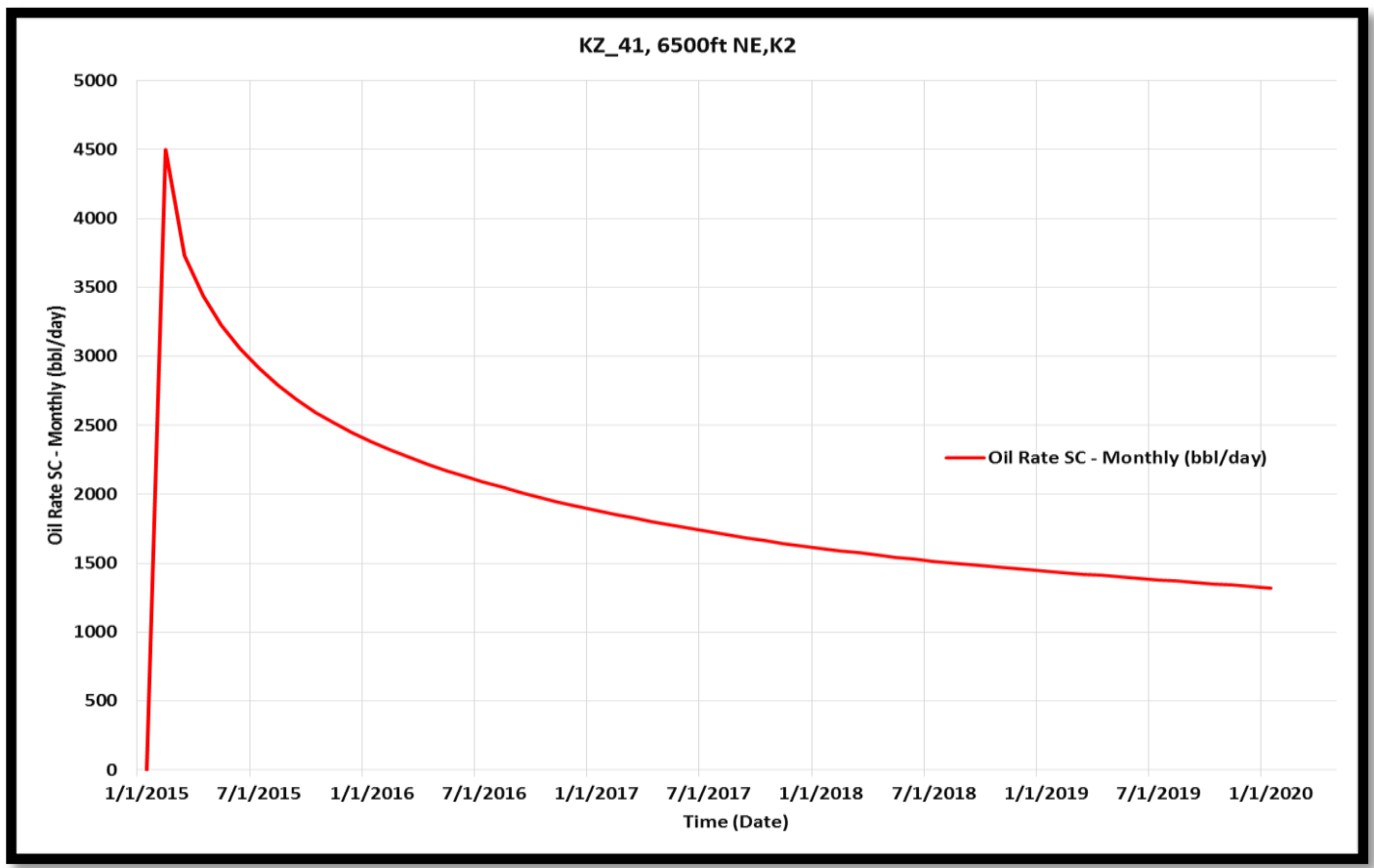

Figure 47: Optimal horizontal well's placement and lateral length in the northeast of the reservoir with average production rate of $2000 \mathrm{bbl} /$ day 


\section{ChAPTER 5: SUMMARY, CONCLUSIONS, AND RECOMMENDATIONS}

\subsection{SUMMARY}

This study involves the development of a reservoir model for Upper Qamchuqa reservoir in Khabbaz field by using a commercial simulator. The model consists of about 6,000 grid blocks with 16 production wells produced for 25 years. However, the field closed for several years during that period due to different reasons.

A geological model was developed by utilizing Petrel software, where the reservoir structure, grid blocks and fault modeling have been constructed. Also, permeability and porosity values scaled up from available well logs and distributed throughout the reservoir. The geological model was imported to the commercial reservoir simulator (CMG). A base simulation model with dual porosity-dual permeability features has been built for the reservoir. Moreover, the reservoir was produced from an initial pressure of 4,364 psi and a bubble point pressure of 3,815 psi. Also, the historical data of oil production rate was uploaded to the model. Automated and manual history matching techniques were used in reservoir modeling to fine-tune reservoir properties by matching the measured cumulative oil production data. However, sensitivity analysis was also used to help with history matching and to investigate the impact of reservoir properties.

Finally, the matched model was used to predict the performance, indicate the optimum placement, and discover the lateral length for new horizontal wells in the reservoir for five years. 


\subsection{CONCLUSIONS}

The major conclusions that can be made from this thesis are summarized as the following:

1. Reservoir parameters such as fracture permeability and fracture porosity have the most effect on the history matching process and reservoir performance while the fracture spacing has no significant impact.

2. Fracture spacing also has no impact on the production performance of the suggested horizontal wells.

3. Fracture data acquisitions such as image logs and core data analysis is vital for the simulation studies and development of the field.

4. A 3D seismic survey will be very helpful to better understand the fracture network in the field.

5. Several scenarios were recommended for drilling new horizontal wells depending on their location and lateral length. Also, the oil production rate capacity of the proposed horizontal wells was compared with current vertical wells' in the reservoir.

6. A horizontal well with 6,500 feet lateral in the southeast of the reservoir will produce as much as five to six existing vertical wells in the five-year prediction period.

7. Unit $B(K 2)$ has better oil saturation left and gives more oil production than Unit A (K1) when drilling horizontal wells.

8. Increasing the lateral length of the proposed horizontal well by 1,000 feet will increase the production by $300 \mathrm{bbl} /$ day. 


\subsection{RECOMMENDATIONS FOR FUTURE WORK}

In this study, the performance of horizontal wells have been evaluated in a naturally fractured carbonate reservoir. The following recommendations are indicated for future research.

- To make history matching more accurate and confident, upgrade the model with newly available data and have a more realistic fracture model by incorporating the seismic and fluid loss data.

- Assess drilling hydraulic fractured horizontal wells to develop the eastern part of the reservoir where permeability is very low.

- Study EOR methods such as water flooding and gas injection in the reservoir to improve the hydrocarbon production.

- Evaluate the performance of horizontal wells in a naturally fractured carbonate reservoir in the area with an active water drive. 


\section{REFERENCES}

Aguilera, R. (2003). Geologic and engineering aspects of naturally fractured reservoirs. CSEG Recorder, 28(2), 44-49.

Ahr, W. M. (2008). Geology of carbonate reservoirs: The identification, description, and characterization of hydrocarbon reservoirs in carbonate rocks. Hoboken, N.J: Wiley.

Al-Qayim, B., Qadir, F., \& Al-Biaty, F. (2010). Dolomitization and porosity evaluation of the Cretaceous Upper Qamchuqa (Mauddud) Formation, Khabbaz oil field, Kirkuk area, northern Iraq. GeoArabia, Journal of the Middle East Petroleum Geosciences, 15(4), p-49.

Alsharhan, A. S., \& Nairn, A. E. (1997). Sedimentary basins and petroleum geology of the Middle East. Amsterdam: Elsevier.

Barenblatt, G. I., Zheltov, I. P., \& Kochina, I. N. (1960). Basic concepts in the theory of seepage of homogeneous liquids in fissured rocks [strata].Journal of applied mathematics and mechanics, 24(5), 1286-1303.

Belyadi, A. (2011). Modeling studies to evaluate performance of the horizontal wells completed in shale. West Virginia University.

Bratton, T., Canh, D. V., Van Que, N., Duc, N. V., Gillespie, P., Hunt, D., ... \& Nelson, R. (2006). The nature of naturally fractured reservoirs. Oilfield Review, 18(2), 4-23.

Buday, T., \& Jassim, S. Z. (1987). The regional geology of Iraq, vol 2: tectonism, magmatism and metamorphism. Publication of GEOSURV, Baghdad, 352.

Burgess, T., \& Van de Slijke, P. (1991). Horizontal Drilling Comes of Age. Oil Field Review, 2(3), 22-23.

CMG [Computer software]. (2012). Computer Modeling Group. 
Coats, K. H. (1987, January 1). Reservoir Simulation (1987 PEH Chapter 48). Society of Petroleum Engineers. doi:NA

Cosentino, L. (2001). Integrated reservoir studies. Editions Technip.

Ertekin, T., Abou-Kassem, J. H., \& King, G. R. (2001). Basic applied reservoir simulation. Richardson, Tex: Society of Petroleum Engineers.

Giger, F. M., Reiss, L. H., \& Jourdan, A. P. (1984, January). The reservoir engineering aspects of horizontal drilling. In SPE Annual Technical Conference and Exhibition. Society of Petroleum Engineers.

Gong, B. (2007). Effective models of fractured systems (Vol. 68, No. 09).

Guo, B., Lyons, W. C., \& Ghalambor, A. (2007).Petroleum production engineering: A computer-assisted approach. Burlington, MA: Gulf Professional Pub.

Hubbert, M. K., \& Willis, D. G. (1955). Important fractured reservoirs in the United States. 45th World Pet. Cong. Proc., Section I/A-1, 58-81.

Jassim, S. Z., \& Goff, J. C. (2006). Geology of Iraq (1st ed.). Brno;Prague;: Dolin.

Kazemi, H., Merrill Jr, L. S., Porterfield, K. L., \& Zeman, P. R. (1976). Numerical simulation of water-oil flow in naturally fractured reservoirs. Society of Petroleum Engineers Journal, 16(06), 317-326.

Lorenz, J. C., Farrell, H. E., Hanks, C. L., Rizer, W. D., \& Sonnenfeld, M. D. (1997). Characteristics of natural fractures in carbonate strata. Carbonate seismology: Society of Exploration Geophysicists, Geophysical Development Series, 6, 179202.

Lu, J., Zhu, T., \& Tiab, D. (2009). Pressure Behavior of Horizontal Wells in Dual-Porosity, Dual-Permeability Naturally Fractured Reservoirs. Society of Petroleum Engineers. doi:10.2118/120103-MS

Mattax, C. C., \& Dalton, R. L. (1990). Reservoir Simulation. Richardson, TX: Henry L. Doherty Memorial Fund of AIME, Society of Petroleum Engineers. 
Nelson, R. (2001). Geologic analysis of naturally fractured reservoirs. Gulf Professional Publishing.

Netto, S., Schiozer, D. J., Ligero, E. L., \& Maschio, C. (2003). History matching using uncertainty analysis. Paper presented at the Canadian International Petroleum Conference. Petroleum Society of Canada.

Novy, R. A. (1995). Pressure drops in horizontal wells: when can they be ignored?. SPE reservoir engineering, 10(01), 29-35.

Odeh, A. (1969). reservoir simulation ..what is it. Journal of Petroleum Technology, 21(11), 1383-1388. doi:10.2118/2790-PA

Peaceman, D. W., \& Rachford, Jr, H. H. (1955). The numerical solution of parabolic and elliptic differential equations. Journal of the Society for industrial and Applied Mathematics, 3(1), 28-41.

Pendleton, L. E. (1991, January). Horizontal drilling review. In Archie Conference on Reservoir Definition and Description. Society of Petroleum Engineers.

Petrel [Computer software]. (2012). Schlumberger

Qadir, Fuad M. "Formation Evaluation of Reservoir, Khabbaz Oil Field, Kirkuk Area, Northeastern Iraq." (2008): n. page. EI Source Book. EI Source Book, June 2008.

Schlumberger. (2008). Characterization of Naturally Fractured Reservoirs. [Brochure]. "Author".

Shahkarami, A. (2012). Artificial intelligence assisted history matching--proof of concept. WEST VIRGINIA UNIVERSITY.

Sharifi Haddad, A., Hassanzadeh, H., Abedi, J., \& Chen, Z. (2012, January). Impact of Adsorption on Mass Transfer in Fractured Reservoirs. In SPE Heavy Oil Conference Canada. Society of Petroleum Engineers. 
Stearns, D. W., \& Friedman, M. (1972). Reservoirs in fractured rock: Geologic exploration methods.

Stone, H. L. (1970). Probability model for estimating three-phase relative permeability. Journal of Petroleum Technology, 22(02), 214-218.

Stone, H. L. (1973). Estimation of three-phase relative permeability and residual oil data. J. Pet. Technol.;(United States), 12(4).

Taghavi, A. A. (2005, January). Improved Permeability Estimation through use of Fuzzy logic in a carbonate reservoir from Southwest, Iran. In SPE Middle East Oil and Gas Show and Conference. Society of Petroleum Engineers.

The Economist. (2009). [Photograph]. Retrieved from http://www.economist.com/node/1374332.

Thomas, L. K., Dixon, T. N., \& Pierson, R. G. (1983). Fractured reservoir simulation. Society of Petroleum Engineers Journal, 23(01), 42-54.

Todd, M. R., O'Dell, P. M., \& Hirasaki, G. J. Methods of increased accuracy in numerical reservoir simulators. SPEJ, 12 (6): 515-530, December 1972. Petrol. Trans. AIME, 253.

Van Golf-Racht, T. D. (1996). Naturally-fractured carbonate reservoirs. Developments in Petroleum Science, 44, 683-771.

Warren, J. E., \& Root, P. J. (1963). The behavior of naturally fractured reservoirs. Society of Petroleum Engineers Journal, 3(03), 245-255.

Watts, J. W. (1997). Reservoir simulation: Past, present, and future. SPE Computer Applications, 9(06), 171-17

Wilkirson, J. P., Smith, J. H., Stagg, T. O., \& Walters, D. A. (1988). Horizontal Drilling Techniques at Prudhoe Bay, Alaska. Journal of petroleum technology, 40(11), 1445. 
Yaghi, H. M. (1999). Petroleum reservoir simulation using 3-D finite element method with parallel implementation.

Zhang, L. (1998). Analysis of fluid flow to horizontal and slant wells. University of Waterloo. 